\title{
Chlorophylls and Their Derivatives Used in Food Industry and Medicine
}

\author{
Katalin Solymosi ${ }^{1 \#}$ and Beata Mysliwa-Kurdziel ${ }^{2 \# *}$ \\ ${ }^{1}$ Department of Plant Anatomy, Eötvös Loránd University, Budapest, Hungary; \\ ${ }^{2}$ Department of Plant Physiology and Biochemistry, Faculty of Biochemistry, Biophysics and Biotechnology, \\ Jagiellonian University, Krakow, Poland
}

\begin{abstract}
Thylakoids and chloroplasts harbor several vital metabolic processes, but are most importantly associated with photosynthesis. The undisturbed functioning of this process necessitates the ceaseless synthesis of photosynthetic pigments, including closed tetrapyrroles such as chlorophylls (Chls). Chls probably represent the most abundant natural pigment molecules which are via photosynthesis not only crucial for the autotrophic production of food sources for heterotrophic organisms but have also contributed to oxygen production essential for aerobic metabolism. This review first briefly discusses the physico-chemical properties, biosynthesis, occurrence, in vivo localization and roles of the different Chl pigments. Then we provide a detailed overview about their potential applications in the food industry and medicine. These include the use of Chls and their derivatives (different chlorophyllins) as food colorants (identified as E140 and E141 in the European Union). Different sources used for industrial extraction as well as different factors influencing pigment stability during processing are also critically reviewed. The problems surrounding the nomenclature, the production and the composition of different chlorophyllin mixtures are also discussed. Finally, a comprehensive overview of the health benefits and potential medicinal applications of these pigments and the future directions of research in these fields are provided.
\end{abstract}

Keywords: Antioxidant, cancer, chemoprevention, chlorophyll, chlorophyllin, food colorant, photodynamic therapy.

\section{INTRODUCTION}

Molecules containing four pyrroles forming a macrocycle (e.g., a porphyrin ring) are classified as closed tetrapyrroles. Chlorophylls (Chls) are conjugated, closed tetrapyrroles to which a cyclopentanone ring has been also added.

Tetrapyrrole pigments play essential roles in photosynthesis, in the absorption of sunlight and its conversion into chemical energy, finally used to reduce $\mathrm{CO}_{2}$. This energy conversion is the foundation for autotrophy in some prokaryotes (e.g., cyanobacteria), in eukaryotic algae and plants, and is essential for life. In addition, $\mathrm{O}_{2}$ is formed as a byproduct during photosynthesis, and its massive production by ancestral photosynthetic organisms present in the oceans and its accumulation in the atmosphere and the formation of the ozone layer enabled the dominance of organisms with aerobic metabolism and the colonization of the land. Chlorophyllous pigments are characteristic to some bacteria (including cyanobacteria), algae and green plants, and are thus present and synthesized in large amounts in these organisms and in all green plant parts, especially in leaves. According to estimations, the total natural production of Chls in the biosphere is around $10^{9}-10^{12}$ tons per year, the majority of which is produced by photosynthetic marine microorganisms [1,2].

*Address correspondence to this author at the Department of Plant Physiology and Biochemistry, Faculty of Biochemistry, Biophysics and Biotechnology, Jagiellonian University, Gronostajowa 7 Krakow, 30 387, Poland; Tel: 4812 664-63-64; Fax: 4812 664-69-02; E-mail: b.mysliwakurdziel@uj.edu.pl

"These authors contributed equally to the work.
Chls were first isolated by Pelletier and Caventou in 1818 who coined this term meaning 'green leaf' $(\chi \lambda \omega \rho$ ós $\varphi v ́ \lambda \lambda o v$, chloros phullon) [3]. The major features (e.g., the presence of $\mathrm{Mg}$ ) and the empirical formula of Chl was established by Willstätter and Stoll in 1913 [4], while the detailed and complete structure of the closed tetrapyrrole (porphyrin) ring was described by Fischer and collaborators $[5,6]$. Woodward et al. [7,8] have achieved and published the total chemical synthesis of Chls. However, for industrial (e.g., food-grade) applications the pigments are still extracted from plants and/or algae (see Section 4.3). Richard Willstätter (in 1915), Hans Fischer (in 1930) and Robert Woodward (in 1965) were awarded Nobel prizes for their pioneering studies elucidating Chl structure and chemical synthesis.

Among several naturally existing Chls, Chls $a, b$ and $c$ were recognized as the first chlorophyllous pigments, already in the $19^{\text {th }}$ century $[3,9,10]$. Chl $d$ [11] was discovered much later than Chls $a, b$, and $c$ however, its presence was finally confirmed in the cyanobacterium Acaryochloris marina as major pigment only in 1996 $[12,13]$. This identification clarified controversies concerning its later never confirmed artefactual presence in red algae [11], but only in their epiphytic cyanobacteria [14] and in other endolithic Acaryochloris species [15]. Chl $f$ has been only very recently identified in filamentous cyanobacteria from stromatolites [16].

In addition to their natural presence in food products derived from photosynthetic organisms, tetrapyrroles are extracted and used as natural colorants, coloring food, and/or 
antioxidants to restore the natural level of these molecules in food products, in dietary supplements, and/or to prepare fortified and functional products $[17,18]$. Chls along with phycobilins and phycobiliproteins [19] represent almost the only versatile alternatives to natural food colorants with greenish and/or bluish color. First, we review their chemical and physical properties, biosynthetic pathways as well as their role and occurrence in vivo. Finally, their applications and importance in the food industry along with their health benefits are also discussed.

\section{CHEMICAL AND PHYSICAL PROPERTIES OF CHLOROPHYLLS}

Chl belongs to tetrapyrroles, which probably represent the oldest prosthetic groups and play important roles in living organisms (reviewed by [20]). They are organic compounds consisting of four connected pyrrole rings, having a variety of side chains and/or differing in their reduction state. Closed tetrapyrroles like hemes and Chls have a metal ion inside the tetrapyrrole backbone. In case of Chls, four pyrroles form a closed ring substituted with an additional cyclopentanone ring and a long hydrocarbon chain as another substituent (Fig. 1). The conjugated double bonds on the tetrapyrrole backbone are responsible for the ability to absorb the electromagnetic radiation.

A) chlorin-type

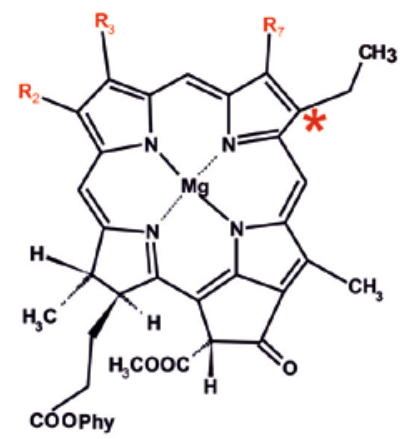

\begin{tabular}{|l|c|c|c|}
\hline Chl-s & $\mathrm{R}_{2}$ & $\mathrm{R}_{3}$ & $\mathrm{R}_{7}$ \\
\hline $\mathrm{Chl} \boldsymbol{a}$ & $\mathrm{CH}_{3}$ & $\mathrm{CH}=\mathrm{CH}_{2}$ & $\mathrm{CH}_{3}$ \\
\hline $\mathrm{Chl} b$ & $\mathrm{CH}_{3}$ & $\mathrm{CH}=\mathrm{CH}_{2}$ & $\mathrm{CHO}$ \\
\hline Chl $d$ & $\mathrm{CH}_{3}$ & $\mathrm{CHO}$ & $\mathrm{CH}_{3}$ \\
\hline $\mathrm{Chl} f$ & $\mathrm{CHO}$ & $\mathrm{CH}=\mathrm{CH}_{2}$ & $\mathrm{CH}_{3}$ \\
\hline
\end{tabular}

B) porphyrin-type

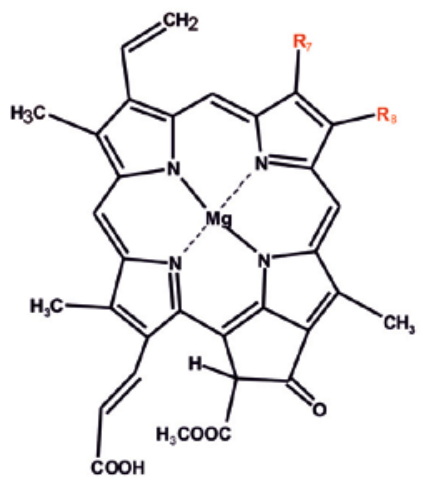

\begin{tabular}{|l|c|c|}
\hline Chl-s & $\mathrm{R}_{1}$ & $\mathrm{R}_{4}$ \\
\hline $\mathrm{Chl} c_{1}$ & $\mathrm{CH}_{2}$ & $\mathrm{CH}_{2}-\mathrm{CH}_{2}$ \\
\hline $\mathrm{Chl} c_{2}$ & $\mathrm{CH}_{3}$ & $\mathrm{CH}=\mathrm{CH}_{2}$ \\
\hline $\mathrm{Chl} c_{2}$ & $\mathrm{COOCH}$ & $\mathrm{CH}=\mathrm{CH}_{2}$ \\
\hline
\end{tabular}

Fig. (1). Chemical structures of natural chlorophylls (Chls). A) Chls having chlorin-type macrocycle. B) Chl $c$ having porphyrin-type macrocycle. Please note that $\mathrm{Chl} c$ is typically non-esterified (as shown here), however, similarly to other Chls it can also bind phytol (not shown). Phy, phytyl chain $\left(\mathrm{C}_{20} \mathrm{H}_{39}\right)$. In the case of divinyl Chl $a$ and divinyl Chl $b$, the ring substituent at $*$ is $-\mathrm{CH}=\mathrm{CH}_{2}$.

Five major Chls have been identified so far in natural photosynthetic organisms. They were named Chl $a, b, c, d$ and $f$ (reviewed in $[9,10,17,21,22]$ ). All of them have $\mathrm{Mg}^{2+}$ in the center of the tetrapyrrole macrocycle, however, they differ in the side-substituents (Fig. 1). Among Chls, Chl $a$ is the most abundant and present in all organisms performing oxygenic photosynthesis, including cyanobacteria, algae and higher plants (Table 1; reviewed in [21]). Chl $a$ occurs both in reaction centers and in antenna complexes. Due to its physicochemical properties and functional compatibility with neighbouring electron transport cofactors, Chl $a$ is a universal pigment playing a role both in light harvesting and in energy conversion [23]. Chl $b$ and $c$ were found in lightharvesting complexes but not in reactions centers in different groups of photosynthetic organisms (Table 1; see also Section 4.1). Chl $d$ is the major pigment in Acaryochloris marina, accompanied by Chl $a[12,24,25]$. Obviously, Chl $d$ acts as the light-harvesting pigment [26,27]. Nevertheless, it is still the only known Chl which was shown to replace Chl $a$ in reaction center of both photosystems [28-31]. The chemical structure of the recently discovered Chl $f$ [16] has already been confirmed by several techniques [32], although its function is still being investigated [33-36].

In general, Chls are green, which is a simple consequence of their absorption properties. They absorb energy in the blue (Soret band) and red ranges $\left(\mathrm{Q}_{\mathrm{x}}\right.$ and $\mathrm{Q}_{\mathrm{y}}$ bands) corresponding to $\mathrm{S}_{0}-\mathrm{S}_{2}$ and $\mathrm{S}_{0}-\mathrm{S}_{1}$ transitions, respectively, and reflect and/or scatter most of the green light, because of the gap in the absorption spectrum (for reviews see $[9,23])$. Absorption spectra of different Chls differ in the positions of their maxima (Table $\mathbf{1}$ ). 
Table 1. Occurrence of various chlorophylls (Chls) among major photosynthetic taxa and their $\mathbf{Q}_{\mathrm{y}}$ absorption maxima in organic solvents.

\begin{tabular}{|c|c|c|c|c|c|c|}
\hline & & Chl $a$ & Chl $b$ & Chl $c$ & Chl $d$ & Chl $f$ \\
\hline \multirow{12}{*}{$\begin{array}{l}\text { Occurrence in } \\
\text { various major taxa } \\
\text { of photosynthetic } \\
\text { organisms }^{(1)}\end{array}$} & Cyanobacteria $^{(2)}$ & + & + & - & + & + \\
\hline & Glaucophytes & + & - & - & - & - \\
\hline & Red algae & + & - & - & - & - \\
\hline & Brown algae & + & - & + & - & - \\
\hline & Diatoms & + & - & + & - & - \\
\hline & Haptophytes & + & - & + & - & - \\
\hline & Cryptophytes & + & - & + & - & - \\
\hline & Dinoflagellates & + & - & + & - & - \\
\hline & Green algae & + & + & - & - & - \\
\hline & Euglenids & + & + & - & - & - \\
\hline & Chlorarachniophytes & + & + & - & - & - \\
\hline & Land plants & + & + & - & - & - \\
\hline $\begin{array}{l}\text { Qy absorption } \\
\text { maximum }\end{array}$ & $100 \%$ methanol $^{(3)}$ & 665 & 652 & $626-629$ & 696 & 707 \\
\hline
\end{tabular}

(1) After [21,37]

(2) Concerning cyanobacteria, Acaryochloris marina and related taxa contain Chl $a$ but their predominant photosynthetic pigment is Chl $d$ [12-15,24,25]; Chl $b$ - was found only in prochlorophytes as accessory pigment to Chl $a$ [38]; Chl $f$ was found only in filamentous cyanobacteria from stromatolites like e.g., Halomicronema hongdechloris [16,33].

${ }^{(3)}$ Absorption maxima are given after [9], with the exception of Chl $c$ for which maxima in 100\% acetone are provided from [39].

The Qy absorption maximum of Chls $d$ and $f$ is significantly red-shifted as compared to Chls $a, b$ and $c$, and thus Chl $d$ - and $f$-containing cyanobacteria were found in some niches with high level of infrared-radiation (reviewed in $[9,40])$. The differences in the absorption properties originate from the degree of unsaturation of the tetrapyrrole macrocycle and/or from different substituents and their different positions on the macrocycle (Fig. 1). The fully unreduced family of $\mathrm{Chl} c$ (Fig. 1), which belong to porphyrins, has the most blue-shifted $\mathrm{Q}_{\mathrm{y}}$ absorption maximum among Chls, i.e., about 626-629 nm [23,39]. The different absorption properties of Chls $a, b, d$ and $f-$ all having chlorin-type ring structure with 10 double bonds originate from different positions of the formyl substituent of the macrocycle [9] (Fig. 1). Obviously, phytyl increases the lipophilicity of Chls but influences only slightly their absorption and fluorescence properties [41,42]. Phytyl being a long and bulky substituent may contribute to the stabilization of Chl conformation, which may be crucial for fine tuning of the pigment by apoproteins [42].

It is commonly known that Chls show red fluorescence. Measurement of in vivo Chl fluorescence is a widely used method for the determination of the photosynthetic activity of various organisms, especially for the investigation of photosynthesis under stress conditions (reviewed in [43]). Chl fluorescence imaging is also a useful technique to monitor food quality during storage (further discussed in Section 5.1).

Chl $c$, similarly to the Chl biosynthesis intermediates, chlorophyllides (Chlides) and protochlorophyllides (Pchlides) (see Section 3), lacks the phytol chain and is dissolvable in water and polar solvents. (However, it should be noted that occasionally Chl $c$ can also be esterified [39].) Phytylated Chls (i.e., Chls $a, b, d$ and $f$ ) are hydrophobic and can be extracted from plant material with organic solvents, for example acetone, ethanol, benzene and others, resulting in greenish-colored solution.

Extracted Chls can be purified and separated from accompanying pigments (e.g., carotenoids) using phase separation or HPLC methods, and determined using spectrophotometry or fluorimetry (reviewed in $[17,44-47]$ ). Broad-scale industrial extraction of pigments is further discussed in Section 4.3.

\section{BIOSYNTHESIS OF CHLOROPHYLLS}

The biosynthesis of Chl involves the synthesis of two moieties: (1) a chlorin ring, which is synthesized by a specific branch of tetrapyrrole biosynthesis, and (2) a phytol chain produced by the isoprenoid (terpenoid) biosynthesis pathway (Fig. 2). 
ISOPRENOID BIOSYNTHESIS

Isopentenyl diphosphate + Dimethylallyl diphosphate

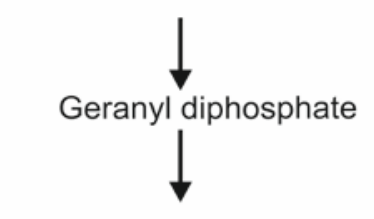

Geranylgeranyl diphosphate

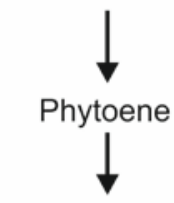

\section{CAROTENOIDS}

Fig. (2). The overall scheme of tetrapyrrole biosynthesis and its relation to isoprenoid biosynthesis providing the phytol side chain for chlorophylls $a, b, d$ and $f$. Abbreviations: ALA, 5-aminolevulinic acid; Chlide, chlorophyllide; Pchlide, protochlorophyllide; Proto IX, protoporphyrin IX.

Tetrapyrrole biosynthesis is a multi-branched and conserved metabolic pathway being extensively studied for a long time. These works led to the identification of both the metabolic intermediates and the enzymes catalyzing particular reactions (reviewed in [9,20,44,48-53]). As it supplies a variety of biologically important compounds, tetrapyrrole biosynthesis is precisely regulated at different levels (reviewed in [44,50,52,54-57]). In plants, plastids are thought to be the place of photosynthetic tetrapyrrole biosynthesis, however, there is some variation in the distributions of the particular enzymes involved in this process among the membranes (thylakoids and inner envelope) and the stroma fraction (reviewed in [20]).

One can distinguish three stages in Chl biosynthesis, each leading to a key intermediate or to a branch point (Fig. 2): (1) the biosynthesis of 5-aminolevulinic acid (ALA), which is the common precursor of all tetrapyrroles, i.e., Chls, hemes, phycobilins and other compounds; (2) the formation of protoporphyrin IX (PROTO IX) and (3) the Chl synthesis branch, which is also called the $\mathrm{Mg}$ branch of tetrapyrrole biosynthesis. In plant cells, the enzymes catalyzing the reactions of this branch were identified in the thylakoid membranes or in the inner chloroplast envelope membrane fractions, whereas the earlier reactions were localized in the plastid stroma (reviewed in [20]).

In plants, algae, cyanobacteria and most photosynthetic bacteria, ALA is synthesized via a so-called $\mathrm{C}_{5}$ pathway [58-61]. This process starts from glutamate and includes three enzymatic steps: (1) the activation of glutamate by tRNA ${ }^{\text {Glu }}$, (2) the reduction of glutamyl-tRNA ${ }^{\text {Glu }}$ into glutamate-1-semialdehyde [62] and (3) the transamination of glutamate-1-semialdehyde [63]. The reduction of glutamyl-tRNA ${ }^{\text {Glu }}$ is catalyzed by glutamyltRNA $^{\text {Glu }}$ reductase, which is one of the regulatory sites of Chl biosynthesis. The second part of Chl biosynthesis starting from ALA and leading to PROTO IX formation (Fig. 2) coincides with the biosynthesis of other tetrapyrroles. An asymmetric condensation of two ALA molecules leads to the formation of porphobilinogen (a monopyrrole), which is the building block of tetrapyrroles. Four molecules of porphobilinogen are condensed head-totail to produce hydroxymethylbilane, a linear tetrapyrrole. This linear molecule is then converted to the conjugated closed macrocycle of PROTO IX in several subsequent reactions including (1) ring closure and isomerization resulting in uroporphyrinogen III formation, (2) decarboxylation of acetate side chains leading to 
coproporphyrinogen III and (3) two successive oxidation reactions. PROTO IX sits at the branching point between chlorophyll and heme synthesis, also known as Mg-branch and Fe-branch, respectively. The Mg-branch, leading finally to the formation of $\mathrm{Chl} a$, starts from the incorporation of $\mathrm{Mg}^{2+}$ ion into the backbone of PROTO IX, which is catalyzed by $\mathrm{Mg}$ chelatase. $\mathrm{Mg}$ chelatase is a heterologous complex composed of three subunits designated I, D and $\mathrm{H}$, and is relatively unstable $[9,52,53]$. The assembly of the complex is thoroughly regulated by the level of $\mathrm{Mg}^{2+}$, among others, and the complex requires ATP for catalysis [64-66]. The incorporation of $\mathrm{Mg}$ is followed by the methylation of Mg-protoporphyrin IX and the formation of the cyclopentanone ring, which is characteristic to Chl related pigments. Then two successive reductions lead to the formation of chlorophyllide (Chlide). One of them is the reduction of the C8-vinyl group to an ethyl group, in which divinyl protochlorophyllide (DV-Pchlide) is converted to monovinyl protochlorophyllide (MV-Pchlide). In the other reaction, the $\mathrm{C} 17-\mathrm{C} 18$ double bond of the ring $\mathrm{D}$ of protochlorophyllide (Pchlide) becomes reduced resulting in Chlide formation. (However, the order of these two reductions is not strictly determined, i.e., DV-Chlide can be also transformed to MV-Chlide after the transformation of DV-Pchlide to DV-Chlide.) The Pchlide to Chlide reduction changes the symmetry of the conjugated double bond system of the tetrapyrrole macrocycle from porphyrin to chlorin (i.e., containing 11 or 10 double bonds, respectively) and results in a significant red-shift of the absorption and fluorescence maxima of Chlide when compared to Pchlide. Photosynthetic organisms developed independently two different enzymes catalyzing the reduction of Pchlide, that is, light-dependent Pchlide oxidoreductase (LPOR) and lightindependent Pchlide oxidoreductase (DPOR), reviewed in $[51,52,67]$. Even though DPOR and LPOR catalyze the same stereospecific reaction, both the enzymes and the mechanisms of the reduction are completely unrelated. Nevertheless, recently some similarity between amino acid sequences of these enzymes was shown [68], although the functional role of this fragment has not yet been elucidated. LPOR appeared probably later than DPOR during evolution, which is interpreted as a consequence of the evolution of oxygenic photosynthesis and oxygenic atmosphere, toxic to DPOR (reviewed in [67]).

DPOR consists of three polypeptides, L, B and $\mathrm{N}$ (reviewed in [67]). Concerning the amino acid sequence, structure and catalytic mechanism, DPOR is a nitrogenaselike enzyme [69-72], which operates in all photosynthetic organisms that can perform Chl synthesis in darkness (for further details see [9,73]). DPOR is the only enzyme catalyzing Pchlide reduction in anoxygenic bacteria such as Rhodobacter capsulatus and Rhodobacter sphaeroides [73]. In the majority of the photosynthetic organisms (i.e., cyanobacteria, most eukaryotic algae, lower plants and gymnosperms) both DPOR and LPOR participate in Chl biosynthesis. Angiosperms are exceptions: they require light to perform Chl synthesis because they do not have the genes encoding DPOR polypeptides. In these plants, the LPORcatalyzed Pchlide reduction is one of the key steps in the regulation of Chl biosynthesis besides playing an important role in the regulation of plant development and the assembly of the photosynthetic apparatus (reviewed in [74,75]). LPOR is a single polypeptide enzyme classified as short-chain dehydrogenase/reductase (SDR) enzyme [76,77]. The mechanism and regulation of light-triggered Pchlide reduction has been the subject of several reviews [78-80]. The light-triggered Pchlide photoreduction plays a fundamental role in plant deetiolation, which is the switch between the growth in the absence (skotomorphogenesis) and in the presence (photomorphogenesis) of light (reviewed in $[74,75])$. Pchlide reduction is not triggered in darkgerminated angiosperms, therefore $\mathrm{Chl}$ biosynthesis is arrested and Pchlide gets accumulated in peculiar plastids developing in the absence of light, the so-called etioplasts. The characteristic feature of the inner membranes of etioplasts is the presence of a highly regular threedimensional paracrystalline lattice that is built of tubular membranes containing ternary complexes of Pchlide:LPOR:NADPH (reviewed in [75,79,81,82]).

Chlide esterification catalyzed by chlorophyll synthase is the last step in Chl biosynthesis (reviewed in $[83,84])$. The addition of the diterpene side chain to the C17 propyl moiety of Chlide only slightly influences the spectral properties of the pigment and its photophysical properties [41], although it increases the lipophilicity of the product. Both Chlide $a$ and Chlide $b$, and both MV- and DVsubstituted Chlides are accepted as substrates by the enzyme and are converted to respective Chl $a$ and Chl $b$. The other substrates of this reaction, geranylgeranyl diphosphate or phytyl diphosphate, are C20 isoprenoid alcohol side chains originating from the isoprenoid biosynthesis pathway (Fig. 2). Reduction of geranylgeranyl to phytol can occur either before or after Chlide esterification and is catalyzed by a hydrogenase using NADPH as hydrogen donor (reviewed in [83]). However, in etiolated plants illuminated with light most Chlide is phytylated first with geranylgeraniol, which is subsequently reduced to phytol in a four step process [85]. Alternatively, Pchlide can be accepted as substrate by Chl synthase resulting in the formation of protochlorophyll (Pchl). However, Pchl cannot be converted by LPOR and accumulates as a side product in the seed coats of some Cucurbitaceae such as Cucurbita pepo [86-89], Luffa cylindrica [90] and Cyclanthera explodens [91]. Relatively small amounts of Pchl was also found in etiolated plant material (e.g., [92], reviewed in [82]) as well as under natural growth conditions in cabbage heads [93,94], different young organs $([95,96])$ including the innermost leaves of buds [97-99] (reviewed in [74,75,82]). It may be noted that etiolated plants only contain Pchlide $a$, reports about the presence of Pchlide $b$ by the Reinbothe group [67] represent probably artefacts [100].

Chl biosynthesis is tightly regulated, mainly to prevent the accumulation of unsaturated porphyrin/chlorin compounds which readily absorb light energy and act as photosensitizers (e.g., [101-103]). Moreover, this regulation is required to keep the right proportions between the synthesis of different tetrapyrroles, i.e., hemes, Chls, phytochromes, phycobilins, etc., which are important for different metabolic processes. The mechanisms of this regulation are still intensively investigated and the current state of knowledge is summarized in [50,74,79,104,105]. 
Chl $d$ is synthesized from Chl $a$, whereas the biosynthesis of Chl $f$ has not yet been elucidated [9]. Similarly, little is known about $\mathrm{Chl} c$ biosynthesis (reviewed in $[39,106])$. It has been suggested that MV- and DV-Pchlide are converted into $\mathrm{Chl} c_{1}$ and $c_{2}$ due to oxidation followed by dehydration of the propionyl side-chain to form a double bond, however, the respective oxidase $\left(17^{1}\right.$ oxidase) is still hypothetical and may be responsible for several reactions [106]. It was confirmed that $\mathrm{Chl} c_{1}$ has identical chemical structure to Pchlide $a$ except a double bond in the side chain at C-17 (Fig. 1B) and is thus a competitive inhibitor of LPOR [107].

\section{OCCURRENCE, LOCALIZATION AND ROLES OF CHLOROPHYLLS IN VIVO}

Except chemoautotrophy and special bacteriorhodopsin- or proteorhodopsin-based photosynthesis present in some prokaryotes (archaea), global autotrophy strongly relies on Chl-based photosynthetic processes. The latter can be observed in some primitive non-oxygenevolving (i.e., anoxygenic) bacteria, and oxygen-evolving organisms such as cyanobacteria (the chloroxybacteria sensu lato including Chl $b$ containing prochlorophytes and organisms having $\mathrm{Chl} d$ like Acaryochloris marina), eukaryotic algae and plants. Chl (or bacteriochlorophyll) molecules are essential for all these photosynthetic organisms and are, therefore, widely distributed among them (Table 1) [108].

\subsection{Occurrence and Roles}

Even anoxygenic green sulfur bacteria and heliobacteria contain traces of minor variants of Chl $a$ functioning as an intermediate in the electron transport chain, however, most anoxygenic prokaryotes (e.g., purple bacteria, green sulfur bacteria, green non-sulfur bacteria and heliobacteria) use various bacteriochlorophylls during photosynthesis [108].

In oxygen-evolving (oxygenic) photosynthetic organisms, Chl $a$ has crucial role in the photosynthetic energy conversion process in the reaction center where it is present in a dimeric form (with Chl $a$ ' isomer representing the half of the P700 reaction centers). In some algae (i.e., dinoflagellates) Chl $a$ and a special carotenoid, peridinin form light-harvesting antenna complexes [108]. Prochlorococcus, a prochlorophyte, exceptionally contains DV-Chl $a$ instead of MV-Chl $a$ [109].

Other chlorophyllous pigments, carotenoids (reviewed e.g., in [110]) and phycobilins (reviewed in [19]) are involved in photosynthetic light capture as accessory pigments absorbing and transferring sunlight energy from the antennae towards the reaction centers, while pheophytin is an essential component of photosystem II and the electron transport chain [108].

Algae have various accessory pigments both in terms of carotenoids (especially xanthophylls [110]) and chlorophyllous pigments (Table 1). For instance, Chl $b$ is the major accessory pigment of prochlorophytes, euglenoids, chlorarachniophytes, green algae and plants, while Chl $c$ is present in cryptophytes, haptophytes, dinoflagellates and stramenopiles (also known earlier as heterokontophytes including major taxa like Bacillariophyceae, Chrysophyceae, Xanthophyceae, and different brown algae) (Table 1) $[37,108]$.

It has to be mentioned that in addition to the 'real' autotrophic photosynthetic organisms discussed above and relevant for industrial extraction of Chls, some protozoans (foraminifera and ciliates) and metazoans (like sacoglossans of Elysia, Tridacna and Placobranchus genera) may also acquire and harbor intracellularly intact and functional chloroplasts (so-called kleptoplasts) from photosynthetic organisms, and thus, may also contain Chls [111].

\subsection{Localization}

In vivo, photosynthetic tetrapyrroles are bound to lipid-containing photosynthetic protein complexes located in membranes, and have photosensitizing effect when not bound to proteins. In prokaryotes (cyanobacteria and prochlorophytes) Chls and photosynthesis are located in the thylakoids in the cytoplasm, while in eukaryotes, Chls and photosynthesis is located in the thylakoid membranes of chloroplasts of various origins and structures [112,113].

Obviously, chloroplasts represent the major sites of Chl accumulation and photosynthesis in eukaryotes, where the light phase of photosynthesis and Chls are located to thylakoids, and the dark phase proceeds in the stroma (Fig. 3) [108]. In land plants, stacked grana and unstacked stroma thylakoids can be distinguished (Fig. 3A), which also differ in the distribution of photosynthetic pigment-protein complexes. However, in most photosynthetic eukaryotic algal groups thylakoids are parallelly arranged into 2-6 layered assemblies, the so-called lamellae [37,112] (Fig. 3B). Organisms having phycobilisomes (most cyanobacteria, rhodophytes and glaucophytes) represent an exception to this rule and contain single thylakoid lamellae [19,37,112].

In addition to photosynthesis, plastids harbor several crucial metabolic pathways. The structural and functional specialization of plastids can be already observed in some algae [112], but becomes more prominent in land plants, in which plastid differentiation occurs in several distinct directions [113]. It is noteworthy to mention that Chls and their accumulation can be also observed during all plastid differentiation processes that lead directly to chloroplast formation. Chl synthesis occurs during different stages of greening, i.e., in the single thylakoids of some proplastids (e.g., [95,98,99], or in developing grana of young chloroplasts and/or etio-chloroplasts (e.g., [95,96,98,99]), or along the development of the photosynthetic apparatus during chromoplast-to-chloroplast or amyloplast-tochloroplast transformation pathways. Similarly, Chl (and its breakdown products) can be observed during chloroplast senescence (e.g., [93]) or during all plastid transformation processes starting from chloroplasts such as for instance chloroplast-to-chromoplast or chloroplast-to-amyloplast differentiations during fruit ripening. 


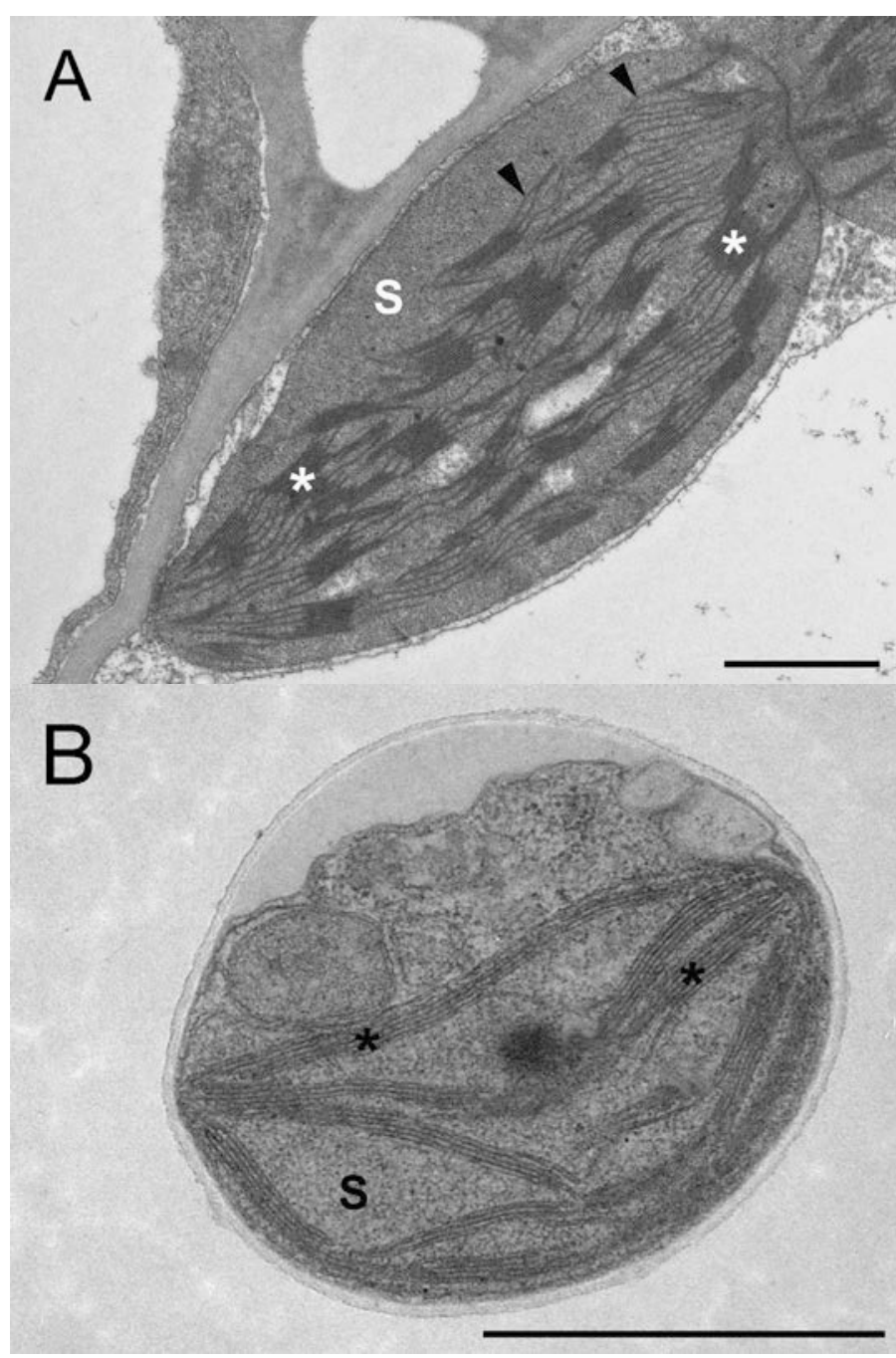

Fig. (3). Chloroplast ultrastructure in various photosynthetic eukaryotes. A) Chloroplast with grana and stroma thylakoids from 14-day-old light-grown pea leaf (Pisum sativum). B) Chloroplast with thylakoid lamellae from the green alga, Pseudochloris wilhelmii. S: stroma; white asterisk: granum; black asterisk: thylakoid lamella; black arrowhead: stroma thylakoid. Bar: 1 um.

Plastid differentiation occurs in parallel with cellular, tissue and organ differentiation observed in land plants. Consequently, Chl accumulation is most prominent in the photosynthetically active chlorenchyma tissues in leaves (i.e., leaf mesophyll cells), green stems, floral parts and fruits. Occasionally, Chl may be observed in the seeds/embryos of some species or in the aerial roots of some epiphytic orchids.

\subsection{Sources for Industrial Extraction}

Green leaves typically contain approx. $0.25 \%$ Chls [114] or up to $1 \%$ Chl on dry weight basis in case of spinach [115]. Taken together, for industrial applications green leaves represent the ideal source for Chl extraction, although emerging techniques and new methods have been developed that rely on cyanobacteria (e.g., Arthrospira [116]) or microalgae (Chlorella [117]) (reviewed in [1,21,118,119]). Leaves of for instance alfalfa, grass [120], nettle [121], and edible plants (including spinach [122,123]) can be also used, but dried alfalfa plants represent the primary source for the production of the food colorant especially in the United States [118,120,124-126].

Dried (dewatered) or fresh plants, and in case of marine species desalted microalgal biomass are extracted in general by conventional organic solvent extraction (using mainly acetone, ethanol or hexane alone or in combination), but supercritical fluid extraction may be also applied [1]. In the Far East, Chl is also extracted from silkworm droppings and mulberry (Morus) leaves, neither being allowed sources in the European Union and the United States [124]. Silkworm droppings are used as folk medicine in the Far East and contain - among others - pheophorbide [127] and 10-hydroxypheophytin $a$, a Chl metabolite [128], and may be even used for the production of food colorants (Na-Cuchloropyllins - for details see Section 5.2) [129].

\section{CHLOROPHYLLS AS HIGH VALUE COMPOUNDS}

Chlorophyllous pigments may be used by the food industry and in medicine. However, pigment stability, composition and purity have to be carefully considered before their potential industrial applications and will be thus reviewed below. In addition to the best known Chl $a$ and $b$ pigments and their direct derivatives discussed below in detail, it is noteworthy to mention that other Chl-s and their precursors are also consumed by humans along with food. For instance Chl $c$ is present in food products of red or brown algal origin, Pchlide and Pchl in cabbage heads [93,94], edible dark-germinated sprouts, pumpkin seeds [8689] and their seed oils [130][130,131], etc. Some of them are also present in products used by the health industry (e.g., in health promoting or medicinal products based on pumpkin seeds and thus containing Pchl but also polyunsaturated fatty acids, tocopherol and phytosterols as active ingredients). However, this review is dedicated to Chl $a$ and $b$ and some of their derivatives directly investigated and used by the food industry and medicine.

\subsection{Stability of Chlorophylls}

When removed from their native environment (i.e., from the Chl-protein complexes of the photosynthetic apparatus) Chls are highly sensitive molecules to light, low $\mathrm{pH}$, high temperature, enzyme reactions and oxygen [17]. This sensibility can be observed both in vivo and in vitro, with Chl $b$ being in general more stable than Chl $a$ (e.g., [132-135]).

In vivo, Chl-containing fresh vegetables and fruits contain a number of enzymes like peroxidases and lipoxygenases, but also other enzymes and substances involved in natural Chl breakdown which can induce pigment degradation from so-called 'free' Chl pigments. The chlorophyllase enzyme (EC 3.1.1.14) is responsible for the cleavage of the phytol chain during Chl breakdown associated with the chloroplast-chromoplast transformation during fruit ripening [136] and with herbivory, where the product, Chlide, has been recently suggested to play a role in protection against herbivores [137]. Chlide is then demetallated by a metal chelating substance to yield 
pheophorbide [138]. However, in contrast with this generally accepted Chl-Chlide-pheophorbide degradation pathway, recently it has been shown that during leaf senescence and Chl breakdown during stress, the removal of $\mathrm{Mg}$ from Chl by this metal chelating agent preceeds deesterification [139]. This results in the formation of pheophytin, which is finally cleaved to pheophorbide by pheophytinase [139]. The removal of the phytol chain increases water solubility and together with the removal of $\mathrm{Mg}$ these steps are leading to the elimination of Chls and their various photosensitizing breakdown products via the Chl degradation pathway (for review see [140]). However, plants with high chlorophyllase content or activity (e.g., Heracleum [114] and other species [141]) must be avoided during Chl extraction (but may be used for Chlide extraction instead).

In addition to these processes, saponification with strong alkali also induces the cleavage of the phytol chain [118], while heat stress or acidification result in the loss of the central $\mathrm{Mg}$ even in enzyme-free systems. Strong light and/or very strong heat treatment (e.g., heating Chl in cottonseed oil at $180{ }^{\circ} \mathrm{C}$ for $60 \mathrm{~min}$ [142]) can lead to complete destruction of the pigments and thus the bleaching of the food product. In addition to preventing Chl degradation in food products, the texture, flavor and nutritional quality of the products must be also preserved.

Taken together, special care has to be applied to avoid these and other Chl degradation reactions (i.e., by inactivation of the above-mentioned enzymatic activities) during the storage, extraction, isolation, processing of $\mathrm{Chl}$ from plants and/or during the treatment of Chl-containing foodstuff and/or medicinal products [17]. This issue is even more delicate for the food industry because consumers often associate changes resulting in olive-green or brownish Chl breakdown products (pheophytins, pheophorbides and/or pyropheophorbides) with wilting, aging and decreased commercial value of the fresh, deep-frozen, canned, sterilized or cooked products. This is probably due to the fact that bright green color is generally perceived as representing freshness, palatability and nutritional quality, while unappealing color rises suspicion about the food quality $[17,143]$. This is evenmore important because the brain associates color with flavor [144] and olive-green color is generally perceived and identified as the least appealing color.

Therefore, the bright green color of Chl containing products can be maintained by using (1) controlled atmosphere and/or low temperature and/or low light (or dark) storage, or (2) post-harvest treatment of the product with adequate phytohormones such as cytokinins or gibberellins, or (3) processing in milder conditions (e.g., using blanching, dehydration, freeze-drying, hightemperature short-time processing method or by $\mathrm{pH}$ adjustment in case of some products) [143]. However, the optimal treatment varies a lot depending on the species and the product under study, and in some cases heat treatment is necessary to inactivate the $\mathrm{Chl}$ degrading enzymes present in the plants in vivo, thus, an optimal treatment for preservation of both the product and its color has to be determined for each commodity [17]. The addition of natural food colorants is an alternative to 're-green' the color of such foodstuff after preservation and other, sometimes unavoidable pretreatments.

In addition to unfavorable changes in the color of the Chl-containing food products, it is also important to avoid such reactions in health care products because these different breakdown products have different solubility, bioavailability and bioactivity. In some countries (e.g., in Japan) the pheophorbide level of food products is regulated by the Food and Health Administration ( $1 \mathrm{mg} \mathrm{g}^{-1}$ ) due to their negative health effects (i.e., photosensitization in the human skin) $[145,146]$.

Chl molecules and their derivatives have light sensitization effects also in the food products. For example their presence (even in sub-ppm levels) may trigger a rapid degradation of the citrus juice flavor, especially at low $\mathrm{pH}$ [147]. As a consequence, analytical methods to detect pigments in crops (and during their ripening - e.g., in lemon using non-invasive Chl fluorescence imaging [148]), and in foodstuff are important in food quality control during processing and storage and sometimes also to detect adulteration (especially in case of synthetic food colorants which are still two to 10 times cheaper than natural ones [17,122]). Similarly, both Chls $a$ and $b$ and pheophytins $a$ and $b$ have strong photooxidation promoting effect on methyl-linoleate and triglycerides in oils indicating that special attention has to be paid to Chl and its degradation products during quality control of vegetable oils $[149,150]$.

\subsection{Use as Food Colorants}

As discussed above (Section 5.1), in order to increase the marketability of the products special care has to be taken during food processing to retain and/or restore the green color of Chls and to avoid the formation of their less attractive colored and/or less healthy breakdown products in all commodities containing Chls (either inherently or as color additives or as medicinal products).

One major problem limiting the use of Chls as direct food colorants is that the central $\mathrm{Mg}$ is easily lost during processing. This can be solved by replacing this ion with other metals within the macrocycle resulting in more stable Chl-metal complexes. The other limiting factor is the high hydrophobicity of the pigment molecule imparted by its long hydrophobic phytol chain (derived from phytol - $\mathrm{C}_{20} \mathrm{H}_{39} \mathrm{OH}$ ) and by a fifth ring (cyclopentanone) in the macrocycle [125]. Chemical modification of these groups can increase the water-solubility of Chl derivatives and provides watersoluble food colorants.

The enhanced color and stability of $\mathrm{Cu}$ and $\mathrm{Zn}$ chelates of Chl derivatives, pheophytins and pheophorbides, was first described by [4]. However, for the same purpose people have been using copper kettles and/or coins to replace $\mathrm{Mg}^{2+}$ by $\mathrm{Cu}^{2+}$ in Chls during fermentation, cooking or brining of pickles since centuries. On the basis of the same phenomenon cupric sulphate (and copper oxide) were also evaluated by the Scientific Commitee for Food as food additive to be used as a color stabilizer of canned green beans and cucumber salad [151,152]. Such molecules (i.e., Zn- or Cu-Chl derivatives such as pheophytins and pyropheophytins) may be also rarely formed spontaneously via complexation with plant-derived $\mathrm{Zn}^{2+}$ or $\mathrm{Cu}^{2+}$ ions during 
for example thermal food processing of plants with high levels of these ions $[153,154]$ or in case of food processing (e.g., blanching) carried out in solutions of these ions (e.g., $\mathrm{Zn}^{2+}$ ) [155]. These protocols result in color improvement of the processed food.

The term chlorophyllin (used sensu lato in the food industry and science) refers to semi-synthetic Chlide derivatives of various structures (and often represents itself a mixture of different pigments including pheophorbides and other pigments without the cyclopentanone ring like e.g., chlorins [125]). Chlorophyllins differ most importantly in the identity of the cations associated with the porphyrin ring (anion). After the extraction from plants (see Section 4.3) the synthesis of different chlorophyllins starts with the alkaline hydrolization (saponification) of natural Chl in alkaline medium (using methanolic sodium hydroxide), that both removes the phytol group and opens the isocyclic ring $[119,125]$ to increase the solubility of the pigment. $\mathrm{Na}^{+}$or $\mathrm{K}^{+}$ ions may bind to the carboxylic groups of the porphyrin ring and stabilize its structure. After saponification (or instead of it), copper sulfate in acidic medium can also be added to replace the central $\mathrm{Mg}^{2+}$ by $\mathrm{Cu}^{2+}$ and to increase this way the chemical stability of the pigment $[118,125]$. Besides the predominantly used $\mathrm{Cu}^{2+}$, divalent cations such as $\mathrm{Fe}^{2+}$ and $\mathrm{Zn}^{2+}$ (e.g., [155]) can be also used to replace the central $\mathrm{Mg}^{2+}$ ion during food processing. This may be especially useful to retain the green color of processed green food products (i.e., thermally processed peas [155]), which would otherwise turn olive-brown due to pheophytin/phephorbide formation. When $\mathrm{Cu}^{2+}$ replaces the central $\mathrm{Mg}^{2+}$ of $\mathrm{Chl}$ and $\mathrm{Na}^{+}$ions bind to the carboxylic groups of the porphyrin ring, the newly formed molecule is termed sodium-copper-Chl (Na$\mathrm{Cu}-\mathrm{Chl}$, but is in fact sodium-copper-pheophytin). Due to the chemical reactions occurring in the semi-synthetic process and also due to the original and natural heterogeneity of $\mathrm{Chl}$ pigments in plants, Cu-chlorophyllins constitute a complex mixture of various chlorin-based compounds [125], and similarly, a multiplicity of pigments can be detected in commercially available color formulations and in (processed) food products supplemented with this pigment [156]. The major component of commercial $\mathrm{Cu}-$ chlorophyllin is Cu chlorin $e_{4}[124,157]$. Semi-synthetic $\mathrm{Cu}-$ chlorophyllin can be made very pure and as it is water soluble it contains no carotenoids [124].

The above-mentioned Chl derivatives may have increased water-solubility and stability than the original Chls, especially to acids [119] and high temperatures [158], and have better tinctorial power [125]. Thus metalsubstituted Chl derivatives have a potential use as blue-green colorants of beverage and are also useful to avoid accumulation of Chl degradation products during processing or storage [1,47]. Liposoluble (hydrophobic) Chl or pheophytin derivatives can be either directly applied in less polar (also lipophilic) products or must be first mixed with a small quantity of vegetable oil to obtain the desired solution to be used later.

Mg-containing 'true' Chls and their direct derivatives are accepted food colorants in the European Union (E140)[126] and several countries (but not in the United States) $[118,120]$. E140i (also termed CI Natural Green 3, color index number 75810) corresponds to liposoluble MgChls $a$ and $b$ as well as their pheophytins directly extracted from plants, while E140ii (also termed CI Natural Green 5, color index number 75815) represents water soluble chlorophyllins (Na- or K-chlorophyllins without phytol and with or without the central $\mathrm{Mg}^{2+}$ ) [17,126]. E140ii is obtained by alkali treatment (saponification) and subsequent neutralization by K and/or Na salts [126].

In accordance with altered European Union regulations, the European Food Safety Authority (EFSA) has very recently reviewed the use of E140ii as individual food colorant [159]. They stated that its safety cannot be actually assessed because of the confusing and inconsistent use of the term chlorophyllin by scientists and the food color industry, and the fact that its composition is not clearly defined. Therefore, chlorophyllins and their structures have been also defined sensu stricto [159] (Fig. 4), while it was pointed out that the commercially available E140ii typically contains chlorin $e_{6}$ and rhodin $g_{7}$ (Fig. 4) which seem to be the primary breakdown products of Chl $a$ and $b$, respectively, upon alkaline hydrolysis [159]. This is due to the fact that this reaction does not only remove the phytol chain (and a methyl side chain), but also often leads to the disruption of the isocyclic (cyclopentanone) ring, therefore, a great variety of different compounds are formed [125]. Chlorophyllins (as defined sensu stricto above, Fig. 4) and other tetrapyrrole compounds present in E140ii (chlorins and rhodins, etc., Fig. 4) have different physico-chemical properties than Chls (E140i) and are not present in the regular human diet and do not represent natural Chl metabolites in humans, therefore, read-across for systemic toxicity data between these compounds is not supported [159]. In addition, due to nomenclature problems, most previous studies on the absorption, distribution, metabolism and excretion (ADME) and toxicity of chlorophyllins (E140ii) were conducted on Cu-substituted chlorophyllins, and are thus not readily acceptable for E140ii typically containing demetallated chlorins. As a consequence, the definition, the identity, and the safety of E140ii has to be carefully and separately revised before its (further) use on the market. Unfortunately, scientific papers also often use only the product and term 'chlorophyllin' sensu lato to describe the commercially available complex mixture of $\mathrm{Chl}$ derivatives. Therefore, later (e.g., below and in Sections 5.3 and 6) we will also use this term in a wider sense, unless otherwise stated. 

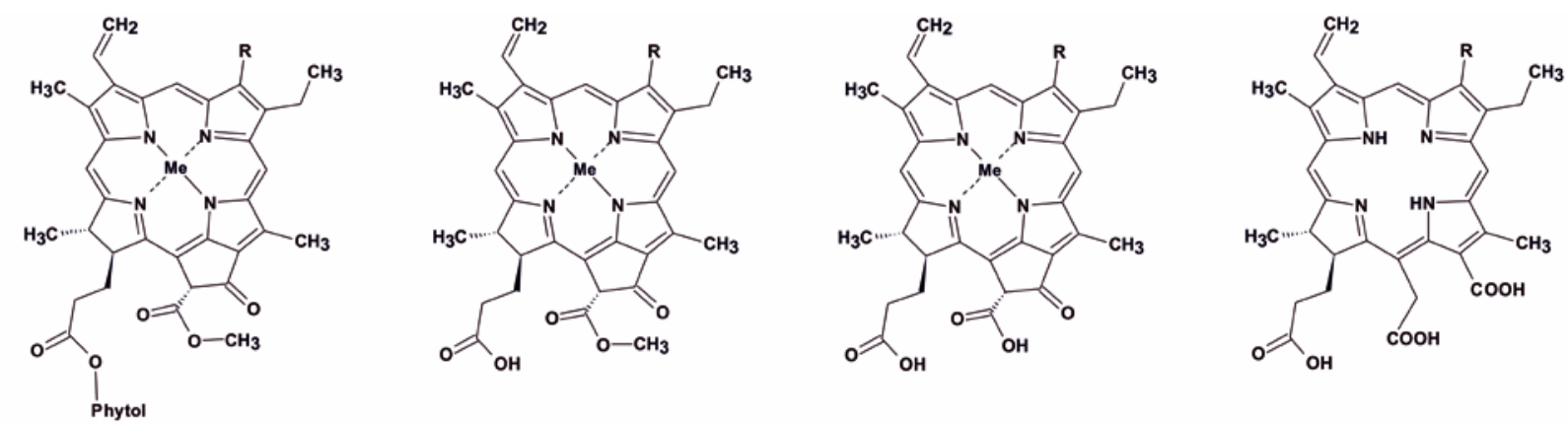

Me R

\begin{tabular}{|c|c|c|c|c|c|}
\hline $\mathrm{Mg}$ & $\begin{array}{l}\mathrm{CH}_{3} \\
\mathrm{CHO}\end{array}$ & $\begin{array}{l}\text { chlorophyll a } \\
\text { chlorophyll b }\end{array}$ & $\begin{array}{l}\text { chlorophyllide a } \\
\text { chlorophyllide b }\end{array}$ & $\begin{array}{l}\text { chlorophyllin a } \\
\text { chlorophyllin b }\end{array}$ & \\
\hline \multirow{2}{*}{$\mathrm{Cu}$} & $\mathrm{CH}_{3}$ & copper pheophytin a & copper pheophorbide a & copper chlorophyllin a & \\
\hline & $\mathrm{CHO}$ & copper pheophytin b & copper pheophorbide b & copper chlorophyllin b & \\
\hline \multirow{2}{*}{ - } & $\mathrm{CH}_{3}$ & pheophytin a & pheophorbide a & & chlorin $\mathrm{e} 6$ \\
\hline & $\mathrm{CHO}$ & pheophytin b & pheophorbide $b$ & & rhodin $\mathrm{g}_{7}$ \\
\hline
\end{tabular}

Fig. (4). Structure of chlorophyll and its major derivatives used by the food industry or produced during food processing or digestion (e.g., pheophytins and pheophorbides).

Copper-Chl food colorings have been produced since 1926 [114]. Chlorophyll(in) derivatives containing $\mathrm{Cu}$ as central ion in the macrocycle and occasionally binding $\mathrm{Na}^{+}$ ions as well are also approved food colorings (E141, color index number 75815) (Figs 4 and 5). E141i represents liposoluble $\mathrm{Cu}-\mathrm{Chls}$ (more exactly Cu-pheophytins, possessing the phytol side chain, and also termed CI Natural Green 3), while E141ii corresponds to water-soluble $\mathrm{Na}-\mathrm{Cu}-$ chlorophyllins and $\mathrm{K}-\mathrm{Cu}$-chlorophyllins (sensu lato, without phytol, also termed CI Natural Green 5) [17,126,152]. E141i is obtained by the addition of $\mathrm{Cu}^{2+}$ salts to the substance obtained by natural extraction of Chls (i.e., a mixture containing both Chl $a$ and $b$, some carotenoids, vaxes, fatty acids, etc.) [126]. E141ii is obtained by saponification of extracted Chl containing substance resulting in the removal of the methyl and phytol ester groups, and partial cleavage of the cyclopentanone ring, followed by addition of $\mathrm{Cu}$ salts to substitute the central $\mathrm{Mg}^{2+}$, and $\mathrm{Na}^{+}$and/or $\mathrm{K}^{+}$ions to neutralize the acid groups [126] (Fig. 5).

After the first extraction step (for E140i) and the addition of $\mathrm{Cu}$ salts (in case of E141i), the organic solvents are removed and a dark green, blue-green or olive-green oleoresin (vaxy solid) is obtained that contains typically 10$20 \%$ Chls along with co-extracted other lipophilic components including carotenoids (predominantly lutein and $\beta$-carotene), vaxes and fatty acids [126]. In case of E140ii and E141ii dark green or blue/black powders are obtained after the saponification process and the purity of tetrapyrroles (chlorophyllins sensu lato) can reach 90-95\% [126] due to the fact that these pigments are water soluble,

$\mathrm{XXX}-\mathrm{XXX} / 14 \$ 58.00+.00$ therefore, the lipophilic compounds (carotenoids, vaxes, etc.) present after the simple extraction step are no longer present. However, these also contain a complex mixture of compounds.

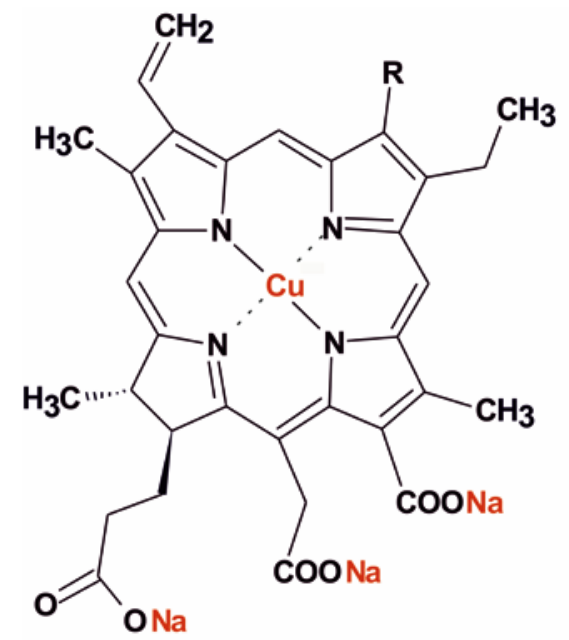

Fig. (5). Structure of Na-Cu-chlorin $e_{6}\left(\mathrm{R}=\mathrm{CH}_{3}\right)$ and Na$\mathrm{Cu}$-rhodin $g_{7}(\mathrm{R}=\mathrm{CHO})$ present in E141ii.

The European Union has approved the use of $\mathrm{Cu}-$ chlorophyllin and $\mathrm{Cu}-\mathrm{Chl}$ complexes in a broad range of foodstuffs [160]. Na-Cu-chlorophyllin is also an approved food colorant in the United States exempt from certification [120]; however, at present its usage is restricted to dry mix citrus-based beverages at a level not exceeding 0.2\% [120], 
and the source for isolation is restricted to alfalfa (21 CFR 73.125) $[120,124]$. In addition to the European Union, K-NaCu-chlorophyllin has been also listed for use in the United States as a color additive in toothpastes that are either drugs (21 CFR 73.1125) or cosmetics (21 CFR 73.2125) [120]. Oil-soluble Cu-chlorophyllin complex can be also used in polymethylmethacrylate bone cement (21 CFR 73.3110) [120]. For this purpose natural Chls are extracted from a mixture of fescue and rye grasses, then acid- and $\mathrm{Cu}$-treated to replace $\mathrm{Mg}^{2+}$ by $\mathrm{Cu}^{2+}$, and finally diluted to $5 \%$ concentration in a mixture of palm oil, peanut oil and hydrogenated peanut oil [120].

The Acceptable Daily Intake (ADI) for Cu complexes of Chls and chlorophyllins is $0-15 \mathrm{mg} \mathrm{kg}^{-1}$ body weight [159,161,162], however, the US Food and Drug Administration (FDA) permits the over-the-counter use of $\mathrm{Cu}$-chlorophyllin complex as an internal deodorant in typical doses of $100-200 \mathrm{mg}$ and in some cases up to $300 \mathrm{mg}$ daily (21 CFR 357.850) [163].

Except for Chl containing vegetables and some fruits, the green color is in general not too much appreciated in food and beverages. Therefore, the use of these colorants (E140 and E141) is quite limited in the food industry, although they are almost the only alternative for green (bluish) colorants of natural origin. E140 is used to (re)color a variety of foods and beverages green including pasta, absinthe, cheeses, preserved (canned) vegetables, vegetables in vinegar, brine and/or oil, mustard, and jam industry products (jams, marmalades and jellies) [164], flavored fermented milk products, bakery wares, breakfast cereals, as well as soups and broths [159]. E141 is similarly used, for instance in cheeses, sweets (e.g., ice cream), soups, preserved (canned) vegetables and fruits, jam industry products and beverages [164]. Interestingly, E141ii was recently discovered as adulterant to restore the green hue of table olives, a practice not allowed in the European Union [165].

Taken together, the development of sophisticated identification and detection protocols of the different Chl derivatives is of great importance for the food industry [17,157,165-167] especially in case of products containing high amounts of emulsifiers, gelatine or fats [156]. These methods must have high sensitivity as the dose rates used for food coloring vary between 0.005-0.01 for oil-soluble, and 0.002-0.01 for water soluble products, respectively [114].

\subsection{Health Promoting and Medicinal Effects}

Below we review literature data related to toxicology and medicinal effects of chlorophylls and their derivatives first of all in humans. The role of dietary Chl metabolites and derivatives in animals and humans is reviewed in detail elsewhere [115,125,168-170]. Ideally, medicinal studies with Chl derivatives should use a single compound with verified purity and/or with stable and well-characterized composition [171,172]. However, often this is not the case. Most studies on for instance cancer-related research of Chl derivatives used the relatively cheap, stable, commercially available and water-soluble food-grade $\mathrm{Cu}$-chlorophyllin, the composition and purity of which was often not standardized [171,172] (see Section 5.2).
Therefore, often it is difficult to compare and to evaluate the significance of sometimes conflicting literature data. As even similar Chl derivatives may have completely different absorption properties, metabolism and biological effects, this represents a real problem in case of chlorophyllin 'mixtures' [172]. Thus, we focused on data available on purified Chl derivatives. There is some controversy about the exaggerated healing properties of Chl, especially when applied externally, and scientific evidences to support consistent health protecting roles of Chls (especially confirmation of in vitro effects in humans in vivo) are still required [173]. For instance, the Mg content of dietary Chls seems to be of little relevance to $\mathrm{Mg}$ nutrition in humans [174]. For further information about clinical trials, history, pharmacology, interactions, adverse effects, toxicology and dosing the authors are directed towards an evidence-based systematic review published recently by the Natural Standard Research Collaboration [169].

Data dealing with bioavailability and safety, antioxidant activity and miscellaneous medicinal applications of Chl derivatives will be discussed below. Several Chl derivatives seem to be promising anticancer compounds due to their light-activated photosensitizing effect during photodynamic therapy (PDT), to cancer chemoprevention by their chelating, antimutagenic, anticlastogenic and antigenotoxic activities, to their antioxidant and anti-inflammatory properties as well as to their direct anticancer therapeutic effects based on apoptosis induction.

\subsubsection{Bioavailability and Safety}

Until recently it was generally accepted that during digestion of Chl containing food, the $\mathrm{Mg}$ and/or the phytol are lost, resulting in pheophytin, pheophorbide and/or Chlide formation. Clearly, $\mathrm{Mg}$ can be lost in the highly acidic gastric fluid and later during gastrointestinal ingestion, but no other important degradation or conversion was observed during Chl digestion by dogs [175]. Dogs fed with spinach containing diet had an apparent Chl derivative absorption of 2.5-4\% (determined from the feces), however, no Chl derivatives could be detected in their peripheral blood until 150 min after consumption outlining their low absorption and/or fast metabolization [175]. In vivo human studies have shown that $90-95 \%$ of ${ }^{14} \mathrm{C}$-labelled orally fed pheophytin was excreted with the feces mostly unchanged, and that less than 5\% of the phytol of ingested cooked spinach was absorbed in the thoracic lymph duct [176]. Taken together, pheophytins $a$ and $b$ represent the major metabolites of Chls observed in human and dog feces [175], cleavage of the phytol chain is unlikely during digestion [159].

This fact is evenmore important, because de-esterified natural tetrapyrroles (e.g., pheophorbides) have been shown to be appr. 65-fold better absorbed than phytylated ones from the food matrix by Caco-2 intestinal epithelial cells in a simulated digestion model system, allowing their larger accumulation in the human body [177]. Pheophorbide was shown to be 5-fold better absorbed than pheophytin in mouse myeloma cells (P3X63Ag8) in vitro [178]. Phytylated Chl derivatives (Chls and pheophytins) showed passive absorption by diffusion, while pheophorbides showed 
passive absorption by facilitated diffusion at low concentrations [177]. Some data show that pheophorbide $a$ and pyropheophorbide serve as substrate for $\mathrm{ABC}$ transporters (specifically BCRP/ABCG2 transporters) facilitating apical efflux and thus limiting/controlling the bioavailability of these molecules in human cell lines [179] and animals [180].

Pheophorbide was located (using its fluorescence properties) to mitochondria after uptake by Jurkat cells (human lymphoid tumor cell line) [181], Hep3B human hepatocellular carcinoma cells [182], RAW 264.7 murine macrophage cells [183], MCF-7 human breast tumor cell line [184] and MES-SA human uterine sarcoma cell line [185]. Chlorophyllin $e_{4}[186,187]$ and chlorophyllin $f$ [188] were localized to mitochondria and lysosomes in human bladder cancer cells in vitro. Pyropheophorbide $a$ derivatives showed concentration dependent localization to lysosomes (low concentration) and/or mitochondria (high concentration) in human pharyngeal squamous cell carcinoma (FaDu) cells and murine radiation-induced fibrosarcoma mutant cells [189].

It is also noteworthy to mention that pheophorbide was 25-fold better absorbed by myeloma cells than by normal, non-tumor mouse splenocytes [178], indicating the increased affinity of tumor cells to bind and absorb Chl derivatives, a property useful and widely used in PDT of cancer cells (reviewed in [190], see Section 5.3.3). Similarly, the uptake of several Chl derivatives (e.g., Na-pheophorbide $a$ [191]) administered either in vitro or in vivo (orally or intraperitoneally) was clearly demonstrated during studies dealing with PDT (see Section 5.3.3).

The digestion and absorption of Chl derivatives used in food industry - e.g., Cu-chlorophyll(in)s and or Znderivatives [192,193] - was thought to be similar to that of Chls, with very low amounts of these pigments being absorbed by the body. However, in contrast to $\mathrm{Mg}$, $\mathrm{Cu}$ or $\mathrm{Zn}$ remains in general bound to the porphyrin even after digestion [192]. Interestingly, intraperitoneally administered (Mg-)Chlide $a$ and Zn-Chlide $a$ were both absorbed by the body of tumor-bearing mice [193]. However, the uptake and clearance of Zn-Chlide $a$ was much slower than that of MgChlide $a$, and it showed ten times higher but aspecific (uniform) accumulation in most tissues and/or organs, while Mg-Chlide $a$ preferentially accumulated in the intestine and the liver [193]. This clearly shows that the pharmacokinetics of the Chl derivatives depend on the central metal ion, and that some derivatives (e.g., Zn-Chlide $a$ ) may be weakly recognized by the system of active transport of xenobiotics and of the enzymes responsible for Chl metabolization [193].

Despite the limited amount of toxicological studies on dietary natural Chls and Chl food additives, they are considered as safe compounds not raising toxicologic concerns due to their widespread and long-term ingestion by humans and their limited absorption (e.g., 5\% and 95\% pheophytin absorbed and excreted, respectively, in the feces in vivo - [176], 5-10\% absorbed Chl derivatives, especially pheophytins by Caco-2 human cells in vitro [192,194]) by the human body [17]. No photosensitization and Cu-related toxicity as well as no adverse effects or toxicity symptoms were observed in normal albino rats fed up to three percent of K-Na-Cu-chlorophyllin in their diets over their entire life span [195].

In vitro studies using the water soluble food colorant and dietary supplement $\mathrm{Na}-\mathrm{Cu}$-chlorophyllin in different models have shown that its major compound $\mathrm{Cu}$-chlorin $e_{4}$ remained relatively stable during simulated gastric and small intestinal digestion, while $90 \%$ of Cu-chlorin $e_{6}$ was degraded to undetermined products [194]. Co-administration of the food colorant with apple sauce could partially prevent this degradation process [194]. Similarly to natural Chl from processed spinach [192], Na-Cu-chlorophyllin (and its major compound Cu-chlorin $e_{4}$ ) was effectively absorbed by the Caco-2 human intestinal cell lines in vitro [194], suggesting that this food colorant is at least partly absorbed from the human intestine. This fact was further confirmed by data showing chlorophyllin uptake by e.g., lymphocytes [196], and by a randomized, double-blind clinical trial in China showing that after the consumption of $3 \times 100 \mathrm{mg} \mathrm{Cu}-$ chlorophyllin daily during 4 months, the blood sera of volunteers became green and contained low but detectable levels of Cu-chlorin $e_{4}$ as well as its ethyl ester suggesting that the pigments are distributed into total body water $[197,198]$. Similarly, chlorophyllin was detected in mice sera after intraperitoneal addition of chlorophyllin or oral gavage by as much as $2000 \mathrm{mg} \mathrm{kg}^{-1}$ body weight without any side effects [199]. In addition to green blood serum, orally administered chlorophyllin may result in yellow or black tongue color, and green discoloration of the urine and feces [200]. Thus, it may give false positive results in guaiac fecal occult blood test [201]. Occasionally diarrhea, cramps [163] or mild burning and itching [202] may be associated to its oral [163] or topical [202] administration, respectively.

Several data - such as for instance fast distribution of chlorophyllin in skin and other tissues of mice [203], no toxicity in Salmonella [204], rainbow trouts [205], rats and mice $[195,203,206]$, or in normal human liver cell lines [207], no toxicity or ill effects observed in 62 geriatric human patients in vivo [208], or in patients receiving chlorophyllin intravenously [209] or orally [197] - suggest that both oral and parenteral administration of these pigments did not produce any gross adverse effect on health. Therefore, they are considered to be safe and are permitted to be used in most countries as food additive [1,114,125] and/or dietary supplement. However, the concentration of free ionisable $\mathrm{Cu}$ in the coloring must be kept below 200 ppm under current regulations [120] and care has to be taken not to exceed the value permitted by the United States' Food and Drug Administration, because there are few reports on the toxic effects of Cu-chlorophyllins (e.g., tumor promoting effect [210-218]) that are not easy to interpret [125]. The $\mathrm{LD}_{50}$ of K-Na-Cu-chlorophyllin was established as $190 \mu \mathrm{g}$ gram $^{-1}$ body weight for mice [125].

It seems that both toxic (e.g., few reports about phototoxicity and the cytotoxic or tumor promoting effect of $\mathrm{Cu}$-chlorophyllin during mutagen-induced carcinogenesis) and positive health effects (e.g., antioxidant activity) of Chl derivatives strongly depend on the pigment concentration, pigment structure/composition and the experimental conditions (cell type, mutagen employed, mode of absorption, bioavailability, bioaccessibility, length and mode of treatment, model system, etc.), but also on the presence of 
non-Chl derivatives (including free $\mathrm{Cu}$ in the commercially available pigment mixtures - [219], reviewed in $[125,172,190])$. Clearly, the toxicity and safety of food and medicinal products should be first assessed in case of carefully planned experiments using well characterized concentrations of known single Chl derivatives.

\subsubsection{Antioxidant Properties}

Most neurodegenerative and inflammatory diseases, cancer, diabetes mellitus, atherosclerosis, reperfusion injury, aging processes, etc. can be associated with excessive formation of free radicals resulting in oxidative stress and/or impaired antioxidant defense system of the organism. However, disease may be prevented or the symptoms or effects may be alleviated by the therapeutic use of different antioxidants.

It is well-established that Chls and their derivatives (especially Na-Cu-chlorophyllin $[194,220,221]$ or pheophorbide $a$ [222] and $b$ [220]) have antioxidant properties [168]. They are effective scavengers of reactive oxygen species (ROS), e.g., singlet oxygen [221-223], hydroxyl radical [221,224], hydrogen peroxide [221] and they also inhibit lipid peroxidation both in vitro $[220,223]$, in vivo in splenic mice lymphocytes [196], and ex vivo in mice brain, liver and testis [223].

Several natural Chl derivatives were shown to inhibit hydroperoxide formation by lipid peroxidation during the exposure of linolenic acid to ferric nitrilotriacetate in the dark: Chl $a$ had the strongest antioxidant activity, Chlide $a$ had slightly less, while Chl $b$, pheophorbide $a$, pyropheophorbide $a$ and bacteriochlorophyll $a$ had much less antioxidant activity, and phytol was not involved in the antioxidant mechanism [225]. Chl $a$ derivatives were more effective quenchers of two long-lived free radicals than Chl $b$, and the presence of the central metal ion (in $\mathrm{Mg}-\mathrm{Chl}, \mathrm{Zn}-$ pheophytin, Zn-pyropheophytin, Cu-pheophytin $a$, Cuchlorophyllin) also seemed to enhance the antioxidant activity when compared with that of metal-free chlorins, pheophytins and pyropheophytins in vitro [226]. Similarly, Chl $a$ and pheophytin $a$ more efficiently prevented cell growth inhibition of yeast caused by the endocrine disruptor p-nonylphenol-mediated ROS generation in Saccharomyces cerevisiae than $\mathrm{Na}-\mathrm{Cu}$-chlorophyllin [227].

In another study analyzing the in vitro protective action of six natural Chl derivatives and $\mathrm{Cu}$-chlorophyllin on lipid oxidation, pheophorbide $b$ and pheophytin $b$ had the highest antioxidant activity among natural Chl derivatives [220], but chlorophyllin had the strongest antioxidant property among all derivatives $[194,220]$. Clearly, the nature of the pigments with strongest antioxidant and radical scavenging capacity may depend on the free radical studied, the experimental conditions and, thus, the actual mode of action $[220,226]$. However, it has to be noted, that most data about the antioxidant properties of Chl derivatives are obtained in vitro, therefore, their relevance in vivo needs further investigations.

The antioxidant activity of purified and isolated Na$\mathrm{Cu}$-chlorins (i.e., $\mathrm{Na}_{2}$-Cu-isochlorin $e_{4}$ and $\mathrm{Na}_{3}$-Cu-chlorin $\left.e_{6}\right)$ on $\mathrm{Fe}^{2+}$ - and ascorbic acid-induced lipid peroxidation in rat liver homogenates were about 8 -fold greater than that of the commercially available Na-Cu-chlorophyllin mixture, and that of $\mathrm{Na}_{2}-\mathrm{Cu}$-isochlorin $e_{4}$ was about $20 \%$ higher than that of $\mathrm{Na}_{3}$-Cu-chlorin $e_{6}$ [228]. These data indicate that the above-mentioned two compounds may account for about $92 \%$ of the antioxidant activity of Na-Cu-chlorophyllin mixtures [228]. Obviously, differences between the concentrations of these compounds in commercially available $\mathrm{Na}-\mathrm{Cu}$-chlorophyllin may substantially influence the antioxidant properties of the latter.

Data show that the antioxidant activity of chlorophyllins is mostly based on the upregulation of heme oxygenase-1 (HO-1) and $\mathrm{NAD}(\mathrm{P}) \mathrm{H}$ quinone dehydrogenase 1 (NQO1) at least during $\mathrm{H}_{2} \mathrm{O}_{2}$-induced oxidative stress in human umbilical vein endothelial cells (HUVEC) in vitro [229,230]. Similarly, Chl and chlorophyllin can induce mammalian phase 2 proteins involved in cellular protection against oxidants and electrophiles in murine and human cell lines in vitro [231].

The radioprotector activity of chlorophyllin in irradiated mice splenic lymphocytes was clearly correlated to its antioxidant property [196]. Chlorophyllin was effective in preventing oxidative stress induced by various agents including ionizing radiation ( $\gamma$-radiation [223,224,232]), photosensitization [223,224], ascorbate- $\mathrm{Fe}^{2+}$, NADPH-ADP$\mathrm{Fe}^{3+}$ and azobis-amidopropane hydrochloride both in vitro and ex vivo [223]. Chl derivatives (chlorophyllin [233] and pheophytin $a$ [234]) also efficiently inhibited superoxide anion generation by 12-O-tetradecanoylphorbol-13-acetate (TPA) in differentiated HL-60 cells [233] and in mouse macrophage cells [234], and the production of hydroxyl radicals by Fenton reaction [233]. This antioxidant activity seems to be crucial for cancer chemoprevention. Chlorophyllin [235] as well as pheophorbide $a$ and pheophytin $a$ [236] effectively alleviated nitrosative and oxidative stress in lipopolysaccharide-stimulated RAW 264.7 murine macrophage cells by inhibiting nitric oxide production, cyclooxygenase-2 (COX-2) expression and hydroxyl radical-induced cytotoxicity.

Based on their antioxidant activities discussed above, Chl derivatives may be useful therapeutic compounds in the treatment of various diseases related to oxidative stress (e.g., inflammation, cancer, etc.).

On the other hand, when present and accumulated in 'free' form and irradiated with strong light (e.g., during PDT or during exposure to sunlight, but even without these [183]), tetrapyrroles may themselves generate ROS [183] and may thus be responsible for oxidative stress and apoptotic and necrotic processes associated to it.

\subsubsection{Photodynamic Therapy (PDT)}

Several Chl precursors, analogs, derivatives and metabolites (e.g., 10-hydroxypheophytin a) can be used as photosensitizers in medicine for PDT of cancer (see Table 2). During PDT, direct and selective tumor cell destruction is obtained by selective accumulation and light-activated ROSmediated phototoxicity of photosensitizing agents within tumor cells and/or the surrounding vasculature. During this process, excited photosensitizers transfer their excitation energy to surrounding molecules (e.g., to oxygen) to produce singlet oxygen and other ROS and free radicals. In addition 
to substantial phototoxicity, photosensitizers used in PDT should preferably have low or no dark toxicity and low uptake by normal (non-cancer) cells. One of the major advantage of Chl derivatives in PDT - for instance when compared with Photofrin, a hematoporphyrin widely applied in PDT - is that they absorb better penetrating light (wavelengths above $650 \mathrm{~nm}$ ), and can be, thus, used to treat larger and more deeply seated tumors [237]. In addition, they may be used to detect tumor cells by fluorescence [238].

Table 2. Medicinal use of different Chl derivatives in photodynamic therapy (PDT).

\begin{tabular}{|c|c|c|c|}
\hline Used pigment & In vitro target & In vivo target & Reference \\
\hline \multirow[t]{2}{*}{$\begin{array}{l}\text { 10-hydroxy- } \\
\text { pheophytin } a\end{array}$} & $\begin{array}{l}\text { several human and mouse tumor } \\
\text { cell lines }\end{array}$ & - & [128] \\
\hline & vesicular stomatitis virus & - & [239] \\
\hline Chlorophyllin $\mathrm{e}_{4}$ & $\begin{array}{l}\text { T24 and } 5637 \text { human bladder } \\
\text { cancer cells }\end{array}$ & - & {$[186,187]$} \\
\hline Chlorophyllin $f$ & $\begin{array}{l}\text { T24 and } 5637 \text { human bladder } \\
\text { cancer cells }\end{array}$ & - & [188] \\
\hline \multirow[t]{2}{*}{ Na-pheophorbide $a$} & $\begin{array}{l}\text { methicillin-resistant } \\
\text { Staphylococcus aureus }\end{array}$ & $\begin{array}{l}\text { methicillin-resistant } \\
\text { Staphylococcus aureus induced } \\
\text { osteomyelitis in rats }\end{array}$ & {$[240,241]$} \\
\hline & Hu09 human osteosarcoma cells & - & [191] \\
\hline \multirow[t]{12}{*}{ Pheophorbide $a$} & $\begin{array}{l}\text { human pancreatic carcinoma } \\
\text { cells }\end{array}$ & $\begin{array}{l}\text { human pancreatic carcinoma in } \\
\text { athymic mice }\end{array}$ & [242] \\
\hline & HT29 human colonic tumor cells & HT29 human colonic tumor in mice & [243] \\
\hline & human Jurkat leukemia cells & - & [181] \\
\hline & B16F10 melanoma cells & $\begin{array}{l}\text { B16F10 melanoma cells in } \\
\text { C57BL/6J mice tumor model }\end{array}$ & [127] \\
\hline & $\begin{array}{l}\text { Hep3B human hepatocellular } \\
\text { carcinoma cells }\end{array}$ & $\begin{array}{l}\text { Hep3B human hepatocellular } \\
\text { carcinoma in nude mice }\end{array}$ & [182] \\
\hline & $\begin{array}{l}\text { HuH-7 human hepatocellular } \\
\text { carcinoma cells }\end{array}$ & - & [244] \\
\hline & $\begin{array}{l}\text { HeLa human cervical cancer, } \\
\text { HepG2 human hepatocarcinoma, } \\
\text { MCF-7 human breast } \\
\text { adenocarcinoma, B78-H1 murine } \\
\text { amelanotic melanoma cells }\end{array}$ & 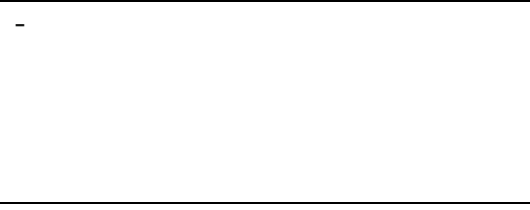 & {$[237]$} \\
\hline & $\begin{array}{l}\text { multidrug resistant } \mathrm{R}-\mathrm{HepG2} \\
\text { human hepatoma cell line }\end{array}$ & $\begin{array}{l}\text { multidrug resistant R-HepG2 } \\
\text { human hepatoma cell line in nude } \\
\text { mice tumor model }\end{array}$ & [245] \\
\hline & $\begin{array}{l}\text { MES-SA human uterine sarcoma } \\
\text { cells }\end{array}$ & - & [185] \\
\hline & $\begin{array}{l}\text { AT-84 murine oral squamous } \\
\text { cell carcinoma }\end{array}$ & $\begin{array}{l}\text { AT- } 84 \text { murine oral squamous cell } \\
\text { carcinoma in C3H mice }\end{array}$ & [246] \\
\hline & MCF-7 human breast tumor cells & $\begin{array}{l}\text { MCF-7 human breast tumor in } \\
\text { mouse xenograft model }\end{array}$ & [184] \\
\hline & $\begin{array}{l}\text { A432 and G361 human skin } \\
\text { cancer cells }\end{array}$ & $\begin{array}{l}\text { A432 and G361 human skin cancer } \\
\text { in a cell-xenograft chorioallantoic } \\
\text { membrane assay model in chicken }\end{array}$ & [247] \\
\hline Pheophorbide $b$ & $\begin{array}{l}\text { HuH-7 human hepatocellular } \\
\text { carcinoma cells }\end{array}$ & - & [244] \\
\hline Pheophytin $a$ & $\begin{array}{l}\text { HuH-7 human hepatocellular } \\
\text { carcinoma cells }\end{array}$ & - & [244] \\
\hline Pheophytin $b$ & $\begin{array}{l}\text { HuH-7 human hepatocellular } \\
\text { carcinoma cells }\end{array}$ & - & [244] \\
\hline $\begin{array}{l}\text { Pyro-pheophorbide } \\
a\end{array}$ & $\begin{array}{l}\text { SKOV3 human ovarian cancer } \\
\text { cells }\end{array}$ & - & [248] \\
\hline $\begin{array}{l}\text { Pyropheophorbide } a \\
\text { methylester }\end{array}$ & HCT-116 colon cancer cells & - & $\begin{array}{lll}{[249]} & \text { and } & \text { referenc } \\
\text { therein } & & \\
\end{array}$ \\
\hline $\begin{array}{l}\text { Pyro-pheophorbide } \\
\text { a derivatives with } \\
\text { different ether side } \\
\text { chain }\end{array}$ & & $\begin{array}{l}\text { radiation-induced fibrosarcoma } \\
\text { tumor model in C3H mice }\end{array}$ & {$[250]$} \\
\hline
\end{tabular}


Pheophorbide $a$ (but also pheophorbide $b$, pheophytin $a$ and $b$ [181,182,184,185,237,244-247], and chlorophyllin $f$ [188] and $\left.e_{4}[186,187]\right)$ decreased the growth of several different cancer cells by inducing ROS- and mitochondrialmediated apoptosis [181,182,184-186,188,244-247] and/or autophagy [187,188,247], and lipid peroxidation [237]. Pyropheophorbide $a$ methylester exerted its photosensitizing effect also via the same pathways although this derivative has been localized to the endoplasmic reticulum/Golgi system and lysosomes in vitro [249]. Using gentle or stronger PDT protocols (e.g., lower or higher photosensitizer concentrations), temporary growth arrest, apoptosis induction or, additionally, necrosis induction could be observed and were, thus, responsible for the anti-cancer effect of Chl derivatives [237,242,244]. Our better understanding of the molecular mechanisms responsible for the anti-cancer effect of Chl derivatives may be useful to find improved cancer treatments. For instance, the combined use of pheophorbide $a$ and gene-silencing molecules against PDT-activated antioxidant enzymes should potentiate PDT [237]. Similarly, autophagy inhibitors enhanced the apoptotic cell death of non-muscle invasive bladder cancer cells mediated by PDT using chlorophyllin $f$ [188] or chlorophyllin $e_{4}$ [187].

Interestingly, in addition to its photodynamic and apoptosis-inducing effect, pheophorbide $a$ increased the immunogenicity of human hepatoma cell line HepG2 during PDT resulting in increased cancer immunity (triggered phagocytic capture by human macrophages) in the tumor host [251]. Pheophorbide $a$ also successfully inhibited the multidrug resistance mechanism via downregulating the expression of P-glycoprotein [245]. In addition to its strong photosensitizing activity on human and mouse tumor cell lines in vitro [128], 10-hydroxypheophytin $a$ efficiently photoinactivated vesicular stomatitis virus during PDT [239].

Most studies dealing with PDT analyze the effects of one Chl derivative, few compare newly developed photosensitizers with existing and/or widely used ones (e.g., $[243,248])$, and only few works compare the photodynamic effect of various Chl derivatives. These data show that significant PDT effect could be obtained in vitro on $\mathrm{HuH}-7$ human hepatocarcinoma cell lines using the same low concentrations of pheophorbide $a$ and $b$, while twice and four times higher pheophytin $b$ and $a$ concentrations, respectively, were needed to achieve similar effect [244]. Similarly, the pyropheophorbide $a$ derivative with optimal lipophilicity (i.e., ester side chain length) had the strongest photodynamic effect, indicating that not only cellular uptake, biodistribution and overall tumor pharmacokinetics, but also pharmacodynamics can influence PDT activity [250].

The photodynamic effect of Chl derivatives can be also applied in food safety and storage. Due to the photodynamic effect of Chl derivatives, both Na-Mgchlorophyllin and $\mathrm{Na}-\mathrm{Cu}$-chlorophyllin may be used in edible gelatin films and coatings with photosensitized antibacterial activity against normal and thermoresistant Staphylococcus aureus, Bacillus cereus and Listeria monocytogenes strains in food products (e.g., frankfurters) [252-255]. Similarly, Na-chlorophyllin photosensitization was efficiently applied for microbial decontamination of strawberries inoculated with Listeria monocytogenes [256]. The antibacterial effect of PDT using these photosensitizers was similar or better than that of conventional antimicrobials, and did not affect product quality, which outlines their potential in the development of human and environmentally friendly surface decontamination methods, especially without thermal treatment.

As the application of Na-pheophorbide $a$ mediated PDT to normal mouse knee joint caused minimal and reversible changes to the joint tissue, Na-pheophorbide $a$ may be safely used to treat bacterial septic arthritis [257], especially as Na-pheophorbide $a$ showed antibacterial effect during PDT in vitro [240]. PDT with the same pigment also inhibited bone destruction during bacterial osteomyelitis in rats in vivo [241].

Considering the above-described potent photodynamic effect of these Chl derivatives (Table 2), understanding absorption, chemical modification and the presence of such photosensitizing agents in the commercially available food colorants and in absorbed dietary Chls is of great importance. Several photosensitizing pigments have been shown to accumulate in animal feed (e.g., pheophorbide in leaf protein preparations used as feed and consequently in animals [141]) and human food or food supplements (e.g., pheophorbides and pyropheophorbides in nori [146], pheophorbide $a$ and its ester in Chlorella tablets [258]). Other photosensitizing pigments (e.g., the Chl metabolite phytoporphyrin detected in blood sera in grazers [259]) probably represent metabolites of the ingested natural Chls. The accumulation of these photosensitizing pigments in tissues may result in photosensitization and allergy to sunlight reported both in animals (albino rats [260], cattle, sheep and alpaca with clinical photosensitive facial eczema [259]) and in humans [146,258]. In humans, swelling followed by erythematopurpuric lesions appear on sunexposed skin areas containing excess amount of photosensitizing Chl derivatives [258]. Similarly, dietinduced phototoxicity, protoporphyria and other porphyrinrelated toxicities and disorders may develop in animals (e.g., mice [180]) or in humans with low or no ABC-transporter (BCRP) activity, as these transporters are involved in handling and regulating both exogenous and endogenous porphyrins within the organism [180]. Similarly, the accumulation of 'free' or not properly bound Chl precursors (e.g., Pchlide [74,101-103,190]) and Chl derivatives has photosensitizing effect in plant tissues. Therefore, the level of these pigments and their organization in vivo is strictly regulated in plants $[20,50,74,84]$. Taken together, special care has to be taken during animal feed production. While purified Chls of spinach and protein extract from ryegrass had no photosensitization effect on albino rats, protein extract from alfalfa contained high levels of pheophorbide [260], and the level of photodynamic natural Chl breakdown products was correlated with the chlorophyllase activity of the processed plants [141].

Some data (see above and in Section 5.3.1) clearly indicate an increased absorption of pheophorbides when compared to other Chl derivatives by the human body [177]. Therefore, more information is needed about the 
bioaccessibility and bioavailability, and the alterations of the amounts of different $\mathrm{Chl}$ derivatives in food products and during their industrial conservation processes. For example, freezing, canning and cooking increase Chl bioavailability (with highest increase observed in cooked frozen pea) when compared with fresh peas [261], making the pigment's quantity in the processed food exceed $100 \%$ of the value measured before processing [262]. Special attention has to be paid to highly absorbed pigments with strong photodynamic effects. For example one cannot rule out that the contradictory results about Na-Cu-chlorophyllin - being a potent inhibitor of skin cancer in one experiment [203] but promoting tumor formation in the skin (while inhibiting tumorigenesis in other organs) in another experiment [263] may not be independent from the accumulation of possible photosensitizing agents in the skin in the second experiment. However, the problematic nomenclature and composition of Chl derivatives, as well as the different experimental setups (chlorophyllin received by gavage and skin cancer induced by topically applied carcinogenic chemicals [203] versus orally administered chlorophyllin in drinking water and cancer induction by applying other carcinogenic agents by gavage [263]), and/or the well-known chemoprotective properties (see Section 5.3.4) of Chl derivatives may be also responsible for the observed differences.

\subsubsection{Chemoprevention, Anticlastogenicity, Antigenotoxicity and Anticancer Therapeutical Activity}

Several in vitro and in vivo data indicate that natural Chls (both Chl $a$ and $b$ ) and their most important dietary derivatives (e.g., various chlorins, pheophytins, pyropheophytins, Zn-pheophytins, Zn-pyropheophytins, Cuchlorophyllins, Cu-pheophytin a) $[178,226]$, but also Na-Cuchlorophyllins (used in most studies) can have antimutagenic, mutagen trapping, antigenotoxic, anticlastogenic and anticarcinogenic effects and can modulate xenobiotic metabolism both in simple model organisms (e.g., Salmonella), in animals (e.g., Drosophila, rainbow trouts, mice and rats) and in humans [125,170,171,178,203,219,263-270]. For instance, Chl and $\mathrm{Na}-\mathrm{Cu}$-chlorophyllin can also prevent liver cancer in adults exposed to the carcinogen aflatoxin [198,269,271]. Therefore, Chl derivatives (especially chlorophyllin) are available as dietary supplements with anticarcinogenic/chemopreventive effect.

The suggested biological activities attributed to Chl derivatives consistent with cancer chemoprevention include modulation of xenobiotic metabolism, interaction with multiple molecules and pathways involved in the metabolism of carcinogens and mutagens and in signal transduction of cancer initiation and progression (cell proliferation, invasion, angiogenesis). Closed tetrapyrroles are most importantly involved in mutagen trapping in the gastrointestinal tract [264,272] or in the target organ and/or target cells [168,205], but they can also induce apoptosis of cancer cells and have antioxidant activity (see Section 5.3.2). However, critical overview of the huge available literature data about the anticarcinogenic effects of Chl derivatives (especially chlorophyllins) is provided elsewhere [125,168$170,266,270]$ and is to some extent hindered by the compositional and nomenclature problems of studies using commercially available Cu-chlorophyllins and chlorophyllins.

Both Chl and chlorophyllins (as well as Chlide $a$ and $b$ and pheophorbide $a$ and $b$ [273]) have been shown to inhibit the mutagenic and carcinogenic activities of several mutagens including polycyclic aromatic hydrocarbons, heterocyclic amins, and the mycotoxin, aflatoxin in several models both in vitro [204,216,273-280] and in vivo [203,212,263,272,275,277,281-284] (reviewed in $[125,170,211,266,270,274])$. Their antimutagenic activity is primarily based on preferential binding to these or other mutagens in the digestive tract, influencing their pharmacokinetics and decreasing their bioavailability, thus, reducing the possibility of DNA-adduct formation [203,212,264,267-269,272,273,277,279,283,285-288]. This chemoprotective effect of both chlorophyllin, Chl and spinach was efficient in a transplacental carcinogenesis model where the formation of lymphoma and lung tumor was significantly reduced in the offsprings of mutagen-fed mice [286].

However, some authors have shown that the tumor preventive effects of Chls and their derivatives may be (also) explained by their absorption and their observed postabsorptive chemopreventive effects on enzymes and other processes $[125,197,203,216,286]$. Irrespectively from the site of the interaction (i.e., in the gut or in the target organ or cell), Chl and its derivatives are interceptor molecules that inhibit mutagenicity of several compounds by molecular complex formation with the mutagen [266] thus reducing its bioactivity, bioavailabillity and/or enhancing its excretion.

In addition to this complex formation (realized probably via strong $\pi$ - $\pi$-interactions between the planar unsaturated porphyrin ring and the aromatic ring/s/ of the mutagens) [178], Chl derivatives also inhibit [289] and/or downregulate [290] cytochrome P450 enzyme and other hepatic drug-metabolizing enzyme systems involved in the bioactivation of carcinogens in the liver. Alternatively, they may be involved in enhancing the degradation of activated species of the mutagen, or in the detoxification mechanisms of the cells (e.g., pheophorbides enhance the aflatoxin detoxifying gluthatione $S$-transferase enzymes in Hepa-1 murine hepatoma cells in vitro [273]), or in cellular protection against oxidative stress or other processes induced by the mutagen.

Both Chls (Chl $a$ and $b$ ) and Cu-chlorophyllin $[178,269,278,291]$ as well as the 15 most important dietary Chls and their derivatives [226] inhibited mutations in the Ames Salmonella system caused by 3-methylcholanthrene $[178,278]$ or benzo[a]pyrene $[226,278]$, or had similar protective effect against methyl methanesulphonate (MMS) induced genotoxicity in V79 mammalian cell line [291], or inhibited aflatoxin uptake by human volunteers [269]. These data indicate that the porphyrin ring rather than the central ion or the ester side chain or other peripheral groups are responsible for this effect, although other inhibitory mechanisms (e.g., inactivation of the enzymatic transformation of the mutagen) cannot be excluded, and in 
case of different models and/or mutagens different specific mechanisms of action may need to be taken into account $[178,219]$, and thus different Chl derivatives may be more efficient.

For instance, pheophorbide seemed to be more effective than esterified pheophytin and pyropheophytin during chemoprevention of N'-nitro-N'-nitrosoguanidine mutagenicity in vitro [178]. Similarly, several authors reported increased chemoprevention and anticancer activity for chlorophyllin when compared with Chl $a$ and $b$ or pheophytins (e.g., in reducing aflatoxin genotoxicity and liver tumor induction in vivo [266] or during other mutagenicity studies in vitro [292,293]). Maybe this is the reason why most works used this commercially easily available and - maybe even more importantly - watersoluble material for testing the chemopreventive and/or anticancer activity of Chl derivatives. However, it has to be noted, that in some experimental models (e.g., acrylamide toxicity in rats [294], acetaldehyde-induced genotoxicity in mouse bone marrow cells in vivo [295], aflatoxin $\beta 1$ toxicity treated post-initiation [296]) chlorophyllin showed no chemopreventive action at all. In other works analyzing the prevention of heme-induced cytotoxic and hyperproliferative effects in the rat colon in vivo, natural Chls (and green vegetables) have been shown to be an effective antitumor agent $[297,298]$, while water-soluble chlorophyllin and $\mathrm{Cu}-$ chlorophyllin had no such effect [297]. Thus, evidently, the effect of the different purified Chl derivatives has to be carefully evaluated on a case by case basis. This is even more important as some studies show that depending on the experimental conditions (test species, initiating mutagen agent, exposure protocol, concentration of the mutagen, the chemopreventive agent, and especially $\mathrm{Cu}$ [213]) Chl derivatives may act as tumor promoter (carcinogen, clastogen) [210-218] or anticarcinogen [213,215,216].

The potential anticlastogenic activity of $\mathrm{Cu}-$ chlorophyllins has been demonstrated and is proposed to be based on its protective role against chromosomal damage induced by gamma rays [299] and against genotoxic effects induced by clastogenic chemicals (e.g., ethyl methane sulfonate - [300], reviewed in [125]). However, its antioxidant activity $[223,224,232]$ as well as its positive effect on hematopoietic stem cells, granulopoesis, and on the prosurvival pathways in bone marrow cells and lymphocytes may also importantly contribute to its prophylactic action against radiation-induced mortality in mice [199].

In addition to their chemo- and, thus, tumorpreventive effect and use in PDT, Chl derivatives have been recently shown to have direct cancer therapeutic effects in vitro. Thus, chlorophyllin (and Chls and other Chl derivatives) have the potential to be effective in the clinical setting in the treatment of cancer. Chl derivatives (pheophorbide $a$ [207] and chlorophyllin [301-304]) cause growth arrest [304], have antiproliferative effect [301], induce cell differentiation and/or trigger apoptosis (via mitochondrial or other pathways) [207,301-303,305] and/or via interaction with putative 'death receptor' located to the plasma membrane of cancer cells [303]. Chlorophyllin has been also shown to efficiently inhibit cytogenotoxicity of mycotoxins or other mutagens by its protective effect against oxidative stress and/or by its activity to regulate gene expression and/or signaling involved in stress and/or tumorigenesis $[305,306]$. For instance chlorophyllin was shown to inhibit the progression of papillomagenesis in a two-stage mouse skin carcinogenesis model in vivo [275]. Pheophorbide $a$ [222], pheophytin $a$ and $b$ [307] were shown to have anti-tumor-promoting activity in experimentally induced skin cancer model in mice, anti-inflammatory activity in mouse ear models [222,307] and also had antioxidant activity in HL-60 human promyelocytic leukemia cells [222]. Studies have shown that the cellular uptake and cell multiplicity inhibition of pheophorbide $a$ is higher than that of pheophytin $a$, however, when calculated on the amount of cell-associated Chl derivative, pheophytin $a$ had stronger cytotoxic and cytostatic effect than pheophorbide $a$ on P3X63Ag8 mouse myeloma cells [178]. This work clearly demonstrates that absorption, bioavailability, metabolization and cytotoxicity of single Chl derivatives has to be carefully understood when optimizing their doses for eventual clinical trials.

\subsubsection{Other Medicinal Applications}

Data related to further miscellaneous medicinal effects of Chl derivatives are summarized in Table 3 . In addition to PDT-induced virus inactivation (Table 2), some Chl derivatives (such as pheophytins) have been shown to have antiviral effect in recent bioactivity-guided screening studies. At subtoxic concentrations 3 special pheophytin derivatives inhibited the absorption and penetration of herpes simplex virus to host cells in vitro [308]. Pheophytin $a$ inhibited hepatitis C virus activity by inhibition of viral proteins and RNA expression without observable cytotoxic activity in vitro [309]. Pheophorbide was identified as the major antitumor component of Scutellaria barbata inducing apoptosis in viral-induced human hepatocellular carcinoma cell line Hep3B while being non-toxic to normal human liver cells (WRL-68) [207].

In contrast to natural Chl derivatives, chlorophyllins (especially commercial-grade $\mathrm{Na}-\mathrm{Cu}$-chlorophyllins) have been relatively safely and widely used in human (alternative) medicine for many years and were extensively studied (see Tables 2 and 3) [168]. For instance, water soluble Chl derivatives can be also used topically in the treatment of slow-healing wounds as was demonstrated in several experimentally induced lesions in animals [316,317]. The same wound healing properties of Chl derivatives were also reported from several early human case reports using either chlorophyllin solutions (with different Na-chlorophyllins, Na-Fe-chlorophyllin, Na-Cu-chlorophyllin, the Mgcontaining form being the less irritating to the mucosal membranes in otorhinolaryngology) or ointments and suppositories containing chlorophyllin, $\mathrm{Chl} a$ or $\mathrm{Chl} b$ [209,315,318,320,322]. There are reports about the application of Chl and derivatives in various suppurative and acute diseases, oral sepsis and/or infections, chronic ulcer and other ulcers [209,318-320,322], and post-operative wounds from rectal surgery [315]. However, it has to be noted that other reports found no positive wound healing property of chlorophyllin in the treatment of human burns, 
surgical infections and ulcers [333]. Some of these early investigations reported fibroblast stimulating [209,321] and mild bacteriostatic activities of soluble chlorophyllins at least against some bacteria [209,315,321], while others observed no antibacterial activity during bacteriological studies [208]. Obviously, these compounds were more effective in wound healing or in the treatment of suppurative diseases when combined with antibacterial and/or other agents (e.g., penicillin and/or papain/urea)

Table 3. Reports on the miscellaneous direct therapeutic effects of chlorophyll (Chl) derivatives. For antioxidant, photosensitizing, chemopreventive, antimutagenic, anticlastogenic, antigenotoxic and anticancer activities see the Sections 5.3.2, 5.3.3 and 5.3.4.

\begin{tabular}{|c|c|c|}
\hline Used pigment & Treatment & Reference \\
\hline Chl $a$, Chl $b$ & $\begin{array}{l}\text { treatment of chronic ulcers and impetigo contagiosa, chronic lesions of the } \\
\text { rectum, cervicitis associated with leucorrhea in humans }\end{array}$ & [209] \\
\hline $\begin{array}{l}\text { Chlorophyllin } \\
\text { 'mixture'and its } \\
\text { isolated components: } \\
\mathrm{Na}_{2}-\mathrm{Cu} \text {-isochlorin } e_{4} \text {, } \\
\text { oxidized } \mathrm{Na}_{2}-\mathrm{Cu} \text { - } \\
\text { isochlorin } e_{4}\end{array}$ & inhibition of hyaluronidase activity in vitro & [310] \\
\hline \multirow[t]{15}{*}{ Chlorophyllin } & $\begin{array}{l}\text { decreased body, fecal and urinary odor, eased constipation and flatus in } \\
\text { geriatric, ileostomy and colostomy patients }\end{array}$ & {$[208,311]$} \\
\hline & treatment of trimethylaminuria in humans & [312] \\
\hline & $\begin{array}{l}\text { decreased deposition of calcium oxalate crystals in rat kidney induced by } \\
\text { hydroxy-L-proline, ethylene glycol or Na-oxalate treatment in vivo }\end{array}$ & {$[313,314]$} \\
\hline & mild bacteriostatic effect on some bacteria & {$[209,315]$} \\
\hline & $\begin{array}{l}\text { accelerated healing of experimentally induced clean or infected wounds or } \\
\text { lesions (infected with Staphylococcus pyogenes or Streptococcus } \\
\text { hemolyticus), and in different burns in guinea pigs, rats, rabbits and dogs in } \\
\text { vivo }\end{array}$ & $\begin{array}{l}{[316,317] \text { and }} \\
\text { references therein }\end{array}$ \\
\hline & $\begin{array}{l}\text { healing of suppurative diseases, various post-operative surgical infections, } \\
\text { diverse lesions, open wounds, empyema, streptococcic septicemia, bacterial } \\
\text { endocarditis, osteomyelitis, ulcers in humans }\end{array}$ & {$[209,318-320]$} \\
\hline & treatment of rhinitis, rhinosinusitis, chronic otitis in humans & [209] \\
\hline & $\begin{array}{l}\text { treatment of oral infections, gingival inflammation, Vincent's stomatitis, } \\
\text { pyorrhea in humans }\end{array}$ & {$[209,321,322]$} \\
\hline & $\begin{array}{l}\text { treatment of acute and chronic rectal infections and wound healing in } \\
\text { proctology in humans }\end{array}$ & [315] \\
\hline & $\begin{array}{l}\text { treatment of mild-moderate photodamage and solar lentigines in a human } \\
\text { pilot study }\end{array}$ & [323] \\
\hline & $\begin{array}{l}\text { treatment of mild-moderate facial acne and large visible pores in a human } \\
\text { pilot study }\end{array}$ & [324] \\
\hline & treatment of facial redness, rosacea in human case studies & [325] \\
\hline & $\begin{array}{l}\text { immunostimulatory effect, inhibition of homeostasis driven proliferation in } \\
\text { CD4+ T cells in vitro, and in lymphopenic mice in vivo }\end{array}$ & [326] \\
\hline & $\begin{array}{l}\text { immunomodulatory and immunosuppressive effect on lipopolysaccharide- } \\
\text { stimulated murine splenic mononuclear cells in vitro }\end{array}$ & [327] \\
\hline & $\begin{array}{l}\text { anti-inflammatory effect in lipopolysaccharide-stimulated RAW } 264.7 \\
\text { murine macrophage cell line in vitro }\end{array}$ & [328] \\
\hline $\begin{array}{l}\text { Pheophorbide } a \text {, } \\
\text { Cu-pheophorbide } a\end{array}$ & anti-inflammatory activity in ICR mouse ear model in vivo & [222] \\
\hline \multirow[t]{2}{*}{ Pheophorbide $a$} & $\begin{array}{l}\text { immunostimulatory effect and enhancement of phagocytic activity in RAW } \\
264.7 \text { murine macrophage cell line in vitro }\end{array}$ & [183] \\
\hline & $\begin{array}{l}\text { anti-inflammatory activity in lipopolysaccharide-stimulated RAW } 264.7 \\
\text { murine macrophage cells in vitro }\end{array}$ & [236] \\
\hline $\begin{array}{l}\text { Pheophorbide } a \text { and its } \\
\text { methyl ester }\end{array}$ & inhibition of acyl-CoA:cholesterol acyltransferase in vitro & {$[329,330]$} \\
\hline Pheophytin derivatives & $\begin{array}{l}\text { inhibition of absorption and penetration of herpes simplex virus (HSV-1 } \\
\text { strain F) in Vero cell line (African green monkey kidney cell line) in vitro }\end{array}$ & [308] \\
\hline
\end{tabular}




\begin{tabular}{lll}
\hline Pheophytin $a$ & inhibition of edema formation and inflammation induced by 12-O- & {$[234,307]$} \\
& tetradecanoylphorbol-13-acetate in BALB/c mouse ear in vivo & \\
\hline & anti-inflammatory effect in vitro (inhibition of the functional activation of & {$[331]$} \\
& human polymorphonuclear neutrophils) & \\
\hline & $\begin{array}{l}\text { synergistic enhancement of neurodifferentiation by nerve growth factor in } \\
\text { PC12 rat phaeochromocytoma cells in vitro }\end{array}$ & {$[332]$} \\
& $\begin{array}{l}\text { inhibition of hepatitis C virus (HCV) proteins (NS3 protease) and RNA } \\
\text { expression in replicon cells and cell culture infectious system in vitro }\end{array}$ & {$[309]$} \\
\hline anti-inflammatory activity in LPS-stimulated RAW 264.7 murine & {$[236]$} \\
& macrophage cells in vitro & {$[307]$} \\
\hline Pheophytin $b$ & $\begin{array}{l}\text { inhibition of edema formation and inflammation induced by 12-O- } \\
\text { tetradecanoylphorbol-13-acetate in BALB/c mouse ear in vivo }\end{array}$ & \\
\hline & $\begin{array}{l}\text { anti-inflammatory effect in vitro (inhibition of the functional activation of } \\
\text { human polymorphonuclear neutrophils) }\end{array}$ & {$[331]$} \\
\hline
\end{tabular}

A recent study has shown that chlorophyllin (and its components) are potent inhibitors of hyaluronidase in vitro, thus, being able to maintain hyaluronic acid homeostasis (increase its level in the dermal extracellular matrix) and to serve as anti-aging agents in cosmeceuticals [310]. This study outlined an important difference among fresh and old commercial chlorophyllin preparations: i.e., the biologically less active oxidized Cu-isochlorin $e_{4}$ was present in increased concentration in old lotions [310]. Topically applied gel with a liposomal dispersion of $\mathrm{Na}-\mathrm{Cu}-$ chlorophyllin was clinically effective and well tolerated against facial acne and large visible pores in a human pilot study [324], in the treatment of facial redness and rosacea in case studies [325], and mild-moderate photodamage and solar lentigines in a human pilot study [323].

In addition, chlorophyllins were primarily used to successfully control body, fecal and urinary odor in geriatric patients as internal deodorant (e.g., as the over-the-counter drug Derifil) [208] but may be also used by ostomy patients or patients with fecal incontinence, or to decrease the foul odor associated with suppurative diseases [209,321]. They also aided in easing chronic constipation and excessive flatus [208].

Cu-chlorophyllin (commercialized under Saclophyl brand) effectively decreased the urinary levels of free trimethylamine by forming non-absorbable complex with this compound accumulating in people having trimethylaminuria [312]. This metabolic disorder is characterized by inability to oxidize and convert dietaryderived, strong smelling trimethylamine to trimethylamine $\mathrm{N}$-oxide. Thus, treatment with chlorophyllin can improve the quality of life of patients having this metabolic disorder.

Chlorophyllin was successfully applied in the treatment of gingival inflammation [322]. Chlorophyllin [326-328] and pheophorbide $a$ [183] have been shown to have immunostimulatory and immunomodulatory effects [183,326], they inhibited lymphopenia driven proliferation [326] and enhanced the phagocytic activity of RAW 264.7 murine macrophage cells [183], respectively. In addition, pheophorbide $a$, pheophytin $a$ [236] and chlorophyllin $[327,328]$ exerted their anti-inflammatory effect in lipopolysaccharide-induced RAW 264.7 murine macrophage cells by (1) their antioxidant activity resulting in alleviation of nitrosative stress [236], (2) by suppression of interleukin$1 \beta$ expression [328], and (3) by attenuated interferon- $\gamma$ expression in lipopolysaccharide-stimulated murine splenic mononuclear cells via suppression of interleukin-12 production [327]. The anti-inflammatory effect of pheophorbide $a$ and Cu-pheophorbide $a$ observed in ICR mouse ear models was associated with suppression of leukocyte activation [222]. Pheophytin $a$ and $b$ also efficiently decreased edema formation and inflammatory reaction induced by $12-O$-tetradecanoylphorbol-13-acetate in BALB/c mouse ear skin [234,307] and suppressed superoxide anion formation in mouse macrophages induced by the same compound [234]. The same pigments efficiently suppressed the activation of human polymorphonuclear neutrophils associated with inflammatory reactions [331]. These data indicate the potential future therapeutic application of Chl derivatives in the prevention of autoimmune disorders. However, further careful experimental examination and a better understanding of the signaling pathways blocked and/or enhanced by Chl derivatives are needed.

In the presence of nerve growth factor, pheophytin $a$ synergistically enhanced neurodifferentiation in PC12 rat pheochromocytoma cells in vitro, and may be thus useful to develop new therapeutic agents against neurodegeneration disorders [332].

Antithrombic (heparin-like) activity has been also associated to chlorophyllin preparations in an early work [335]. Some data reported that chlorophyllin inhibited chemically induced kidney stone formation in rats [313,314]. During bioactivity-guided assays with different plant extracts, pheophorbide $a$ and its methyl ester were identified as successful natural inhibitors of acyl-CoA:cholesterol acyltransferase (also termed sterol O-acyltransferase) involved in the regulation of cholesterol metabolism and, thus, in different pathologies associated with abnormalities in lipid metabolism in humans [329,330].

Taken together, all these data clearly demonstrate, that further bioactivity-guided assays may provide data for potential new medicinal applications of Chl derivatives.

\subsection{Other Industrial Applications of Chlorophylls}

The application of different Chl derivatives for artificial photosynthesis and biophotovoltaics in natural dyesensitized solar cells (e.g., $\mathrm{TiO}_{2}$ solar cells [336]) is beyond the scope of this review, but is mentioned as possible industrial application reviewed elsewhere [337-339]. Chl 
derivatives may be also considered as environment-friendly solutions to dye wool, acetate fibers and cotton [339,340]. The use of Chl derivatives in bone cement and cosmeceuticals (i.e., often in toothpastes) has been already mentioned (21 CFR 73.3110) [120] in Section 5.2.

\section{CONCLUSIONS AND FUTURE PERSPECTIVES}

Clearly, there is still an expensively growing demand on natural colorings, especially on those with green/blue hues like the tetrapyrrole derivatives including phycobilins and phycobiliproteins [19] as well as Chls and their derivatives discussed in this review. However, the problems surrounding the nomenclature, the composition and the legislation of E140ii as food colorant [159] may lead to its ban in the European Union (similarly to the United States) and necessitate the revision and re-evaluation of its content and toxicologic effects. As E140ii and E141ii were almost the only widely available water-soluble bluish-greenish food colorants, probably the use of E141ii food colorant and the different phycobilins (phycobiliproteins or spirulina extracts) [19] as coloring food will become even more important in the upcoming years.

In addition to freshly harvested plants, Chls may alternatively be obtained from other 'green' industrial byproducts of plant origin or from green (micro)algae. However, optimization of extraction, bioavailability, purification, standardization, stability (for instance in the presence of preservatives), rheological properties of these pigments are needed when used alone or in combination with other pigments in different food products and/or dietary supplements or medicines.

The potential health effects also have to be very strictly, consistently and carefully evaluated in long-term experiments as often the in vivo relevance of the different in vitro data and treatments cannot be really assessed. Problems surrounding the absorption and metabolism of $\mathrm{Chl}$ derivatives also need further research. For instance, quite different Chl degradation products are formed during senescence, post-harvest and food processing procedures as well as during digestion [173], and our understanding of these processes and of the absorption and potential health effects of the different compounds is still rather scarce. Therefore, animal single-dose treatments, and intraperitoneal administration of the pigments may show some in vitro effects, however, more complex and more 'natural' in vivo (and human) studies need to be carried out to fully understand the potential toxicity and/or beneficiary effects of tetrapyrroles and the mechanisms underlying these effects. Research into the impact of digestive factors on Chl structure and bioaccessibility, absorption and antioxidant properties is ongoing as these may prove beneficial in the treatment and prevention of cancer [168]. In particular, the possible appearance of free phytol as the product of digestion need to be examined, because phytol is readily absorbed in the bloodstream in its free form [173], and - when administered in large quantities - it may cause Chl intolerance in patients suffering from Refsum disease [176]. However, the exact biological effect(s) of phytol and its metabolites (e.g., phytenic acid and phytanic acid) should be also elucidated in lipid metabolism and in the modulation of other metabolic processes (including cell signaling and gene regulation).

In addition, several new and synthetic Chl derivatives (e.g., low-cost chlorophyllin $f$ [188] and chlorophyllin $e_{4}$ [186]) can be tested for their effectiveness in PDT $[186,188,248,341,342]$ or in the treatment of various diseases. However, the experimental settings (e.g., used light sources during PDT) may of course need optimization [240]. Synthetic derivatization may importantly increase (or decrease) the phototoxicity of the pigments and may also modify their intracellular localization, and thus, their main target sites $[248,249]$. Tetrapyrrole derivatives may be suitable to form bioconjugates with antibody fragments [248] or with anticancer drugs such as doxorubicin and paclitaxel [238] for targeted and/or improved PDT and, thus, represent a huge potential in the battle against cancer. The production of the smart biomedicine, pheophorbide $a$ conjugated heparin/gold nanoparticle photosensitizer enabled gluthation-mediated switchable photoactivity, and the conjugates also had better cellular uptake, prolonged circulation and better antitumor effect in mice models in vivo than pheophorbide $a$ alone [343]. Co-administration of chlorophyllin with antitumor agents (like cyclophosphamide) may diminish the intensity of the discomforting side effects of the chemotherapy and also decreases the mutagenicity of the compound [344]. Similarly, combined use of PDT and sonodynamic therapy can increase the tumor inhibitory effect and induce tumor necrosis much deeper than either of the single modalities, showing that different combined treatments may be useful to treat non-superficial or nodular tumors in the future [341]. These data outline the huge potential of different Chl derivatives in improved PDT therapy.

In addition, bioactivity-guided screening may help us to successfully discover new potential applications of Chl and its derivatives (e.g., antiviral $[308,309]$ and/or antitumor activities [207]). The chemopreventive and anticancer potential of chlorophyllin is supported by many data, however, further expensive investigations (about bioavailability of the different Chl derivatives, distribution, pharmacokinetics, molecular interference, and thus, dosage) need to be carried out before any clinical application $[170,212,284]$. It should be also elucidated whether the suggested post-absorptive effects of commercially available Cu-chlorophyllins with highly variable chemical composition can be attributed to some distinct chlorinderivatives or to a synergism among chlorins, and the potential negative effects of non-Chl derivatives (including free $\mathrm{Cu}$ ) present in such products also need to be ruled out [125].

It is noteworthy to mention that ${ }^{99 \mathrm{~m}} \mathrm{Tc}$-pheophorbide $a$ complex was successfully applied to distinguish infection from inflammation by nuclear imaging in bacterially infected and sterile inflamed rat model [345] proving the potential of this compound as radiopharmaceutical agent.

There are several patents related to Chl derivatives. For instance, the chemopreventive action of Chl derivatives (e.g., chlorophyllin) and especially their ability to form complexes with mutagens (including polycyclic aromatic 
hydrocarbons and compounds present in cigarette smoke) may be used in cigarette filters containing such pigments [346].

Clearly, tetrapyrroles are crucial molecules for photosynthesis, and thus life on earth. Additionally, they can be also considered as products with high added value in the food industry and potentially also in medicine.

\section{CONFLICT OF INTEREST}

The authors confirm that this article content has no conflict of interest.

\section{ACKNOWLEDGEMENTS}

We apologize to all authors whose works were not cited due to space limitations. We are grateful to Csilla Jónás for electron microscopic sample preparation, and to the editor and the anonymous reviewers for their valuable comments and suggestions. The work of BMK was supported by grant UMO-2013/10/E/NZ3/00748 from the Polish National Science Centre (NCN). The Faculty of Biochemistry, Biophysics and Biotechnology of Jagiellonian University is a partner of the Leading National Research Center (KNOW) supported by the Ministry of Science and Higher Education. This work was supported by the János Bolyai Research Scholarship of the Hungarian Academy of Sciences (to K.S.).

\author{
ABBREVIATIONS \\ ALA $=5$-aminolevulinic acid \\ Chl = chlorophyll \\ Chlide $=$ chlorophyllide \\ $\mathrm{DV}=$ divinyl \\ DPOR = light-independent Pchlide oxidoreductase \\ LPOR = light-dependent protochlorophyllide oxidoreductase \\ $\mathrm{MV}=$ monovinyl \\ $\mathrm{PDT}=$ photodynamic therapy \\ PROTO IX = protoporphyrin IX \\ Pchl $=$ protochlorophyll \\ Pchlide $=$ protochlorophyllide \\ ROS $=$ reactive oxygen species
}

\section{REFERENCES}

[1] Hosikian, A.; Lim, S.; Halim, R.; Danquah, M.K. Chlorophyll extraction from microalgae: A review on the process engineering aspects. Int. J. Chem. Eng., 2010, 2010, 391632.

[2] Grimm, B.; Porra, R.J.; Rüdiger, W.; Scheer, H. Chlorophylls and Bacteriochlorophylls: Biochemistry, Biophysics, Functions and Applications; Springer Netherlands: Dordrecht, Advances in Photosynthesis and Respiration Vol. 25; 2006.

[3] Pelletier, F.; Caventou, J.B. Sur la matière verte des feuilles. Ann. Chim. Phys., 1818, 9, 194-196.

[4] Willstätter, R.; Stoll, A. Untersuchungen über Chlorophyll: Methoden und Ergebnisse; Julius Springer: Berlin, 1913.

[5] Fischer, H.; Orth, H. Die Chemie des Pyrrols, Bd. II. Pyrrolfarbstoffe. 1. Hälfte.; Akademische Verlagsgesellschaft: Leipzig, 1937.

[6] Fischer, H.; Stern, A. Die Chemie des Pyrrols Bd. II. Pyrrolfarbstoffe 2. Hälfte; Akademische Verlagsgesellschaft: Leipzig, 1940.

[7] Woodward, R.B.; Ayer, W.A.; Beaton, J.M.; Bickelhaupt, F.; Bonnett, R.; Buchschacher, P.; Closs, G.L.; Dutler, H.; Hannah, J.; Hauck, F.P.; Itô, S.; Langemann, A.; Le Goff, E.; Leimgruber, W.; Lwowski, W.; Sauer, J.; Valenta, Z.; Volz, H. The total synthesis of chlorophyll. J. Am. Chem. Soc., 1960, 82(14), 3800-3802.

[8] Woodward, R.B.; Ayer, W.A.; Beaton, J.M.; Bickelhaupt, F.; Bonnett, R.; Buchschacher, P.; Closs, G.L.; Dutler, H.; Hannah, J.; Hauck, F.P.;
Itô, S.; Langemann, A.; Le Goff, E.; Leimgruber, W.; Lwowski, W.; Sauer, J.; Valenta, Z.; Volz, H. The total synthesis of chlorophyll a. Tetrahedron, 1990, 46(22), 7599-7659.

[9] Chen, M. Chlorophyll modifications and their spectral extension in oxygenic photosynthesis. Annu. Rev. Biochem., 2014, 83(1), 317-340.

[10] Scheer, H. In: Chlorophylls; Scheer, H., Ed. CRC Press: Boca Raton, 1991; pp. 3-33.

[11] Manning, W.M.; Strain, H.H. Chlorophyll d, a green pigment of red algae. J. Biol. Chem., 1943, 151, 1-19.

[12] Miyashita, H.; Ikemoto, H.; Kurano, N.; Adachi, K.; Chihara, M.; Miyachi, S. Chlorophyll d as a major pigment. Nature, 1996, 383(6599), 402.

[13] Loughlin, P.; Lin, Y.; Chen, M. Chlorophyll d and Acaryochloris marina: current status. Photosynth. Res., 2013, 116(2), 277-293.

[14] Murakami, A.; Miyashita, H.; Iseki, M.; Adachi, K.; Mimuro, M. Chlorophyll $\mathrm{d}$ in an epiphytic cyanobacterium of red algae. Nature, 2004, 303(5664), 1633.

[15] Behrendt, L.; Larkum, A.W.D.; Norman, A.; Qvortrup, K.; Chen, M.; Ralph, P.; Sørensen, S.J.; Trampe, E.; Kühl, M. Endolithic chlorophyll d-containing phototrophs. ISME J., 2011, 5, 1072-1076.

[16] Chen, M.; Schliep, M.; Willows, R.D.; Cai, Z.-L.; Neilan, B.A.; Scheer, H. A red-shifted chlorophyll. Science, 2010, 329(5997), 1318-1319.

[17] Schoefs, B. In: Handbook of Analysis of Active Compounds in Functional Foods; Nollet, L., Toldrá, F., Eds. CRC Press: Boca Raton, London, New York, 2012; pp. 665-685.

[18] Solymosi, K.; Latruffe, N.; Morant-Manceau, A.; Schoefs, B. In: Colour Additives for Foods and Beverages; Scotter, M J., Ed. Woodhead Publishing-Elsevier: Oxford, 2015; pp. 3-34.

[19] Mysliwa-Kurdziel, B.; Solymosi, K. Phycobilins and phycobiliproteins used in food industry and medicine. Mini-Rev. Med. Chem., SAME ISSUE TO BE UPDATED

[20] Mochizuki, N.; Tanaka, R.; Grimm, B.; Masuda, T.; Moulin, M.; Smith, A.G.; Tanaka, A.; Terry, M.J. The cell biology of tetrapyrroles: a life and death struggle. Trends Plant Sci., 2010, 15(9), 488-498.

[21] Heydarizadeh, P.; Poirier, I.; Loizeau, D.; Ulmann, L.; Mimouni, V.; Schoefs, B.; Bertrand, M. Plastids of marine phytoplankton produce bioactive pigments and lipids. Mar. Drugs, 2013, 11(9), 3425-3471.

[22] Chen, M.; Blankenship, R.E. Expanding the solar spectrum used by photosynthesis. Trends Plant Sci., 2011, 16(8), 427-431.

[23] Björn, L.O.; Papageorgiou, G.C.; Blankenship, R.E.; Govindjee. A viewpoint: Why chlorophyll a? Photosynth. Res., 2009, 99(2), 85-98.

[24] Miyashita, H.; Ikemoto, H.; Kurano, N.; Miyachi, S.; Chihara, M. Acaryochloris marina gen. et sp. nov. (Cyanobacteria), an oxygenic photosynthetic prokaryote containing $\mathrm{Chl} \mathrm{d}$ as a major pigment. $J$. Phycol., 2003, 39(6), 1247-1253.

[25] Miyashita, H.; Adachi, K.; Kurano, N.; Ikemoto, H.; Chihara, M.; Miyachi, S. Pigment composition of a novel oxygenic photosynthetic prokaryote containing chlorophyll $\mathrm{d}$ as the major chlorophyll. Plant Cell Physiol., 1997, 38(3), 274-281.

[26] Schiller, H.; Senger, H.; Miyashita, H.; Miyachi, S.; Dau, H. Lightharvesting in Acaryochloris marina - spectroscopic characterization of a chlorophyll d-dominated photosynthetic antenna system. FEBS Lett., 1997, 410(2-3), 433-436.

[27] Chen, M.; Quinnell, R.G.; Larkum, A.W.D. The major light-harvesting pigment protein of Acaryochloris marina. FEBS Lett., 2002, 514(2-3), 149-152.

[28] Hu, Q.; Miyashita, H.; Iwasaki, I.; Kurano, N.; Miyachi, S.; Iwaki, M.; Itoh, S. A photosystem I reaction center driven by chlorophyll $\mathrm{d}$ in oxygenic photosynthesis. Proc. Natl. Acad. Sci. U. S. A., 1998, 95(22), 13319-13323.

[29] Itoh, S.; Mino, H.; Itoh, K.; Shigenaga, T.; Uzumaki, T.; Iwaki, M. Function of chlorophyll d in reaction centers of photosystems I and II of the oxygenic photosynthesis of Acaryochloris marina. Biochemistry, 2007, 46(43), 12473-12481.

[30] Schlodder, E.; Çetin, M.; Eckert, H.J.; Schmitt, F.J.; Barber, J.; Telfer, A. Both chlorophylls a and $d$ are essential for the photochemistry in photosystem II of the cyanobacteria, Acaryochloris marina. BBA Bioenergetics, 2007, 1767(6), 589-595.

[31] Tomo, T.; Okubo, T.; Akimoto, S.; Yokono, M.; Miyashita, H.; Tsuchiya, T.; Noguchi, T.; Mimuro, M. Identification of the special pair of photosystem II in a chlorophyll d-dominated cyanobacterium. Proc. Natl. Acad. Sci. U. S. A., 2007, 104(17), 7283-7288.

[32] Willows, R.D.; Li, Y.; Scheer, H.; Chen, M. Structure of chlorophyll f. Org. Lett., 2013, 15(7), 1588-1590.

[33] Chen, M.; Li, Y.; Birch, D.; Willows, R.D. A cyanobacterium that contains chlorophyll f - a red-absorbing photopigment. FEBS Lett., 
2012, 586(19), 3249-3254.

[34] Akutsu, S.; Fujinuma, D.; Furukawa, H.; Watanabe, T.; OhnishiKameyama, M.; Ono, H.; Ohkubo, S.; Miyashita, H.; Kobayashi, M.C. Pigment analysis of a chlorophyll f-containing cyanobacterium strain KC1 isolated from Lake Biwa. Photomed. Photobiol., 2011, 33, 35-40.

[35] Li, Y.; Scales, N.; Blankenship, R.E.; Willows, R.D.; Chen, M. Extinction coefficient for red-shifted chlorophylls: Chlorophyll d and chlorophyll f. BBA - Bioenergetics, 2012, 1817(8), 1292-1298.

[36] Li, Y.; Chen, M. Novel chlorophylls and new directions in photosynthesis research. Funct. Plant Biol., 2015, 42, 493-501.

[37] Lee, R.E. Phycology; Cambridge University Press: Cambridge, 2008.

[38] Burger-Wiersma, T.; Post, A.F. Functional analysis of the photosynthetic apparatus of Prochlorothrix hollandica (Prochlorales), a chlorophyll b containing procaryote. Plant Physiol., 1989, 91(2), 770774.

[39] Zapata, M.; Garrido, J.; Jeffrey, S.W. In: Chlorophylls and Bacteriochlorophylls: Biochemistry, Biophysics, Functions and Applications; Grimm, B., Porra, R., Rüdiger, W., Scheer, H., Eds. Springer Netherlands: Dordrecht, 2006; Advances in Photosynthesis and Respiration Vol. 25, pp. 39-53.

[40] Sidler, W.A. In: The Molecular Biology of Cyanobacteria; Bryant, D., Ed. Kluwer Academic Publishers: Dordrecht, 1994; Advances in Photosynthesis Vol. 1, pp. 139-216.

[41] Fiedor, L.; Stasiek, M.; Mysliwa-Kurdziel, B.; Strzałka, K. Phytol as one of the determinants of chlorophyll interactions in solution. Photosynth. Res., 2003, 78, 47-57.

[42] Fiedor, L.; Kania, A.; Mysliwa-Kurdziel, B.; Orzeł, Ł.; Stochel, G. Understanding chlorophylls: Central magnesium ion and phytyl as structural determinants. BBA - Bioenergetics, 2008, 1777(12), 14911500.

[43] Guo, Y.; Tan, J. Recent advances in the application of chlorophyll a fluorescence from photosystem II. Photochem. Photobiol., 2015, 91(1), $1-14$

[44] Moulin, M.; Smith, A.G. Regulation of tetrapyrrole biosynthesis in higher plants. Biochem. Soc. Trans., 2005, 33(4), 737-742.

[45] Porra, R.J. The chequered history of the development and use of simultaneous equations for the accurate determination of chlorophylls a and b. Photosynth. Res., 2002, 73(1), 149-156.

[46] Schoefs, B. Chlorophyll and carotenoid analysis in food products. Properties of the pigments and methods of analysis. Trends Food Sci. Technol., 2002, 13(11), 361-371.

[47] Schoefs, B. Plant pigments: Properties, analysis, degradation. Adv. Food Nutr. Res., 2005, 49, 41-91.

[48] Tanaka, R.; Kobayashi, K.; Masuda, T. Tetrapyrrole metabolism in Arabidopsis thaliana. Arabidopsis Book, 2011, 9(9), e0145.

[49] Tanaka, R.; Tanaka, A. Tetrapyrrole biosynthesis in higher plants. Annu. Rev. Plant Biol., 2007, 58(1), 321-346.

[50] Brzezowski, P.; Richter, A.S.; Grimm, B. Regulation and function of tetrapyrrole biosynthesis in plants and algae. BBA - Bioenergetics, 2015, 1847(9), 968-985.

[51] Masuda, T. Recent overview of the Mg branch of the tetrapyrrole biosynthesis leading to chlorophylls. Photosynth. Res., 2008, 96(2), 121-143.

[52] Masuda, T.; Fujita, Y. Regulation and evolution of chlorophyll metabolism. Photochem. Photobiol. Sci., 2008, 7(10), 1131-1149.

[53] Rebeiz, C.A. Chlorophyll Biosynthesis and Technological Applications; Springer: Dordrecht, 2014.

[54] Czarnecki, O.; Grimm, B. Post-translational control of tetrapyrrole biosynthesis in plants, algae, and cyanobacteria. J. Exp. Bot., 2012, 63(4), 1675-1687.

[55] Fujita, Y.; Tsujimoto, R.; Aoki, R. Evolutionary aspects and regulation of tetrapyrrole biosynthesis in cyanobacteria under aerobic and anaerobic environments. Life, 2015, 5(2), 1172-1203.

[56] Richter, A.S.; Grimm, B. Thiol-based redox control of enzymes involved in the tetrapyrrole biosynthesis pathway in plants. Front. Plant Sci., 2013, 4, 371.

[57] Yin, L.; Bauer, C.E. Controlling the delicate balance of tetrapyrrole biosynthesis. Philos. Trans. R. Soc. Lond. B. Biol. Sci., 2013, 368(1622), 20120262.

[58] Beale, S.I.; Castelfranco, P.A. The biosynthesis of $\delta$-aminolevulinic acid in higher plants. Plant Physiol., 1974, 53, 291-296.

[59] Huang, D.D.; Wang, W.Y.; Gough, S.P.; Kannangara, C.G. Deltaaminolevulinic acid-synthesizing enzymes need an RNA moiety for activity. Science, 1984, 225(4669), 1482-1484.

[60] Beale, S.I.; Chen, N.C. N-methyl mesoporphyrin IX inhibits phycocyanin, but not chlorophyll synthesis in Cyanidium caldarium.
Plant Physiol., 1983, 71(2), 263-268.

[61] Beale, S.I. Biosynthesis of phycobilins. Chem. Rev., 1993, 93(2), 785802.

[62] Schön, A.; Krupp, G.; Gough, S.; Berry-Lowe, S.; Kannangara, C.G.; Söll, D. The RNA required in the first step of chlorophyll biosynthesis is a chloroplast glutamate tRNA. Nature, 1986, 322(6076), 281-284

[63] Smith, M.A.; Grimm, B.; Kannangara, C.G.; von Wettstein, D. Spectral kinetics of glutamate-1-semialdehyde aminomutase of Synechococcus. Proc. Natl. Acad. Sci. U. S. A., 1991, 88, 9775-9779.

[64] Ishijima, S.; Uchibori, A.; Takagi, H.; Maki, R.; Ohnishi, M. Lightinduced increase in free $\mathrm{Mg}^{2+}$ concentration in spinach chloroplasts: Measurement of free $\mathrm{Mg}^{2+}$ by using a fluorescent probe and necessity of stromal alkalinization. Arch. Biochem. Biophys., 2003, 412(1), 126-132.

[65] Reid, J.D.; Hunter, C.N. Magnesium-dependent ATPase activity and cooperativity of magnesium chelatase from Synechocystis sp. PCC6803. J. Biol. Chem., 2004, 279(26), 26893-26899.

[66] Sawicki, A.; Willows, R.D. Kinetic analyses of the magnesium chelatase provide insights into the mechanism, structure, and formation of the complex. J. Biol. Chem., 2008, 283(46), 31294-31302.

[67] Reinbothe, C.; Bakkouri, M.E.; Buhr, F.; Muraki, N.; Nomata, J.; Kurisu, G.; Fujita, Y.; Reinbothe, S. Chlorophyll biosynthesis: Spotlight on protochlorophyllide reduction. Trends Plant Sci., 2010, 15(11), 614-624.

[68] Gabruk, M.; Grzyb, J.; Kruk, J.; Mysliwa-Kurdziel, B. Light-dependent and light-independent protochlorophyllide oxidoreductases share similar sequence motifs - in silico studies. Photosynthetica, 2012, 50(4), 529-540.

[69] Yamamoto, H.; Kurumiya, S.; Ohashi, R.; Fujita, Y. Oxygen sensitivity of a nitrogenase-like protochlorophyllide reductase from the cyanobacterium Leptolyngbya boryana. Plant Cell Physiol., 2009, 50(9), 1663-1673.

[70] Muraki, N.; Nomata, J.; Ebata, K.; Mizoguchi, T.; Shiba, T.; Tamiaki, H.; Kurisu, G.; Fujita, Y. X-ray crystal structure of the lightindependent protochlorophyllide reductase. Nature, 2010, 465(7294), 110-114.

[71] Moser, J.; Lange, C.; Krausze, J.; Rebelein, J.; Schubert, W.-D.; Ribbe, M.W.; Heinz, D.W.; Jahn, D. Structure of ADP-aluminium fluoridestabilized protochlorophyllide oxidoreductase complex. Proc. Natl. Acad. Sci. U. S. A., 2013, 110(6), 2094-2098.

[72] Nomata, J.; Kondo, T.; Mizoguchi, T.; Tamiaki, H. Dark-operative protochlorophyllide oxidoreductase generates substrate radicals by an iron-sulphur cluster in bacteriochlorophyll biosynthesis. Sci. Rep., 2014, 4, 5455.

[73] Armstrong, G.A. Greening in the dark: light-independent chlorophyll biosynthesis from anoxygenic photosynthetic bacteria to gymnosperms. J. Photochem. Photobiol. B Biol., 1998, 43(2), 87-100.

[74] Solymosi, K.; Schoefs, B. Etioplast and etio-chloroplast formation under natural conditions: The dark side of chlorophyll biosynthesis in angiosperms. Photosynth. Res., 2010, 105(2), 143-166.

[75] Solymosi, K.; Aronsson, H. In: Plastid Development in Leaves during Growth and Senescence; Biswal, B., Krupinska, K., Biswal, U. C., Eds. Springer Netherlands: Dordrecht, 2013; Advances in Photosynthesis and Respiration Vol. 36, pp. 39-71.

[76] Oppermann, U.; Filling, C.; Hult, M.; Shafqat, N.; Wu, X.; Lindh, M.; Shafqat, J.; Nordling, E.; Kallberg, Y.; Persson, B.; Jörnvall, H. Shortchain dehydrogenases/reductases (SDR): The 2002 update. Chem. Biol. Interact., 2003, 143-144, 247-253.

[77] Yang, J.; Cheng, Q. Origin and evolution of the light-dependent protochlorophyllide oxidoreductase (LPOR) genes. Plant Biol., 2004, 6(5), 537-544.

[78] Heyes, D.J.; Hunter, C.N. Making light work of enzyme catalysis: protochlorophyllide oxidoreductase. Trends Biochem. Sci., 2005 , 30(11), 642-649.

[79] Schoefs, B. Protochlorophyllide reduction - What is new in 2005? Photosynthetica, 2005, 43(3), 329-343.

[80] Gabruk, M.; Mysliwa-Kurdziel, B. Light-dependent protochlorophyllide oxidoreductase: Phylogeny, regulation, and catalytic properties. Biochemistry, 2015, 54(34), 5255-5262.

[81] Gunning, B.E.S. Membrane geometry of “open” prolamellar bodies. Protoplasma, 2001, 215(1-4), 4-15.

[82] Solymosi, K.; Schoefs, B. In: Plant Cell Compartments - Selected Topics; Schoefs, B., Ed. Research Signpost: Trivandrum, 2008; pp. 151-202.

[83] Rüdiger, W. In: Chlorophylls and Bacteriochlorophylls; Grimm, B., Porra, R., Rüdiger, W., Scheer, H., Eds. Springer Netherlands: Dordrecht, 2006; Advances in Photosynthesis and Respiration Vol. 25, 
pp. 189-200.

[84] Rüdiger, W. In: Tetrapyrroles: birth, life and death; Warren, M.J., Smith, A.G., Eds. Springer: New York, 2009; pp. 263-273.

[85] Schoefs, B.; Bertrand, M. The formation of chlorophyll from chlorophyllide in leaves containing proplastids is a four-step process. FEBS Lett., 2000, 486(3), 243-246.

[86] Böddi, B.; Láng, F.; Soós, J. A study of $650 \mathrm{~nm}$ protochlorophyll form in pumpkin seed coat. Plant Sci. Lett., 1979, 16(1), 75-79.

[87] Houssier, C.; Sauer, K. Optical properties of the protochlorophyll pigments. I. Isolation, characterization, and infrared spectra. BBA Bioenergetics, 1969, 172(3), 476-491.

[88] Singh, D. Structure and development of seedcoat in Cucurbitaceae. Proc. Indian Acad. Sci. B, 1967, 65(6), 267-274.

[89] Sundqvist, C.; Ryberg, H. Structure of protochlorophyll-containing plastids in the inner seed coat of pumpkin seeds (Cucurbita pepo). Physiol. Plant., 1979, 47(2), 124-128.

[90] Sundqvist, C.; Ryberg, H. A long-wavelength absorbing form of protochlorophyll and crystalloids in the inner seed coat of Luffa cylindrica. Physiol. Plant., 1983, 59(1), 42-45.

[91] Ryberg, H.; Liljenberg, C.; Sundqvist, C. Crystalloid formation in protochlorophyll-accumulating plastids from the inner seed coat of Cyclanthera explodens. Physiol. Plant., 1980, 50(4), 333-339.

[92] Böddi, B.; Lindsten, A.; Ryberg, M.; Sundqvist, C. On the aggregational states of protochlorophyllide and its protein complexes in wheat etioplasts. Physiol. Plant., 1989, 76(2), 135-143.

[93] Solymosi, K.; Martinez, K.; Kristóf, Z.; Sundqvist, C.; Böddi, B. Plastid differentiation and chlorophyll biosynthesis in different leaf layers of white cabbage (Brassica oleracea cv. capitata). Physiol. Plant., 2004, 121(3), 520-529.

[94] Kruk, J. Occurrence of chlorophyll precursors in leaves of cabbage heads - the case of natural etiolation. J. Photochem. Photobiol. B Biol., 2005, 80(3), 187-194.

[95] Schoefs, B.; Franck, F. The photoenzymatic cycle of NADPH: Protochlorophyllide oxidoreductase in primary bean leaves (Phaseolus vulgaris) during the first days of photoperiodic growth. Photosynth. Res., 2008, 96, 15-26.

[96] Solymosi, K.; Vitányi, B.; Hideg, É.; Böddi, B. Etiolation symptoms in sunflower (Helianthus annuus) cotyledons partially covered by the pericarp of the achene. Ann. Bot., 2007, 99, 857-867.

[97] Solymosi, K.; Böddi, B. Optical properties of bud scales and protochlorophyll(ide) forms in leaf primordia of closed and opened buds. Tree Physiol., 2006, 26(8), 1075-1085.

[98] Solymosi, K.; Bóka, K.; Böddi, B. Transient etiolation: protochlorophyll(ide) and chlorophyll forms in differentiating plastids of closed and breaking leaf buds of horse chestnut (Aesculus hippocastanum). Tree Physiol., 2006, 26(8), 1087-1096.

[99] Solymosi, K.; Morandi, D.; Bóka, K.; Böddi, B.; Schoefs, B. High biological variability of plastids, photosynthetic pigments and pigment forms of leaf primordia in buds. Planta, 2012, 235(5), 1035-1049.

[100] Scheumann, V.; Klement, H.; Helfrich, M.; Oster, U.; Schoch, S.; Rüdiger, W. Protochlorophyllide b does not occur in barley etioplasts. FEBS Lett., 1999, 445(2-3), 445-448.

[101] Erdei, N.; Barta, C.; Hideg, É.; Böddi, B. Light-induced wilting and its molecular mechanism in epicotyls of dark-germinated pea (Pisum sativum L.) seedlings. Plant Cell Physiol., 2005, 46(1), 185-191.

[102] Hideg, É.; Vitányi, B.; Kósa, A.; Solymosi, K.; Bóka, K.; Won, S.; Inoue, Y.; Ridge, R.W.; Böddi, B. Reactive oxygen species from type-I photosensitized reactions contribute to the light-induced wilting of dark-grown pea (Pisum sativum) epicotyls. Physiol. Plant., 2010, 138(4), 485-492.

[103] Skribanek, A.; Solymosi, K.; Hideg, É.; Böddi, B. Light and temperature regulation of greening in dark-grown ginkgo (Ginkgo biloba). Physiol. Plant., 2008, 134(4), 649-659.

[104] Stenbaek, A.; Jensen, P.E. Redox regulation of chlorophyll biosynthesis. Phytochemistry, 2010, 71(8-9), 853-859.

[105] Grimm, B. In: The Chloroplast; Rebeiz, C.A., Benning, C., Bohnert, H., Daniell, H., Hoober, J.K., Lichtenthaler, H.K., Portis, A.R., Tripathy, B.C., Eds. Springer: Dordrecht, 2010; Advances in Photosynthesis and Respiration Vol. 31, pp. 39-54.

[106] Green, B.R. After the primary endosymbiosis: an update on the chromalveolate hypothesis and the origins of algae with Chl c. Photosynth. Res., 2011, 107(1), 103-115.

[107] Helfrich, M.; Bommer, B.; Oster, U.; Klement, H.; Mayer, K.; Larkum, A.W.; Rüdiger, W. Chlorophylls of the c family: absolute configuration and inhibition of NADPH:protochlorophyllide oxidoreductase. BBA - Bioenergetics, 2003, 1605(1-3), 97-103.
[108] Blankenship, R.E. Molecular Mechanisms of Photosynthesis; Blackwell Science Ltd.: Oxford, 2002.

[109] Partensky, F.; Hess, W.R.; Vaulot, D. Prochlorococcus, a marine photosynthetic prokaryote of global significance. Microbiol. Mol. Biol. Rev., 1999, 63, 106-127.

[110] Gateau, H.; Solymosi, K.; Marchand, J.; Schoefs, B. Carotenoids of microalgae used in food industry and medicine. Mini-Rev. Med. Chem. SAME ISSUE TO BE UPDATED

[111] Rumpho, M.E.; Dastoor, F.P.; Manhart, J.R.; Lee, J. In: The structure and function of plastids; Wise, R., Hoober, K., Eds. Springer: Dordrecht, 2006; Advances in Photosynthesis and Respiration Vol. 23, pp. 451-473.

[112] Solymosi, K. Plastid structure, diversification and interconversions I. Algae. Curr. Chem. Biol., 2012, 6, 167-186.

[113] Solymosi, K.; Keresztes, A. Plastid structure, diversification and interconversions II. Land plants. Curr. Chem. Biol., 2012, 6, 187-204.

[114] Humphrey, A.M. Chlorophyll. Food Chem., 1980, 5, 57-67.

[115] Ma, L.; Dolphin, D. The metabolites of dietary chlorophylls. Phytochemistry, 1999, 50(137), 195-202.

[116] Tong, Y.; Gao, L.; Xiao, G.; Pan, X. Microwave pretreatment-assisted ethanol extraction of chlorophylls from Spirulina platensis. J. Food Process Eng., 2012, 35(5), 792-799.

[117] Kong, W.; Liu, N.; Zhang, J.; Yang, Q.; Hua, S.; Song, H.; Xia, C. Optimization of ultrasound-assisted extraction parameters of chlorophyll from Chlorella vulgaris residue after lipid separation using response surface methodology. J. Food Sci. Technol., 2014, 51(9), 2006-2013.

[118] Wrolstad, R.E.; Culver, C.A. Alternatives to those artificial FD\&C food colorants. Annu. Rev. Food Sci. Technol., 2012, 3(1), 59-77.

[119] Humphrey, A.M. Chlorophyll as a color and functional ingredient. $J$. Food Sci., 2004, 69(5), C422-C425.

[120] GPO Access. Electronic Code of Federal Regulations: Listing of Color Additives Exempt from Certification. http://www.ecfr.gov/cgibin/retrieveECFR?gp=\&SID=3463c48f55ae08efd099682901bb9500\&r =PART\&n=pt21.1.73. (Accessed September 26, 2015).

[121] Hojnik, M.; Škerget, M.; Knez, Ž. Isolation of chlorophylls from stinging nettle (Urtica dioica L.). Sep. Purif. Technol., 2007, 57(1), $37-$ 46.

[122] Lubbe, A.; Verpoorte, R. Cultivation of medicinal and aromatic plants for specialty industrial materials. Ind. Crops Prod., 2011, 34(1), 785801

[123] Jubert, C.; Bailey, G. Isolation of chlorophylls a and b from spinach by counter-current chromatography. J. Chromatogr. A, 2007, 1140(12), 95-100

[124] Mortensen, A. Carotenoids and other pigments as natural colorants. Pure Appl. Chem., 2006, 78(8), 1477-1491.

[125] Tumolo, T.; Lanfer-Marquez, U.M. Copper chlorophyllin: A food colorant with bioactive properties? Food Res. Int., 2012, 46(2), 451459.

[126] European Commission and the Council. Commission Directive 95/45/EC - laying down specific purity criteria concerning colours for use in foodstuffs. Off. J. Eur. Union, 1995, L226, 1-41.

[127] Lim, D.-S.; Ko, S.-H.; Lee, W.-Y. Silkworm-pheophorbide alpha mediated photodynamic therapy against B16F10 pigmented melanoma. J. Photochem. Photobiol. B Biol., 2004, 74(1), 1-6.

[128] Dai, R.; Shoemaker, R.; Farrens, D.; Han, M.J.; Kim, C.S.; Song, P.S. Characterization of silkworm chlorophyll metabolites as an active photosensitizer for photodynamic therapy. J. Nat. Prod., 1992, 55(9), 1241-1251.

[129] Han, J.; Wang, Y.; Ma, J.; Wu, Y.; Hu, Y.; Ni, L.; Li, Y. Simultaneous aqueous two-phase extraction and saponification reaction of chlorophyll from silkworm excrement. Sep. Purif. Technol., 2013 115, 51-56.

[130] Schoefs, B. In: Der Ölkürbis Cucurbita pepo; Murkovic, M., Ed. Technische Universitat: Graz, 2000; pp. 50-59.

[131] Schoefs, B. Analyse der Farbstoffe in Kürbiskernöl. Leb. Biotechnol., 2001, 1, 8-11.

[132] von Elbe, J.H.; Huang, A.S.; Attoe, E.L.; Nank, W.K. Pigment composition and color conversion and veri-green canned beans. $J$. Agric. Food Chem., 1986, 34(1), 52-54.

[133] La Borde, L.F.; von Elbe, J.H. Zinc complex formation in heated vegetable purees. J. Agric. Food Chem., 1990, 38(2), 484-487.

[134] Schwartz, S.J.; Lorenzo, T.V. Chlorophyll stability during continuous aseptic processing and storage. J. Food Sci., 1991, 56(4), 1059-1062.

[135] Weemaes, C.A.; Ooms, V.; Van Loey, A.M.; Hendrickx, M.E. Kinetics of chlorophyll degradation and color loss in heated broccoli 
juice. J. Agric. Food Chem., 1999, 47(6), 2404-2409.

[136] Azoulay Shemer, T.; Harpaz-Saad, S.; Belausov, E.; Lovat, N.; Krokhin, O.; Spicer, V.; Standing, K.G.; Goldschmidt, E.E.; Eyal, Y. Citrus chlorophyllase dynamics at ethylene-induced fruit color-break: a study of chlorophyllase expression, posttranslational processing kinetics, and in situ intracellular localization. Plant Physiol., 2008, 148(1), 108-118.

[137] Hu, X.; Makita, S.; Schelbert, S.; Sano, S.; Ochiai, M.; Tsuchiya, T.; Hasegawa, S.F.; Hörtensteiner, S.; Tanaka, A.; Tanaka, R. Reexamination of chlorophyllase function implies its involvement in defense against chewing herbivores. Plant Physiol., 2015, 167(3), 660670 .

[138] Kunieda, T.; Amano, T.; Shioi, Y. Search for chlorophyll degradation enzyme, Mg-dechelatase, from extracts of Chenopodium album with native and artificial substrates. Plant Sci., 2005, 169(1), 177-183.

[139] Schelbert, S.; Aubry, S.; Burla, B.; Agne, B.; Kessler, F.; Krupinska, K.; Hörtensteiner, S. Pheophytin pheophorbide hydrolase (pheophytinase) is involved in chlorophyll breakdown during leaf senescence in Arabidopsis. Plant Cell, 2009, 21(3), 767-785.

[140] Hörtensteiner, S.; Kräutler, B. Chlorophyll breakdown in higher plants. BBA - Bioenergetics, 2011, 1807(8), 977-988.

[141] Holden, M. Chlorophyll degradation products in leaf protein preparations. J. Sci. Food Agric., 1974, 25, 1427-1432.

[142] Taha, F.S.; Helmy, H.E.; El-Nockrashy, A.S. Changes in cottonseed oil when used for frying vegetable products containing chlorophyll. $J$. Am. Oil Chem. Soc., 1988, 65(2), 267-271.

[143] Gross, J. Pigments in Vegetables. Chlorophylls and Carotenoids; Van Nostrand Reinhold: New York, 1991.

[144] Singh, S. Impact of color on marketing. Manag. Decis., 2006, 44(6), 783-789.

[145] Uchiyama, S. In: Standard Methods of Analysis in Food Safety Regulation; Uchiyama, M., Ed. Japan Food Hygiene Association: Tokyo, 1991; pp. 287-292.

[146] Hwang, D.-F.; Tsai, Y.-S.; Chou, S.-S.; Liu, S.-M.; Wu, J.-T.; Lin, S.J.; Tu, W.-C. HPLC determination of pheophorbide a and pyropheophorbide a in dried laver product implicated in food poisoning. Food Hyg. Saf. Sci., 2005, 46(2), 45-48.

[147] Naka, T.; Sumitani, H. Mechanisms of light-induced off-flavor formation sensitized by chlorophylls and $\mathrm{pH}$ in Citrus juice. J. Japanese Soc. Food Sci. Technol., 2009, 56(9), 469-474.

[148] Nedbal, L.; Soukupová, J.; Whitmarsh, J.; Trtílek, M. Postharvest imaging of chlorophyll fluorescence from lemons can be used to predict fruit quality. Photosynthetica, 2001, 38(4), 571-579.

[149] Usuki, R.; Endo, Y.; Kaneda, T. Prooxidant activities of chlorophylls and pheophytins on the photooxidation of edible oils. Agric. Biol. Chem., 1984, 48(4), 991-994.

[150] Endo, Y.; Usuki, R.; Kaneda, T. Antioxidant effects of chlorophyll and pheophytin on the autoxidation of oils in the dark. I. Comparison of the inhibitory effects. J. Am. Oil Chem. Soc., 1985, 62(9), 1375-1378.

[151] EUR13416 - Reports of the Scientific Committee for Food of the European Committee. Twenty fifth series, First series of food additives of various technological functions; Luxembourg, 1991.

[152] EFSA Panel on Food Additives and Nutrient Sources Added to Food. Copper(II) oxide as a source of copper added for nutritional purposes to food supplements. EFSA J., 2009, 1089, 1-15.

[153] Schanderl, S.H.; Marsh, G.L.; Chichester, C.O. Color reversion in processed vegetables. I. Studies on regreened pea puree. J. Food Sci., 1965, 30, 312-316.

[154] Jones, I.D.; White, R.C.; Gibbs, E.; Butler, L.S.; Nelson, L.A. Experimental formation of zinc and copper complexes of chlorophyll derivatives in vegetable tissue by thermal processing. J. Agric. Food Chem., 1977, 25(1), 149-153.

[155] Canjura, F.L.; Watkins, R.H.; Schwartz, S.J. Color improvement and metallo-chlorophyll complexes in continuous flow aseptically processed peas. J. Food Sci., 1999, 64(6), 987-990.

[156] Scotter, M.J.; Castle, L.; Roberts, D. Method developments and HPLC analysis of retail foods and beverages for copper chlorophyll (E141[i]) and chlorophyllin (E141[ii]) food colouring materials. Food Addit. Contam., 2005, 22, 1163-1175.

[157] Inoue, H.; Yamashitaa, H.; Furuyaa, K.; Nonomuraa, Y.; Yoshioka, N.; Lib, S. Determination of copper (II) chlorophyllin by reversedphase high-performance liquid chromatography. J. Chromatogr. A, 1994, 679, 99-104

[158] Coultate, T.P. Food: The Chemistry of its Components, 5th ed.; RSC Publishing: Cambridge, 2009.

[159] EFSA Panel on Food Additives and Nutrient Sources added to Food.
Scientific opinion on re-evaluation of chlorophyllins (E 140(ii)) as food additives. Off. J. Eur. Union, 2015, 13(5), 1-42.

[160] Socaciu, C. In: Food Colorants, Chemical and Functional Properties; Socaciu, C., Ed. CRC Press: Boca Raton, 2008; Vol. 2, pp. 583-602.

[161] Inanc, A.L. Chlorophyll: structural properties, health benefits and its occurrence in virgin olive oils. Acad. Food J., 2011, 9(2), 26-32.

[162] Wood, R.; Foster, L.; Damant, A.; Key, P. Analytical Methods for Food Additives; CRC Press: New York, 2004.

[163] GPO Access. Electronic Code of Federal Regulations: Miscellaneous Internal Drug Products for Over the Counter Use. http://www.ecfr.gov/cgi-bin/textidx?SID=fca8520c1cf723314cd462d3596b8682\&node=pt21.5.357\&rg n=div5 (Accessed September 26, 2015).

[164] European Commission and the Council. Commission Directive 94/36/EC - on Colours for Use in Foodstuffs. Off. J. Eur. Union, 1994, L237, 13-29.

[165] Gandul-Rojas, B.; Roca, M.; Gallardo-Guerrero, L. Detection of the color adulteration of green table olives with copper chlorophyllin complexes (E-141ii colorant). LWT - Food Sci. Technol., 2012, 46(1), 311-318.

[166] Mortensen, A.; Geppel, A. HPLC-MS analysis of the green food colorant sodium copper chlorophyllin. Innov. Food Sci. Emerg. Technol., 2007, 8(3), 419-425.

[167] Roca, M.; Gallardo-Guerrero, L.; Mínguez-Mosquera, M.I.; Rojas, B.G. Control of olive oil adulteration with copper-chlorophyll derivatives. J. Agric. Food Chem., 2010, 58(1), 51-56.

[168] Ferruzzi, M.G.; Blakeslee, J. Digestion, absorption, and cancer preventative activity of dietary chlorophyll derivatives. Nutr. Res. 2007, 27(1), 1-12.

[169] Ulbricht, C.; Bramwell, R.; Catapang, M.; Giese, N.; Isaac, R.; Le, T.D.; Montalbano, J.; Tanguay-Colucci, S.; Trelour, N.J.-; Weissner, W.; Windsor, R.C.; Wortley, J.; Yoon, H.;

Zeolla, M.M. An evidence-based systematic review of chlorophyll by the Natural Standard Research Collaboration. J. Diet. Suppl., 2014, 11(2), 198-239.

[170] Nagini, S.; Palitti, F.; Natarajan, A.T. Chemopreventive potential of chlorophyllin: A review of the mechanisms of action and molecular targets. Nutr. Cancer, 2015, 67(2), 203-211.

[171] Dashwood, R.H. The importance of using pure chemicals in (anti) mutagenicity studies: Chlorophyllin as a case in point. Mutat. Res. Fundam. Mol. Mech. Mutagen., 1997, 381(2), 283-286.

[172] Chernomorsky, S. Variability of the composition of chlorophyllin. Mutat. Res. - Mutat. Res. Lett., 1994, 324(4), 177-178.

[173] Lanfer-Marquez, U.M. The role of chlorophyll in human feeding: A review. Rev. Bras. Ciências Farm., 2003, 39, 227-242. (in Portuguese)

[174] Bohn, T.; Walczyk, T.; Leisibach, S.; Hurrell, R.F. Chlorophyll-bound magnesium in commonly consumed vegetables and fruits: Relevance to magnesium nutrition. J. Food Sci., 2004, 69(9), S347-S350.

[175] Fernandes, T.M.; Gomes, B.B.; Lanfer-Marquez, U.M. Apparent absorption of chlorophyll from spinach in an assay with dogs. Innov. Food Sci. Emerg. Technol., 2007, 8(3), 426-432.

[176] Baxter, J.H. Absorption of chlorophyll phytol in normal man and in patients with Refsum's disease. J. Lipid Res., 1968, 9(5), 636-641.

[177] Gandul-Rojas, B.; Gallardo-Guerrero, L.; Mínguez-Mosquera, M.I. Influence of the chlorophyll pigment structure on its transfer from an oily food matrix to intestinal epithelium cells. J. Agric. Food Chem., 2009, 57(12), 5306-5314.

[178] Chernomorsky, S.; Segelman, A.; Poretz, R.D. Effect of dietary chlorophyll derivatives on mutagenesis and tumor cell growth. Teratog. Carcinog. Mutagen., 1999, 19(5), 313-322.

[179] Robey, R.W.; Steadman, K.; Polgar, O.; Morisaki, K.; Blayney, M.; Mistry, P.; Bates, S.E. Pheophorbide a is a specific probe for ABCG2 function and inhibition. Cancer Res., 2004, 64(4), 1242-1246.

[180] Jonker, J.W.; Buitelaar, M.; Wagenaar, E.; van der Valk, M.A. Scheffer, G.L.; Scheper, R.J.; Plosch, T.; Kuipers, F.; Elferink, R.P.J.O.; Rosing, H.; Beijnen, J.H.; Schinkel, A.H. The breast cancer resistance protein protects against a major chlorophyll-derived dietary phototoxin and protoporphyria. Proc. Natl. Acad. Sci. U. S. A., 2002, 99(24), 15649-15654.

[181] Lee, W.Y.; Lim, D.S.; Ko, S.H.; Park, Y.J.; Ryu, K.S.; Ahn, M.Y.; Kim, Y.R.; Lee, D.W.; Cho, C.W. Photoactivation of pheophorbide a induces a mitochondrial-mediated apoptosis in Jurkat leukaemia cells. J. Photochem. Photobiol. B Biol., 2004, 75(3), 119-126.

[182] Tang, P.M.-K.; Chan, J.Y.-W.; Au, S.W.-N. Pheophorbide a, an active compound isolated from Scutellaria barbata, possesses photodynamic activities by inducing apoptosis in human hepatocellular carcinoma. 
Cancer Biol. Ther., 2006, 5(9), 1111-1116.

[183] Bui-Xuan, N.-H.; Tang, P.M.-K.; Wong, C.-K.; Chan, J.Y.-W.; Cheung, K.K.Y.; Jiang, J.L.; Fung, K.-P. Pheophorbide a: A photosensitizer with immunostimulating activities on mouse macrophage RAW 264.7 cells in the absence of irradiation. Cell. Immunol., 2011, 269(1), 60-67.

[184] Hoi, S.W.-H.; Wong, H.M.; Chan, J.Y.-W.; Yue, G.G.L.; Tse, G.M.K.; Law, B.K.-B.; Fong, W.P.; Fung, K.P. Photodynamic therapy of pheophorbide a inhibits the proliferation of human breast tumour via both caspase-dependent and -independent apoptotic pathways in in vitro and in vivo models. Phytother. Res., 2012, 26(5), 734-742.

[185] Tang, P.M.-K.; Liu, X.-Z.; Zhang, D.-M.; Fong, W.-P.; Fung, K.-P. Pheophorbide a based photodynamic therapy induces apoptosis via mitochondrial-mediated pathway in human uterine carcinosarcoma. Cancer Biol. Ther., 2009, 8(6), 533-539.

[186] Li, B.; Wu, Z.; Li, W.; Jia, G.; Lu, J.; Fang, J.; Chen, G. Chlorophyllin e4 is a novel photosensitizer against human bladder cancer cells. Oncol. Rep., 2012, 27(5), 1455-1460.

[187] Du, L.; Jiang, N.; Wang, G.; Chu, Y.; Lin, W.; Qian, J.; Zhang, Y.; Zheng, J.; Chen, G. Autophagy inhibition sensitizes bladder cancer cells to the photodynamic effects of the novel photosensitizer chlorophyllin e4. J. Photochem. Photobiol. B Biol., 2014, 133, 1-10.

[188] Du, L.; Zheng, J.; Jiang, N.; Wang, G.; Chu, Y.; Lin, W.; Jing, Q.; Yuanfang, Z.; Gang, C. Photodynamic therapy with the novel photosensitizer chlorophyllin $\mathrm{f}$ induces apoptosis and autophagy in human bladder cancer cells. Lasers Surg. Med., 2014, 46(4), 319-334.

[189] MacDonald, I.J.; Morgan, J.; Bellnier, D.A.; Paszkiewicz, G.M.L.; Whitaker, J.E.; Litchfield, D.J.; Dougherty, T.J. Subcellular localization patterns and their relationship to photodynamic activity of pyropheophorbide-a derivatives. Photochem. Photobiol., 1999, 70(5), 789-797.

[190] Brandis, A.S.; Salomon, Y.; Scherz, A. In: Chlorophylls and Bacteriochlorophylls: Biochemistry, Biophysics, Functions and Applications; Grimm, B., Porra, R., Rüdiger, W., Scheer, H., Eds. Springer: Dordrecht, 2006; Advances in Photosynthesis and Respiration Vol. 25, pp. 461-483.

[191] Nagai, Y.; Aizawa, S.; Iriuchishima, T.; Goto, B.; Nagaoka, M.; Tokuhashi, Y.; Saito, A. Phototoxic effect of Na-pheophorbide a toward osteosarcoma cells in vitro using a laser diode. Photomed. Laser Surg., 2014, 32(9), 481-489.

[192] Ferruzzi, M.G.; Failla, M.L.; Schwartz, S.J. Assessment of degradation and intestinal cell uptake of carotenoids and chlorophyll derivatives from spinach puree using an in vitro digestion and Caco-2 human cell model. J. Agric. Food Chem., 2001, 49(4), 2082-2089.

[193] Szczygieł, M.; Urbańska, K.; Jurecka, P.; Stawoska, I.; Stochel, G.; Fiedor, L. Central metal determines pharmacokinetics of chlorophyllderived xenobiotics. J. Med. Chem., 2008, 51, 4412-4418.

[194] Ferruzzi, M.G.; Failla, M.L.; Schwartz, S.J. Sodium copper chlorophyllin: In vitro digestive stability and accumulation by Caco-2 human intestinal cells. J. Agric. Food Chem., 2002, 50(7), 2173-2179.

[195] Harrisson, J.W. E.; Levin, S.E.; Trabin, B. The safety and fate of potassium sodium copper chlorophyllin and other copper compounds. $J$. Am. Pharm. Assoc., 1954, 43(12), 722-737.

[196] Kumar, S.S.; Shankar, B.; Sainis, K.B. Effect of chlorophyllin against oxidative stress in splenic lymphocytes in vitro and in vivo. BBA - Gen. Subjects, 2004, 1672(2), 100-111.

[197] Egner, P.A.; Stansbury, K.H.; Snyder, E.P.; Rogers, M.E.; Hintz, P.A.; Kensler, T.W. Identification and characterization of chlorin e4 ethyl ester in sera of individuals participating in the chlorophyllin chemoprevention trial. Chem. Res. Toxicol., 2000, 13(9), 900-906.

[198] Egner, P.A.; Muñoz, A.; Kensler, T.W. Chemoprevention with chlorophyllin in individuals exposed to dietary aflatoxin. Mutat. Res. Fundam. Mol. Mech. Mutagen., 2003, 523-524, 209-216.

[199] Suryavanshi, S.; Sharma, D.; Checker, R.; Thoh, M.; Gota, V.; Sandur, S.K.; Sainis, K.B. Amelioration of radiation-induced hematopoietic syndrome by an antioxidant chlorophyllin through increased stem cell activity and modulation of hematopoiesis. Free Radic. Biol. Med., 2015, 85, 56-70.

[200] PDR for Nutritional Supplements, $2^{\text {nd }}$ ed.; Hendler, S., Rorvik, D., Eds. Physicians’ Desk Reference Inc.: Montvale, 2008.

[201] Gogel, H.K.; Tandberg, D.; Strickland, R.G. Substances that interfere with guaiac card tests: implications for gastric aspirate testing. Am. J. Emerg. Med., 1989, 7(5), 474-480.

[202] Smith, L.W. The present status of topical chlorophyll therapy. N. Y. State J. Med., 1955, 55(14), 2041-2150.

[203] Park, K.K.; Surh, Y.J. Chemopreventive activity of chlorophyllin against mouse skin carcinogenesis by benzo[a]pyrene and benzo[a]pyrene-7,8-dihydrodiol-9,10-epoxide. Cancer Lett., 1996, 102(1-2), 143-149.

[204] Ong, T.M.; Whong, W.Z.; Stewart, J.; Brockman, H.E. Chlorophyllin: a potent antimutagen against environmental and dietary complex mixtures. Mutat. Res., 1986, 173(2), 111-115.

[205] Dashwood, R.H.; Breinholt, V.; Bailey, G.S. Chemopreventive properties of chlorophyllin: inhibition of aflatoxin B1 (AFB1)-DNA binding in vivo and anti-mutagenic activity against AFB1 and two heterocyclic amines in the Salmonella mutagenicity assay. Carcinogenesis, 1991, 12(5), 939-942.

[206] Reber, E.F.; Willigan, D.A. The effects of a chlorophyll derivative when included in a ration fed rats. II. Reproduction, blood, and tissue studies. Am. J. Vet. Res., 1954, 15, 643-646.

[207] Chan, J.Y.W.; Tang, P.M.K.; Hon, P.M.; Au, S.W.N.; Tsui, S.K.W.; Waye, M.M.Y.; Kong, S.K.; Mak, T.C.W.; Fung, K.P. Pheophorbide a, a major antitumor component purified from Scutellaria barbata, induces apoptosis in human hepatocellular carcinoma cells. Planta Med., 2006, 72(1), 28-33.

[208] Young, R.W.; Beregi, J.S.J. Use of chlorophyllin in the care of geriatric patients. J. Am. Geriat. Soc., 1980, 28(1), 46-47.

[209] Gruskin, B. Chlorophyll - Its therapeutic place in acute and suppurative disease: Preliminary report of clinical use and rationale. Am. J. Surg., 1940, 49(1), 49-55.

[210] Negraes, P.D.; Jordão, B.Q.; Vicentini, V.E.P.; Mantovani, M.S. The mutagenic potentiator effect of chlorophyllin by the HGPRT assay. Toxicol. Vitr., 2004, 18(1), 147-149.

[211] Sarkar, D.; Sharma, A.; Talukder, G. Chlorophyll and chlorophyllin as modifiers of genotoxic effects. Mutat. Res., 1994, 318(3), 239-247.

[212] McQuistan, T.J.; Simonich, M.T.; Pratt, M.M.; Pereira, C.B.; Hendricks, J.D.; Dashwood, R.H.; Williams, D.E.; Bailey, G.S. Cancer chemoprevention by dietary chlorophylls: A 12,000-animal dose-dose matrix biomarker and tumor study. Food Chem. Toxicol., 2012, 50(2), 341-352.

[213] Blum, C.A.; Xu, M.; Orner, G.A.; Diaz, G.D.; Li, Q.; Dashwood, W.M.; Bailey, G.S.; Dashwood, R. Promotion versus suppression of rat colon carcinogenesis by chlorophyllin and chlorophyll: modulation of apoptosis, cell proliferation, and $\beta$-catenin/Tcf signaling. Mutat. Res., 2003, 523-524, 217-223.

[214] Nelson, R.L. Chlorophyllin, an antimutagen, acts as a tumor promoter in the rat-dimethylhydrazine colon carcinogenesis model. Anticancer Res., 1992, 12(3), 737-739.

[215] Xu, M.; Orner, G.A.; Bailey, G.S.; Stoner, G.D.; Horio, D.T.; Dashwood, R.H. Post-initiation effects of chlorophyllin and indole-3carbinol in rats given 1,2-dimethylhydrazine or 2-amino-3-methylimidazo[4,5-f]quinoline. Carcinogenesis, 2001, 22(2), 309-314.

[216] Romert, L.; Curvall, M.; Jenssen, D. Chlorophyllin is both a positive and negative modifier of mutagenicity. Mutagenesis, 1992, 7(5), 349355.

[217] Sarkar, D.; Sharma, A.; Talukder, G. Chlorophyll and chromosome breakage. Mutat. Res., 1996, 360(3), 187-191.

[218] Cruces, M.P.; Pimentel, E.; Zimmering, S. Evidence suggesting that chlorophyllin (CHLN) may act as an inhibitor or a promoter of genetic damage induced by chromium(VI) oxide $\left(\mathrm{CrO}_{3}\right)$ in somatic cells of Drosophila. Mutat. Res. Toxicol. Environ. Mutagen., 2003, 536(1-2), 139-144.

[219] Chernomorsky, S.; Rancourt, R.; Virdi, K.; Segelman, A.; Poretz, R.D. Antimutagenicity, cytotoxicity and composition of chlorophyllin copper complex. Cancer Lett., 1997, 120(2), 141-147.

[220] Lanfer-Marquez, U.M.; Barros, R.M.C.; Sinnecker, P. Antioxidant activity of chlorophylls and their derivatives. Food Res. Int., 2005, 38(8-9), 885-891.

[221] Kumar, S.S.; Devasagayam, T.P.A.; Bhushan, B.; Verma, N.C Scavenging of reactive oxygen species by chlorophyllin: an ESR study. Free Radic. Res., 2001, 35(5), 563-574.

[222] Nakamura, U.; Murakami, A.; Koshimizu, K. Inhibitory effect of pheophorbide a, a chlorophyll-related compound, on skin tumor promotion in ICR mouse. Cancer Lett., 1996, 108, 247-255.

[223] Kamat, J.P.; Boloor, K.K.; Devasagayam, T.P.A. Chlorophyllin as an effective antioxidant against membrane damage in vitro and ex vivo. BBA - Mol. Cell Biol. Lipids, 2000, 1487(2-3), 113-127.

[224] Boloor, K.K.; Kamat, J.P.; Devasagayam, T.P.A. Chlorophyllin as a protector of mitochondrial membranes against gamma-radiation and photosensitization. Toxicology, 2000, 155(1-3), 63-71.

[225] Hoshina, C.; Tomita, K.; Shioi, Y. In: Photosynthesis: Mechanisms and Effects; Garab, G., Ed.; Kluwer Academic Publishers: Dordrecht, 
1998; Vol. 4, pp. 3281-3284.

[226] Ferruzzi, M.G.; Bohm, V.; Courtney, P.D.; Schwartz, S.J. Antioxidant and antimutagenic activity of dietary chlorophyll derivates determined by radical scavenging and bacterial reverse mutagenesis assays. J. Food Sci., 2002, 67(7), 2589-2595.

[227] Okai, Y.; Higashi-Okai, K. Protective effects of chlorophyll a and pheophytin a derived from green tea (Camellia sinensis) on pnonylphenol-induced cell growth inhibition and oxygen radical generation in yeast (Saccharomyces cerevisiae). J. Sci. Food Agric., 2001, 81(15), 1443-1446.

[228] Sato, M.; Fujimoto, I.; Sakai, T.; Aimoto, T.; Kimura, R.; Murata, T. Effect of sodium copper chlorophyllin on lipid peroxidation. IX. On the antioxidative components in commercial preparations of sodium copper chlorophyllin. Chem. Pharm. Bull. (Tokyo)., 1986, 34(6), 2428-2434.

[229] Zhang, Y.L.; Guan, L.; Zhou, P.H.; Mao, L.J.; Zhao, Z.M.; Li, S.Q.; Xu, X.X.; Cong, C.C.; Zhu, M.X.; Zhao, J.Y. The protective effect of chlorophyllin against oxidative damage and its mechanism. Chinese J. Intern. Med., 2012, 51(6), 466-470.

[230] Zhang, Y.; Guan, L.; Wang, X.; Wen, T.; Xing, J.; Zhao, J. Protection of chlorophyllin against oxidative damage by inducing $\mathrm{HO}-1$ and NQO1 expression mediated by PI3K/Akt and Nrf2. Free Radic. Res., 2008, 42(4), 362-371.

[231] Fahey, J.W.; Stephenson, K.K.; Dinkova-Kostova, A.T.; Egner, P.A.; Kensler, T.W.; Talalay, P. Chlorophyll, chlorophyllin and related tetrapyrroles are significant inducers of mammalian phase 2 cytoprotective genes. Carcinogenesis, 2005, 26(7), 1247-1255.

[232] Abraham, S.K.; Sarma, L.; Kesavan, P.C. Role of chlorophyllin as an in vivo anticlastogen: protection against gamma-radiation and chemical clastogens. Mutat. Res., 1994, 322(3), 209-212.

[233] Park, K.K.; Park, J.H.; Jung, Y.J.; Chung, W.Y. Inhibitory effects of chlorophyllin, hemin and tetrakis(4-benzoic acid)porphyrin on oxidative DNA damage and mouse skin inflammation induced by $12-\mathrm{O}-$ tetradecanoylphorbol-13-acetate as a possible anti-tumor promoting mechanism. Mutat. Res. - Genet. Toxicol. Environ. Mutagen., 2003, 542(1-2), 89-97.

[234] Okai, Y.; Higashi-Okai, K.; City, S. Potent anti-inflammatory activity of pheophytin a derived from edible green alga, Enteromorpha prolifera (Sujiao-nori). Int. J. Immunopharmacol., 1997, 19(6), 355-358.

[235] Cho, K.J.; Han, S.H.; Kim, B.Y.; Hwang, S.G.; Park, K.K.; Yang, K.H.; Chung, A.S. Chlorophyllin suppression of lipopolysaccharideinduced nitric oxide production in RAW 264.7 cells. Toxicol. Appl. Pharmacol., 2000, 166(2), 120-127.

[236] Islam, M.N.; Ishita, I.J.; Jin, S.E.; Choi, R.J.; Lee, C.M.; Kim, Y.S.; Jung, H.A.; Choi, J.S. Anti-inflammatory activity of edible brown alga Saccharina japonica and its constituents pheophorbide a and pheophytin a in LPS-stimulated RAW 264.7 macrophage cells. Food Chem. Toxicol., 2013, 55, 541-548.

[237] Rapozzi, V.; Miculan, M.; Xodo, L.E. Evidence that photoactivated pheophorbide a causes in human cancer cells a photodynamic effect involving lipid peroxidation. Cancer Biol. Ther., 2009, 8(14), 13181327.

[238] You, H.; Yoon, H.-E.; Yoon, J.-H.; Ko, H.; Kim, Y.-C. Synthesis of pheophorbide-a conjugates with anticancer drugs as potential cancer diagnostic and therapeutic agents. Bioorg. Med. Chem., 2011, 19(18), 5383-5391.

[239] Lim, D.S.; Ko, S.H.; Kim, S.J.; Park, Y.J.; Park, J.H.; Lee, W.Y. Photoinactivation of vesicular stomatitis virus by a photodynamic agent, chlorophyll derivatives from silkworm excreta. J. Photochem. Photobiol. B Biol., 2002, 67(3), 149-156.

[240] Yamamoto, T.; Iriuchishima, T.; Aizawa, S.; Okano, T.; Goto, B.; Nagai, Y.; Horaguchi, T.; Ryu, J.; Saito, A. Bactericidal effect of photodynamic therapy using Na-pheophorbide a: evaluation of adequate light source. Photomed. Laser Surg., 2009, 27(6), 849-853.

[241] Goto, B.; Iriuchishima, T.; Horaguchi, T.; Tokuhashi, Y.; Nagai, Y.; Harada, T.; Saito, A.; Aizawa, S. Therapeutic effect of photodynamic therapy using Na-pheophorbide a on osteomyelitis models in rats. Photomed. Laser Surg., 2011, 29(3), 183-189.

[242] Hajri, A.; Coffy, S.; Vallat, F.; Evrard, S.; Marescaux, J.; Aprahamian, M. Human pancreatic carcinoma cells are sensitive to photodynamic therapy in vitro and in vivo. Br. J. Surg., 1999, 86(7), 899-906.

[243] Hajri, A.; Wack, S.; Meyer, C.; Smith, M.K.; Leberquier, C.; Kedinger, M.; Aprahamian, M. In vitro and in vivo efficacy of photofrin ${ }^{\circledR}$ and pheophorbide a, a bacteriochlorin, in photodynamic therapy of colonic cancer cells. Photochem. Photobiol., 2002, 75(2), 140-148.

[244] Li, W.-T.; Tsao, H.-W.; Chen, Y.-Y.; Cheng, S.-W.; Hsu, Y.-C. A study on the photodynamic properties of chlorophyll derivatives using human hepatocellular carcinoma cells. Photochem. Photobiol. Sci., 2007, 6(12), 1341-1348.

[245] Tang, P.M.-K.; Zhang, D.-M.; Xuan, N.-H. B.; Tsui, S.K.-W.; Waye, M.M.-Y.; Kong, S.-K.; Fong, W.-P.; Fung, K.-P. Photodynamic therapy inhibits P-glycoprotein mediated multidrug resistance via JNK activation in human hepatocellular carcinoma using the photosensitizer pheophorbide a. Mol. Cancer, 2009, 8, 56.

[246] Ahn, M.-Y.; Kwon, S.-M.; Kim, Y.-C.; Ahn, S.-G.; Yoon, J.-H. Pheophorbide a-mediated photodynamic therapy induces apoptotic cell death in murine oral squamous cell carcinoma in vitro and in vivo. Oncol. Rep., 2012, 27(6), 1772-1778.

[247] Yoon, H.-E.; Oh, S.-H.; Kim, S.-A.; Yoon, J.-H.; Ahn, S.-G. Pheophorbide a-mediated photodynamic therapy induces autophagy and apoptosis via the activation of MAPKs in human skin cancer cells. Oncol. Rep., 2013, 31, 137-144.

[248] Stamati, I.; Kuimova, M.K.; Lion, M.; Yahioglu, G.; Phillips, D.; Deonarain, M.P. Novel photosensitisers derived from pyropheophorbide-a: uptake by cells and photodynamic efficiency in vitro. Photochem. Photobiol. Sci., 2010, 9(7), 1033-1041.

[249] Matroule, J.Y.; Carthy, C.M.; Granville, D.J.; Jolois, O.; Hunt, D.W.; Piette, J. Mechanism of colon cancer cell apoptosis mediated by pyropheophorbide-a methylester photosensitization. Oncogene, 2001, 20(30), 4070-4084.

[250] Henderson, B.W.; Bellnier, D.A.; Greco, W.R.; Sharma, A.; Pandey, R.K.; Vaughan, L. A.; Weishaupt, K.R.; Dougherty, T.J. An in vivo quantitative structure-activity relationship for a congeneric series of pyropheophorbide derivatives as photosensitizers for photodynamic therapy. Cancer Res., 1997, 57(18), 4000-4007.

[251] Tang, P.M.-K.; Bui-Xuan, N.-H.; Wong, C.-K.; Fong, W.-P.; Fung, K.-P. Pheophorbide a-mediated photodynamic therapy triggers HLA class I-restricted antigen presentation in human hepatocellular carcinoma. Transl. Oncol., 2010, 3(2), 114-122.

[252] López-Carballo, G.; Hernández-Muñoz, P.; Gavara, R.; Ocio, M.J. Photoactivated chlorophyllin-based gelatin films and coatings to prevent microbial contamination of food products. Int. J. Food Microbiol., 2008, 126(1-2), 65-70.

[253] Luksiene, Z.; Paskeviciute, E. Novel approach to decontaminate foodpackaging from pathogens in non-thermal and not chemical way: Chlorophyllin-based photosensitization. J. Food Eng., 2012, 110(2), 317-323.

[254] Luksiene, Z.; Buchovec, I.; Paskeviciute, E. Inactivation of several strains of Listeria monocytogenes attached to the surface of packaging material by Na-chlorophyllin-based photosensitization. J. Photochem. Photobiol. B Biol., 2010, 101(3), 326-331.

[255] Luksiene, Z.; Paskeviciute, E. Microbial control of food-related surfaces: Na-chlorophyllin-based photosensitization. J. Photochem. Photobiol. B Biol., 2011, 105(1), 69-74.

[256] Luksiene, Z.; Paskeviciute, E. Novel approach to the microbial decontamination of strawberries: Chlorophyllin-based photosensitization. J. Appl. Microbiol., 2011, 110(5), 1274-1283.

[257] Iriuchishima, T.; Saito, A.; Aizawa, S.; Taira, K.; Yamamoto, T.; Ryu, $\mathrm{J}$. The minimum influences for murine normal joint tissue by novel bactericidal treatment and photodynamic therapy using Napheophorbide a for septic arthritis. Photomed. Laser Surg., 2008, 26(2), 153-158.

[258] Jitsukawa, K.; Suizu, R.; Hidano, A. Chlorella photosensitization. New phytophotodermatosis. Int. J. Dermatol., 1984, 23(4), 263-268.

[259] Campbell, W.M.; Dombroski, G.S.; Sharma, I.; Partridge, A.C.; Collett, M.G. Photodynamic chlorophyll a metabolites, including phytoporphyrin (phylloerythrin), in the blood of photosensitive livestock: overview and measurement. New Zeal. Vet. J., 2010, 58(3), 146-154.

[260] Lohrey, E.; Tapper, B.; Hove, E.L. Photosensitization of albino rats fed on lucerne-protein concentrate. Br. J. Nutr., 1973, 31, 159-166.

[261] Gallardo-Guerrero, L.; Gandul-Rojas, B.; Mínguez-Mosquera, M.I. Digestive stability, micellarization, and uptake by Caco-2 human intestinal cell of chlorophyll derivatives from different preparations of pea (Pisum sativum L.). J. Agric. Food Chem., 2008, 56(18), 83798386.

[262] Wrolstad, R.E. Handbook of Food and Analytical Chemistry, $1^{\text {st }}$ ed.; Wiley and Sons: Hookoken, 2005.

[263) Guo, D.; Horio, D.T.; Grove, J.S.; Dashwood, R.H. Cancer inhibition by chlorophyllin of 2-amino-3-methylimidazo-methylimidazo-[4,5f]quinoline induced tumorigenesis in male F344 rat. Cancer Lett., 1995, 95, 161-165. 
[264] Breinholt, V.; Arbogast, D.; Loveland, P.; Pereira, C.; Dashwood, R.; Hendricks, J.; Bailey, G. Chlorophyllin chemoprevention in trout initiated by aflatoxin $\mathrm{B}(1)$ bath treatment: An evaluation of reduced bioavailability vs. target organ protective mechanisms. Toxicol. Appl. Pharmacol., 1999, 158(2), 141-151.

[265] Breinholt, V.; Schimerlik, M.; Dashwood, R.; Bailey, G. Mechanisms of chlorophyllin anticarcinogenesis against aflatoxin B1: complex formation with the carcinogen. Chem. Res. Toxicol., 1995, 8(4), 506514.

[266] Dashwood, R.; Negishi, T.; Hayatsu, H.; Breinholt, V.; Hendricks, J.; Bailey, G. Chemopreventive properties of chlorophylls towards aflatoxin B1: A review of the antimutagenicity and anticarcinogenicity data in rainbow trout. Mutat. Res., 1998, 399(2), 245-253.

[267] Hayashi, T.; Schimerlik, M.; Bailey, G. Mechanisms of chlorophyllin anticarcinogenesis: dose-responsive inhibition of aflatoxin uptake and biodistribution following oral co-administration in rainbow trout. Toxicol. Appl. Pharmacol., 1999, 158(2), 132-140.

[268] Hayatsu, H.; Sugiyama, C.; Arimoto-Kobayashi, S.; Negishi, T. Porphyrins as possible preventers of heterocyclic amine carcinogenesis. Cancer Lett., 1999, 143(2), 185-187.

[269] Jubert, C.; Mata, J.; Bench, G.; Dashwood, R.; Pereira, C.; Tracewell, W.; Turteltaub, K.; Williams, D.; Bailey, G. Effects of chlorophyll and chlorophyllin on low-dose aflatoxin B1 pharmacokinetics in human volunteers. Cancer Prev. Res., 2009, 2(12), 1015-1022.

[270] Waters, M.D.; Stack, H.F.; Jackson, M.A.; Brockman, H.E.; De Flora, S. Activity profiles of antimutagens: In vitro and in vivo data. Mutat. Res. - Fundam. Mol. Mech. Mutagen., 1996, 350(1), 109-129.

[271] Egner, P.A.; Wang, J.B.; Zhu, Y.R.; Zhang, B.C.; Wu, Y.; Zhang, Q.N.; Qian, G.S.; Kuang, S.Y.; Gange, S.J.; Jacobson, L. P.; Helzlsouer, K.J.; Bailey, G.S.; Groopman, J.D.; Kensler, T.W. Chlorophyllin intervention reduces aflatoxin-DNA adducts in individuals at high risk for liver cancer. Proc. Natl. Acad. Sci. U. S. A., 2001, 98(25), 14601-14606.

[272] Morita, K.; Ogata, M.; Hasegawa, T. Chlorophyll derived from Chlorella inhibits dioxin adsorption from the gastrointestinal tract and accelerates dioxin excretion in rats. Environ. Health Perspect., 2001, 109(3), 289-294.

[273] Hsu, C.Y.; Chen, Y.H.; Chao, P.Y.; Chen, C.M.; Hsieh, L.L.; Hu, S.P. Naturally occurring chlorophyll derivatives inhibit aflatoxin B1-DNA adduct formation in hepatoma cells. Mutat. Res. - Genet. Toxicol. Environ. Mutagen., 2008, 657(2), 98-104.

[274] Arimoto, S.; Fukuoka, S.; Itome, C.; Nakano, H.; Rai, H.; Hayatsu, H. Binding of polycyclic planar mutagens to chlorophyllin resulting in inhibition of the mutagenic activity. Mutat. Res., 1993, 287, 293-305.

[275] Chung, W.Y.; Lee, J.M.; Park, M.Y.; Yook, J.I.; Kim, J.; Chung, A.S.; Surh, Y.J.; Park, K.K. Inhibitory effects of chlorophyllin on 7,12dimethylbenz[a]anthracene-induced bacterial mutagenesis and mouse skin carcinogenesis. Cancer Lett., 1999, 145(1-2), 57-64.

[276] John, K.; Divi, R.L.; Keshava, C.; Orozco, C.C.; Schockley, M.E.; Richardson, D.L.; Poirier, M.C.; Nath, J.; Weston, A. CYP1A1 and CYP1B1 gene expression and DNA adduct formation in normal human mammary epithelial cells exposed to benzo[a]pyrene in the absence or presence of chlorophyllin. Cancer Lett., 2010, 292(2), 254-260.

[277] Simonich, M.T.; McQuistan, T.; Jubert, C.; Pereira, C.; Hendricks, J.D.; Schimerlik, M.; Zhu, B.; Dashwood, R.H.; Williams, D.E.; Bailey, G.S. Low-dose dietary chlorophyll inhibits multi-organ carcinogenesis in the rainbow trout. Food Chem. Toxicol., 2008, 46(3), 1014-1024.

[278] Lai, C.-N.; Butler, M.A.; Matney, T.S. Antimutagenic activities of common vegetables and their chlorophyll content. Mutat. Res. Toxicol., 1980, 77(3), 245-250.

[279] Hayatsu, H.; Negishi, T.; Arimoto, S.; Hayatsu, T. Porphyrins as potential inhibitors against exposure to carcinogens and mutagens. Mutat. Res., 1993, 290(1), 79-85.

[280] Warner, J.R.; Nath, J.; Ong, T.M. Antimutagenicity studies of chlorophyllin using the Salmonella arabinose-resistant assay system. Mutat. Res., 1991, 262(1), 25-30.

[281] Hasegawa, R.; Hirose, M.; Kato, T.; Hagiwara, A.; Boonyaphiphat, P.; Nagao, M.; Ito, N.; Shirai, T. Inhibitory effect of chlorophyllin on PhIPinduced mammary carcinogenesis in female F344 rats. Carcinogenesis, 1995, 16(9), 2243-2246.

[282] Negishi, T.; Rai, H.; Hayatsu, H. Antigenotoxic activity of natural chlorophylls. Mutat. Res., 1997, 376(1-2), 97-100.

[283] Simonich, M.T.; Egner, P.A.; Roebuck, B.D.; Orner, G.A.; Jubert, C.; Pereira, C.; Groopman, J.D.; Kensler, T.W.; Dashwood, R.H.; Williams, D.E.; Bailey, G.S. Natural chlorophyll inhibits aflatoxin B1induced multi-organ carcinogenesis in the rat. Carcinogenesis, 2007,
28(6), 1294-1302.

[284] Pratt, M.; Reddy, A.P.; Hendricks, J.D.; Pereira, C.; Kensler, T.W.; Bailey, G.S. The importance of carcinogen dose in chemoprevention studies: Quantitative interrelationships between, dibenzo[a,l]pyrene dose, chlorophyllin dose, target organ DNA adduct biomarkers and final tumor outcome. Carcinogenesis, 2007, 28(3), 611-624.

[285] Mata, J.E.; Yu, Z.; Gray, J.E.; Williams, D.E.; Rodriguez-Proteau, R. Effects of chlorophyllin on transport of dibenzo(a,l)pyrene, 2-amino-1methyl-6-phenylimidazo-[4,5-b]pyridine, and aflatoxin B1 across Caco2 cell monolayers. Toxicology, 2004, 196(1-2), 117-125

[286] Castro, D.J.; Löhr, C.V.; Fischer, K.A.; Waters, K.M.; WebbRobertson, B.J.M.; Dashwood, R.H.; Bailey, G.S.; Williams, D.E. Identifying efficacious approaches to chemoprevention with chlorophyllin, purified chlorophylls and freeze-dried spinach in a mouse model of transplacental carcinogenesis. Carcinogenesis, 2009, 30(2), 315-320.

[287] Dashwood, R.H. Protection by chlorophyllin against the covalent binding of 2-amino-3-methylimidazo[4,5-f]qiiinoline (IQ) to rat liver DNA. Carcinogenesis, 1992, 13(1), 113-118.

[288] Dingley, K.H.; Ubick, E.A.; Chiarappa-Zucca, M.L.; Nowell, S.; Abel, S.; Ebeler, S.E.; Mitchell, A.E.; Burns, S.A.; Steinberg, F.M.; Clifford, A.J. Effect of dietary constituents with chemopreventive potential on adduct formation of a low dose of the heterocyclic amines PhIP and IQ and phase II hepatic enzymes. Nutr. Cancer, 2003, 46(2), 212-121.

[289] Yun, C.-H.; Jeong, H.G.; Jhoun, J.W.; Guengerich, F.P. Non-specific inhibition of cytochrome P450 activities by chlorophyllin in human and rat liver microsomes. Carcinogenesis, 1995, 16(6), 1437-1440.

[290] Imai, K.; Aimoto, T.; Sato, M.; Watanabe, K.; Kimura, R.; Murata, T. Effects of sodium metallochlorophyllins on the activity and components of the microsomal drug-metabolizing enzyme system in rat liver. Chem. Pharm. Bull. (Tokyo), 1986, 34(10), 4287-4293.

[291] Bez, G.C.; Jordão, B.Q.; Vicentini, V.E.P.; Mantovani, M.S Investigation of genotoxic and antigenotoxic activities of chlorophylls and chlorophyllin in cultured V79 cells. Mutat. Res. - Genet. Toxicol. Environ. Mutagen., 2001, 497(1-2), 139-145.

[292] Gentile, J.M.; Gentile, G.J. The metabolic activation of 4-nitro-ophenylenediamine by chlorophyll-containing plant extracts: the relationship between mutagenicity and antimutagenicity. Mutat. Res., 1991, 250(1-2), 79-86.

[293] Terwel, L.; van der Hoeven, J.C. Antimutagenic activity of some naturally occurring compounds towards cigarette-smoke condensate and benzo[a]pyrene in the Salmonella/microsome assay. Mutat. Res. Fundam. Mol. Mech. Mutagen., 1985, 152(1), 1-4.

[294] Woo, G.H.; Shibutani, M.; Kuroiwa, K.; Lee, K.Y.; Takahashi, M.; Inoue, K.; Fujimoto, H.; Hirose, M. Lack of preventive effects of dietary fibers or chlorophyllin against acrylamide toxicity in rats. Food Chem. Toxicol., 2007, 45(8), 1507-1515.

[295] Torres-Bezauri, R.; Madrigal-Bujaidar, E.; Alvarez-González, R.I.; Zepeda, G.; Chamorro, G. Effects of chlorophyllin on acetaldehyde: Lack of modulation of the rate of sister-chromatid exchanges in mouse bone marrow, and of complex formation in aqueous solution. Food Chem. Toxicol., 2002, 40(10), 1507-1513.

[296] Orner, G.; Roebuck, B.; Dashwood, R.; Bailey, G. Post-initiation chlorophyllin exposure does not modulate aflatoxin-induced foci in the liver and colon of rats. J. Carcinog., 2006, 5, 6.

[297] de Vogel, J.; Jonker-Termont, D.S.M.L.; Katan, M.B.; van der Meer, R. Natural chlorophyll but not chlorophyllin prevents heme-induced cytotoxic and hyperproliferative effects in rat colon. J. Nutr., 2005 , 135(8), 1995-2000.

[298] de Vogel, J.; Jonker-Termont, D.S.M.L.; van Lieshout, E.M.M.; Katan, M.B.; van der Meer, R. Green vegetables, red meat and colon cancer: Chlorophyll prevents the cytotoxic and hyperproliferative effects of haem in rat colon. Carcinogenesis, 2005, 26(2), 387-393.

[299] Morales-Ramírez, P.; García-Rodríguez, M.C. In vivo effect of chlorophyllin on gamma-ray-induced sister chromatid exchange in murine bone marrow cells. Mutat. Res., 1994, 320(4), 329-334.

[300] Negraes, P.D.; Jordão, B.Q.; Vicentini, V.E.P.; Mantovani, M.S Anticlastogenicity of chlorophyllin in the different cell cycle phases in cultured mammalian cells. Mutat. Res. - Genet. Toxicol. Environ. Mutagen., 2004, 557(2), 177-182.

[301] Chiu, L.C.-M.; Kong, C.K.-L.; Ooi, V.E.C. Antiproliferative effect of chlorophyllin derived from a traditional Chinese medicine Bombyx mori excreta on human breast cancer MCF-7 cells. Int. J. Oncol., 2003, 23(3), 729-735.

[302] Chiu, L.C.; Kong, C.K.; Ooi, V.E. The chlorophyllin-induced cell 
cycle arrest and apoptosis in human breast cancer MCF-7 cells is associated with ERK deactivation and Cyclin D1 depletion. Int. J. Mol. Med., 2005, 16(4), 735-740.

[303] Díaz, G.D.; Li, Q.; Dashwood, R.H. Caspase-8 and apoptosisinducing factor mediate a cytochrome c-independent pathway of apoptosis in human colon cancer cells induced by the dietary phytochemical chlorophyllin. Cancer Res., 2003, 63(6), 1254-1261.

[304] Chimploy, K.; Díaz, G.D.; Li, Q.; Carter, O.; Dashwood, W.; Mathews, C.K.; Williams, D.E.; Bailey, G.S.; Dashwood, R.H. E2F4 and ribonucleotide reductase mediate S-phase arrest in colon cancer cells treated with chlorophyllin. Int. J. Cancer, 2009, 125(9), 20862094.

[305] Thiyagarajan, P.; Senthil Murugan, R.; Kavitha, K.; Anitha, P.; Prathiba, D.; Nagini, S. Dietary chlorophyllin inhibits the canonical NF$\kappa \mathrm{B}$ signaling pathway and induces intrinsic apoptosis in a hamster model of oral oncogenesis. Food Chem. Toxicol., 2012, 50(3-4), 867876.

[306] Domijan, A.-M.; Gajski, G.; Novak Jovanović, I.; Gerić, M.; GarajVrhovac, V. In vitro genotoxicity of mycotoxins ochratoxin A and fumonisin B1 could be prevented by sodium copper chlorophyllin Implication to their genotoxic mechanism. Food Chem., 2015, 170, 455-462.

[307] Higashi-Okai, K.; Otani, S.; Okai, Y. Potent suppressive activity of pheophytin $a$ and $b$ from the non-polyphenolic fraction of green tea (Camellia sinensis) against tumor promotion in mouse skin. Cancer Lett., 1998, 129(2), 223-228.

[308] Sakdarat, S.; Shuyprom, A.; Pientong, C.; Ekalaksananan, T.; Thongchai, S. Bioactive constituents from the leaves of Clinacanthus nutans Lindau. Bioorganic Med. Chem., 2009, 17(5), 1857-1860.

[309] Wang, S.Y.; Tseng, C.P.; Tsai, K.C.; Lin, C.F.; Wen, C.Y.; Tsay, H.S.; Sakamoto, N.; Tseng, C.H.; Cheng, J.C. Bioactivity-guided screening identifies pheophytin a as a potent anti-hepatitis $\mathrm{C}$ virus compound from Lonicera hypoglauca Miq. Biochem. Biophys. Res. Commun., 2009, 385(2), 230-235.

[310] McCook, J.P.; Dorogi, P.L.; Vasily, D.B.; Cefalo, D.R. In vitro inhibition of hyaluronidase by sodium copper chlorophyllin complex and chlorophyllin analogs. Clin. Cosmet. Investig. Dermatol., 2015, 8, 443-448.

[311] Siegel, L.H. The control of ileostomy and colostomy odors. Gastroenterology, 1960, 38, 634-636.

[312] Yamazaki, H.; Fujieda, M.; Togashi, M.; Saito, T.; Preti, G.; Cashman, J.R.; Kamataki, T. Effects of the dietary supplements, activated charcoal and copper chlorophyllin, on urinary excretion of trimethylamine in Japanese trimethylaminuria patients. Life Sci., 2004, 74(22), 2739-2747.

[313] Miyazawa, K.; Suzuki, K.; Tsugawa, R. The quantitative study of inhibitory effect of pentosan polysulfate and chlorophyllin on the experimental calcium oxalate stone. Japanese J. Urol., 1989, 80(6), 861-869.

[314] Tawashi, R.; Cousineau, M.; Sharkawi, M. Effect of sodium copper chlorophyllin on the formation of calcium oxalate crystals in rat kidney. Invest. Urol., 1980, 18(2), 90-92.

[315] Horwitz, B. Role of chlorophyll in proctology. Am. J. Surg., 1951, 81(1), 81-84.

[316] Smith, L.W.; Livingston, A.E. Wound healing: an experimental study of water soluble chlorophyll derivatives in conjunction with various antibacterial agents. Am. J. Surg., 1945, 67(1), 30-39.

[317] Smith, L.W.; Livingston, A.E. Chlorophyll: An experimental study of its water soluble derivatives in wound healing. Am. J. Surg., 1943, 62(3), 358-369.

[318] Cady, J.B.; Morgan, W.S. Treatment of chronic ulcers with chlorophyll: Review of a series of fifty cases. Am. J. Surg., 1948, 75(4), 562-569.

[319] Carpenter, E.B. Clinical experiences with chlorophyll preparations: With particular reference to chronic osteomyelitis and chronic ulcers. Am. J. Surg., 1949, 77(2), 167-171.

[320] Edwards, B.J. Treatment of chronic leg ulcers with ointment containing soluble chlorophyll. Physiotherapy, 1954, 40(6), 177-179.

[321] Goldberg, S.L. The use of water soluble chlorophyll in oral sepsis: An experimental study of 300 cases. Am. J. Surg., 1943, 62(1), 117-123.

[322] Larato, D.C.; Pfau, F.R. Effects of a water-soluble chlorophyllin ointment on gingival inflammation. N. Y. State Dent. J., 1970, 36(5), 291-293.

[323] Sigler, M.L.; Stephens, T.J. Assessment of the safety and efficacy of topical copper chlorophyllin in women with photodamaged facial skin. J. Drugs Dermatol., 2015, 14(4), 401-404.
[324] Stephens, T.J.; McCook, J.P.; Herndon, J.H.J. Pilot study of topical copper chlorophyllin complex in subjects with facial acne and large pores. J. Drugs Dermatol., 2015, 14(6), 589-592.

[325] Vasily, D.B. Topical treatment with liposomal sodium copper chlorophyllin complex in subjects with facial redness and erythematotelangiectatic rosacea: Case studies. J. Drugs Dermatol., 2015, 14(10), 1157-1159.

[326] Sharma, D.; Kumar, S.S.; Sainis, K.B. Antiapoptotic and immunomodulatory effects of chlorophyllin. Mol. Immunol., 2007, 44(4), 347-359.

[327] Yun, C.H.; Son, C.G.; Chung, D.K.; Han, S.H. Chlorophyllin attenuates IFN- $\gamma$ expression in lipopolysaccharide- stimulated murine splenic mononuclear cells via suppressing IL-12 production. Int Immunopharmacol., 2005, 5(13-14), 1926-1935.

[328] Yun, C.H.; Jeon, Y.J.; Yang, Y.; Ju, H.R.; Han, S.H. Chlorophyllin suppresses interleukin-1 beta expression in lipopolysaccharide-activated RAW 264.7 cells. Int. Immunopharmacol., 2006, 6(2), 252-259.

[329] Rho, M.C.; Chung, M.Y.; Song, H.Y.; Kwon, O.E.; Lee, S.W.; Baek, J.A.; Jeune, K.H.; Kim, K.; Lee, H.S.; Kim, Y.K. Pheophorbide amethyl ester, acyl-CoA:cholesterol acyltransferase inhibitor from Diospyros kaki. Arch. Pharm. Res., 2003, 26(9), 716-718.

[330] Song, H.Y.; Rho, M.-C.; Lee, S.W.; Kwon, O.E.; Chang, Y.-D.; Lee, H.S.; Kim, Y.-K. Isolation of acyl-CoA:cholesterol acyltransferase inhibitor from Persicaria vulgaris. Planta Med., 2002, 68(9), 845-847.

[331] Higashi-Okai, K.; Taniguchi, M.; Okai, Y. Potent suppressive activity of pheophytin a and b from non- polyphenolic fraction of green tea (Camellia sinensis) against the activation of oxygen radical generation, cytokine release and chemotaxis of human polymorphonuclear neutrophils (PMNs). J. Ferment. Bioeng., 1998, 85(6), 555-558.

[332] Ina, A.; Hayashi, K.-I.; Nozaki, H.; Kamei, Y. Pheophytin a, a low molecular weight compound found in the marine brown alga Sargassum fulvellum, promotes the differentiation of PC12 cells. Int. J. Dev. Neurosci., 2007, 25(1), 63-68.

[333] Lam, C.R.; Brush, B.E. Chlorophyll and wound healing: Experimental and clinical study. Am. J. Surg., 1950, 80(2), 204-210.

[334] Weir, D.; Farley, K.L. Relative delivery efficiency and convenience of spray and ointment formulations of papain/urea/chlorophyllin enzymatic wound therapies. J. Wound Ostomy Cont. Nurs., 2006, 33(5), 482-490.

[335] Barnard, R.D.; Goldman, B.; Kessler, L.N.; Stanton, H.T. Heparinic effects of cupridihydroporphyrins (water-soluble chlorophyllins). J. Am. Pharm. Assoc., 1954, 43(2), 110-113.

[336] Kay, A.; Graetzel, M. Artificial photosynthesis. 1. Photosensitization of titania solar cells with chlorophyll derivatives and related natural porphyrins. J. Phys. Chem., 1993, 97(23), 6272-6277.

[337] Hug, H.; Bader, M.; Mair, P.; Glatzel, T. Biophotovoltaics: Natural pigments in dye-sensitized solar cells. Appl. Energy, 2014, 115, 216225.

[338] Ludin, N.A.; Al-Alwani Mahmoud, A.M.; Bakar Mohamad, A.; Kadhum, A.A.H.; Sopian, K.; Abdul Karim, N.S. Review on the development of natural dye photosensitizer for dye-sensitized solar cells. Renew. Sustain. Energy Rev., 2014, 31, 386-396.

[339] Shahid, M.; Shahid-Ul-Islam; Mohammad, F. Recent advancements in natural dye applications: A review. J. Clean. Prod., 2013, 53, 310-331.

[340] Berezin, B.D.; Rumyantseva, S.V; Moryganov, A.P.; Berezin, M.B. Chemical transformations of chlorophyll and its application in the design of a new generation of environmentally safe dyes. Russ. Chem. Rev., 2004, 73(2), 185-194.

[341] Jin, Z.-H.; Miyoshi, N.; Ishiguro, K.; Umemura, S.-I.; Kawabata, K.; Yumita, N.; Sakata, I.; Takaoka, K.; Udagawa, T.; Nakajima, S.; Tajiri, H.; Ueda, K.; Fukuda, M.; Kumakiri, M. Combination effect of photodynamic and sonodynamic therapy on experimental skin squamous cell carcinoma in C3H/HeN mice. J. Dermatol., 2000, 27(5), 294-306.

[342] Dagan, A.; Gatt, S.; Cerbu-Karabat, S.; Mazière, J.C.; Mazière, C.; Santus, R.; Engelhardt, E.L.; Yeh, K.A.; Stobbe, C.C.; Fenning, M.C.; Chapman, J.D. Uptake by cells and photosensitizing effectiveness of novel pheophorbide derivatives in vitro. Int. J. Cancer, 1995, 63(6), 831-839.

[343] Li, L.; Nurunnabi; Nafiujjaman; Lee, Y.K.; Huh, K.M. GSH-mediated photoactivity of pheophorbide a-conjugated heparin/gold nanoparticle for photodynamic therapy. J. Control. Release, 2013, 171(2), 241-250.

[344] Te, C.; Entile, J.M.G.; Aguley, B.C.B.; Earson, A.E.P.; Regory, T.G.; Erguson, L.R.F. In vivo effects of chlorophyllin on the antitumour agent cyclophosphamide. Int. J. Cancer, 1997, 89, 84-89.

[345] Ocakoglu, K.; Bayrak, E.; Onursal, M.; Yilmaz, O.; Yurt Lambrecht, 
F.; Holzwarth, A.R. Evaluation of ${ }^{99}$ Tc-Pheophorbide-a use in infection imaging: A rat model. Appl. Radiat. Isot., 2011, 69(9), 1165-1168.

[346] Lesser, C.; von Borstel, R.W. Cigarette filter containing dry water and a porphyrin. U.S. Patent 6,530,377 B1, March 11, 2003. 